2017

\title{
Subsynchronous Resonance
}

\author{
Sadeghi, Roozbeh
}

Sadeghi, R. (2017). Subsynchronous Resonance (Unpublished master's thesis). University of Calgary, Calgary, AB. doi:10.11575/PRISM/27930

http://hdl.handle.net/11023/4169

Downloaded from PRISM Repository, University of Calgary 


\title{
UNIVERSITY OF CALGARY
}

Subsynchronous Resonance

by

\author{
Roozbeh Sadeghi
}

\begin{abstract}
A THESIS
SUBMITTED TO THE FACULTY OF GRADUATE STUDIES

IN PARTIAL FULFILMENT OF THE REQUIREMENTS FOR THE

DEGREE OF MASTER OF SCIENECE
\end{abstract}

GRADUATE PROGRAM IN ELECTRICAL AND COMPUTER ENGINEERING

CALGARY, ALBERTA

SEPTEMBER， 2017

(C) Roozbeh Sadeghi 2017 


\begin{abstract}
Series capacitors have been extensively used as an effective means of increasing power transfer capability of transmission systems. However, series capacitors may excite the subsynchronous resonance and tend to amplify the shaft stress during major network transient event.

A power system model is successfully designed and simulated to emulate subsynchronous oscillation. This modeling includes hardware and software implementation in the power system lab. In this thesis, a part of the larger effort is to identify, characterize and mitigate low frequency oscillations in power systems.
\end{abstract}




\section{Acknowledgments}

First and foremost, I would like to express my sincerest gratitude to my supervisor

Professor Andy Knight for his priceless support and guidance throughout my research and study. This work would not have been possible without his continuous support, suggestions, valuable discussions and patience.

I would like to convey my special thanks to Mr G. Hancock and R. Thomson for their assistance at various stage of this work.

I have gained valuable knowledge during my graduate experience and grateful to have gained new friendship with fine individuals.

Finally, I would like to express my love and thanks to my parents who devoted their life for their children. 
To my parents for their endless love and support 


\section{Table of Contents}

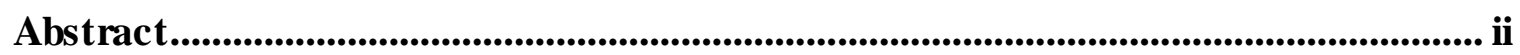

Acknowledgme nts ................................................................................................................................. iii

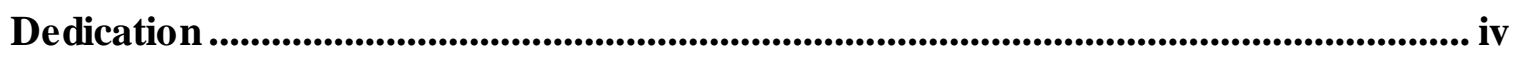

Table of Contents ......................................................................................................................... v

List of Tables ................................................................................................................................... viii

List of Figures...................................................................................................................................... ix

1. Introduction ....................................................................................................................................... 1

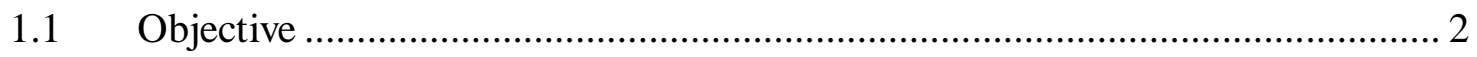

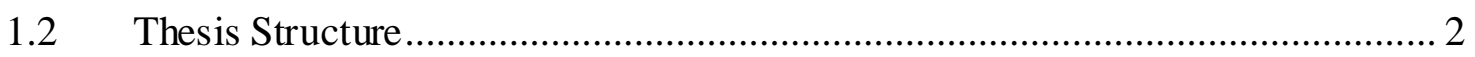

2. Sub-synchronous Interactions ................................................................................................ 4

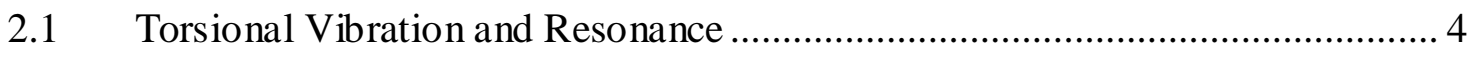

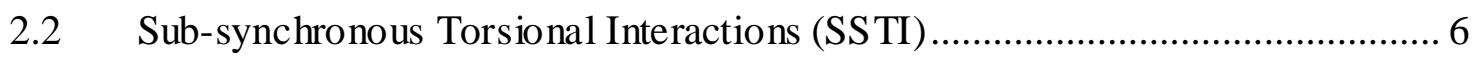

2.3 Sub-synchronous Control Interactions (SSCI) ........................................... 7

2.4 Sub-synchronous Resonance (SSR) ................................................................ 8

2.4.1 Sub-synchronous Resonance Likely Scenario ............................................ 10

2.4.2 Sub-synchronous Resonance Classifications .............................................. 13

2.4.3 Sub-synchronous Resonance Analysis Techniques ..................................... 18

2.4.4 Sub-synchronous Resonance Analysis in Alberta .................................... 20

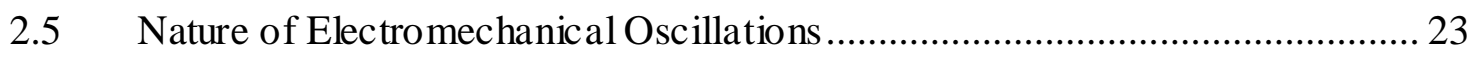

2.5.1 Intra-plant Mode Oscillations …………………................................. 25

2.5.2 Local plant Mode Oscillations …………………................................... 25

2.5.3 Inter-area Mode Oscillations.................................................................. 26

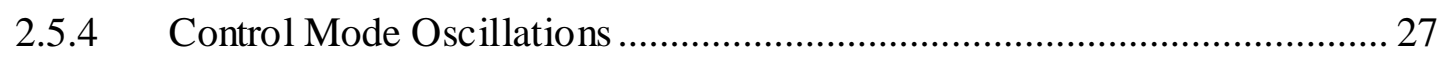




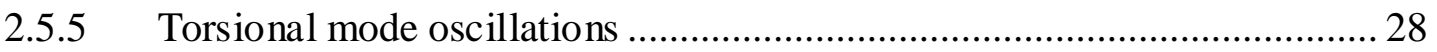

2.6 Role of Oscillations in Power Blackouts ...................................................... 29

3. Lab Grid Connected Power System Model.......................................................... 31

3.1 Transmission Line Parameters Measurement ............................................... 32

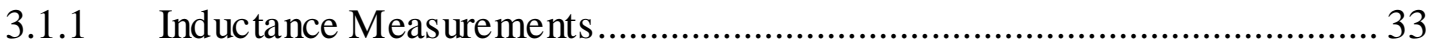

3.1.2 Resistance Measurements ............................................................................ 35

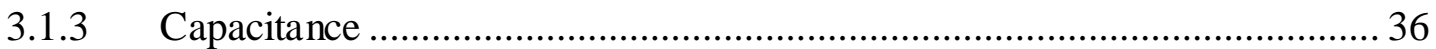

3.2 Synchronous Generator Parameters Measurements ...................................... 36

3.2.1 Synchronous Generator Dynamic Model.............................................. 45

3.3 DC Motor Parameters Measurements ........................................................ 49

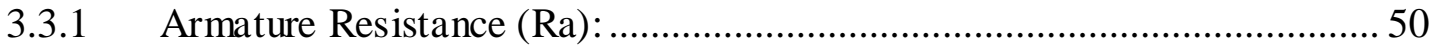

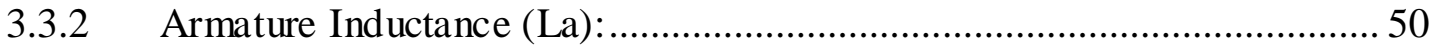

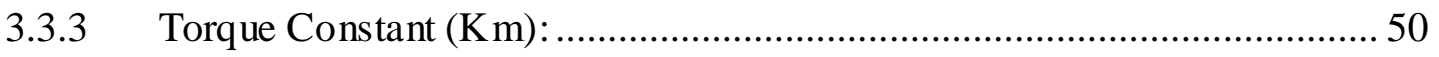

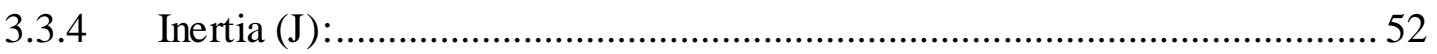

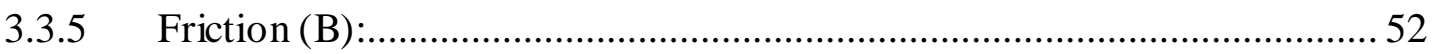

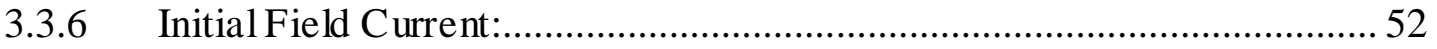

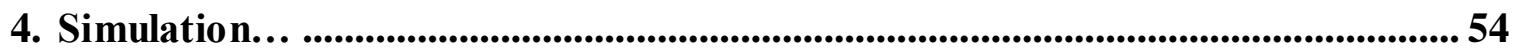

4.1 Validating Synchronous Generator Model ................................................. 54

4.1.1 Synchronous Generator PU Model: ..................................................... 54

4.1.2 Synchronous Generator SI Model:..................................................... 57

4.1.3 PU and SI Simulink Model Comparison ................................................ 59

4.2 Designing Power and Current Control....................................................... 61

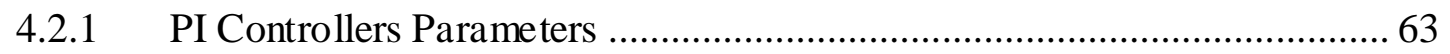

4.3 Designing a Transfer Function with a Controlled Desired Response .............. 63

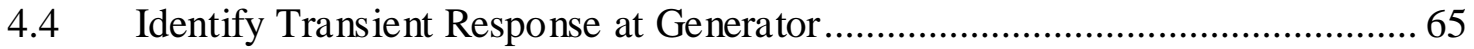

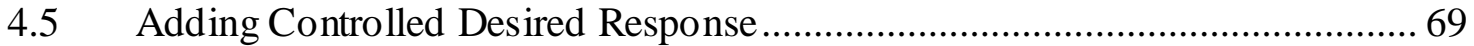

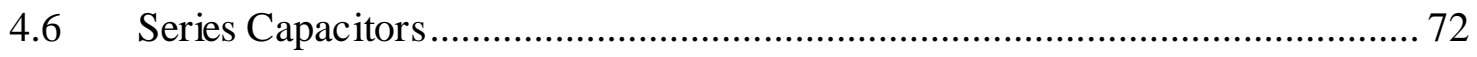

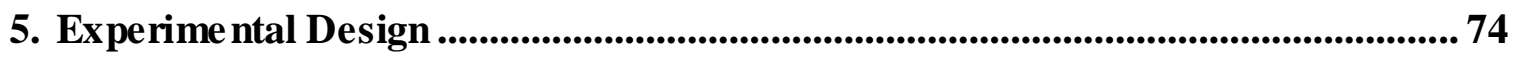

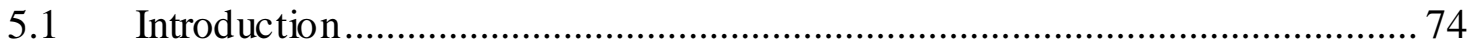

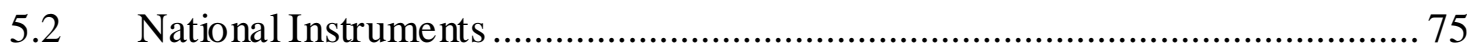


5.3 DC Motor Control and Drive ................................................................. 75

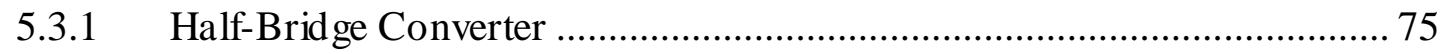

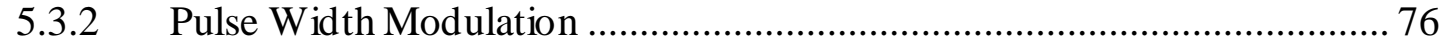

5.3.3 FPGA Based PWM Implemented in LabVIEW ................................... 77

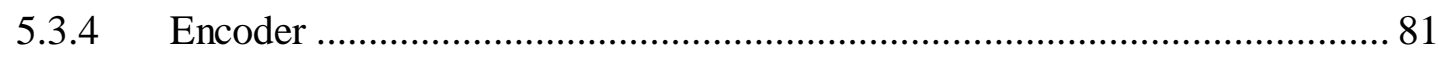

5.4 Tuning PI Controllers In Power System Lab ............................................... 81

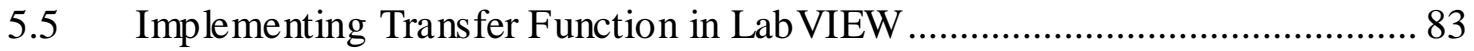

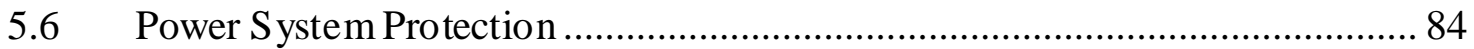

5.7 Fast Fourier Transform Technique (FFT) ................................................. 85

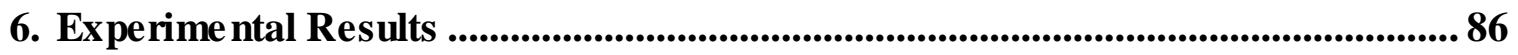

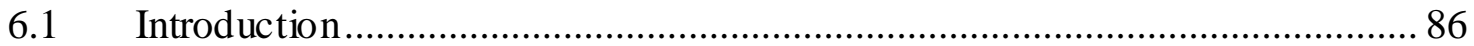

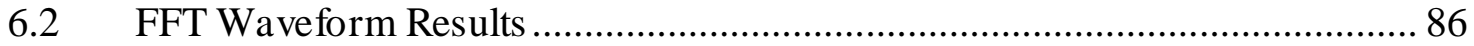

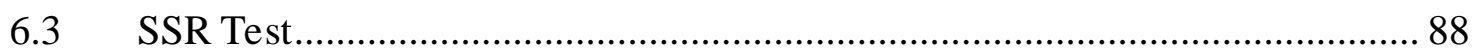

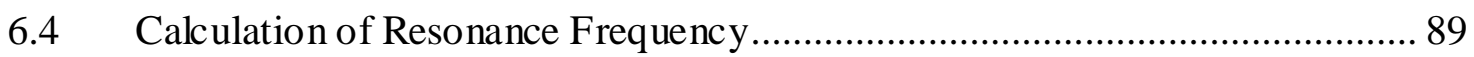

6.5 Series Compensated Line Tests .................................................................. 90

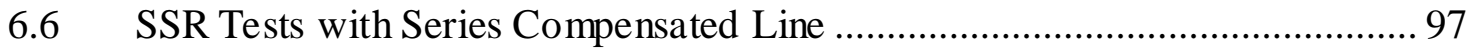

7. Conclusion and Future Work ....................................................................................... 101

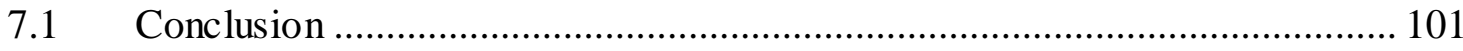

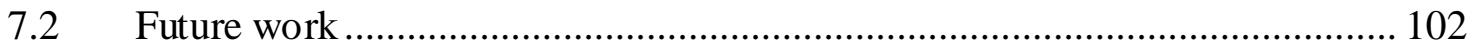

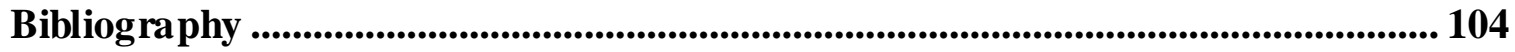

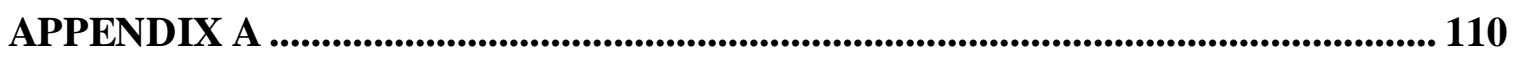

Parameters of the Single Machine Infinite Bus System......................................... 110 


\section{List of Tables}

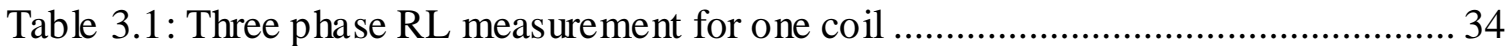

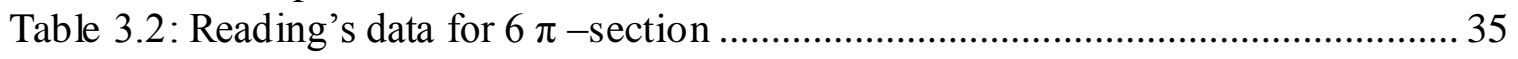

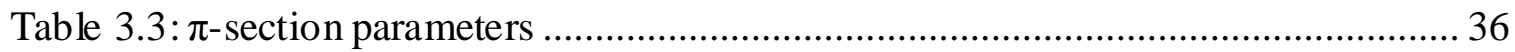

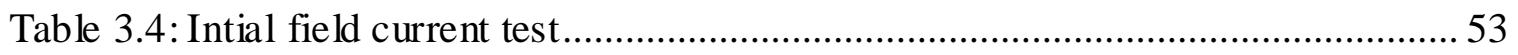

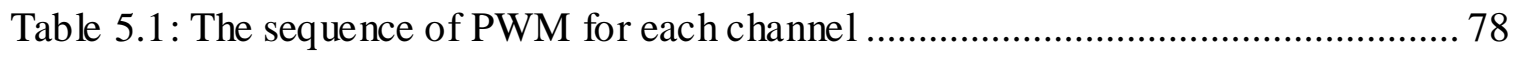

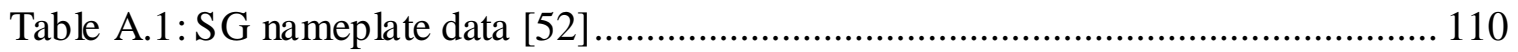

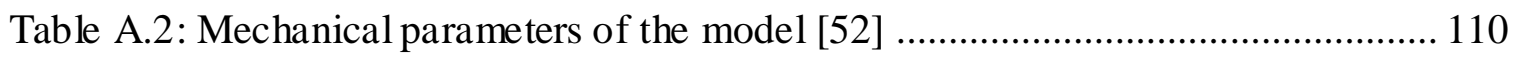

Table A.3: Synchronous Generator PU parameters [50], [52] .................................... 111

Table A.4: The stator base values used in Simulink [44] .......................................... 112 


\section{List of Figures}

Figure 2.1: Illustration of the variation of torsional resonance with speed [15] ................ 5

Figure 2.2: System under the study - IEEE SBM with VSC system [35] .......................... 8

Figure 2.3: Mechanical and electrical sys tem in power system.................................... 9

Figure 2.4: Sub-synchronous Resonance - Torsional Angle Displacement [6] ............... 12

Figure 2.5: Sub-synchronous Resonance - Transient Torque Amplification [6] ............. 14

Figure 2.6: A simple power system network [16] ................................................... 17

Figure 2.7: Wind turbine connected to series-compensated transmission system [32] ... 22

Figure 2.8: A typical example of local oscillation [21] ............................................ 26

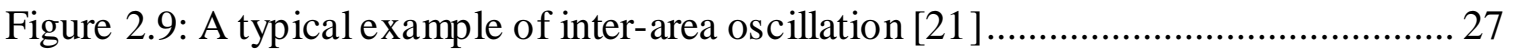

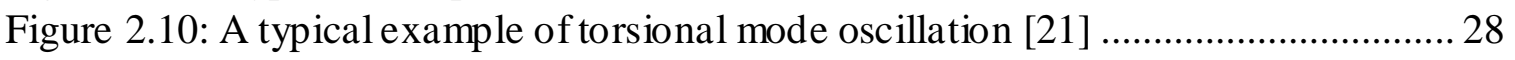

Figure 3.1: Grid connected power system model in ENA power lab ............................. 32

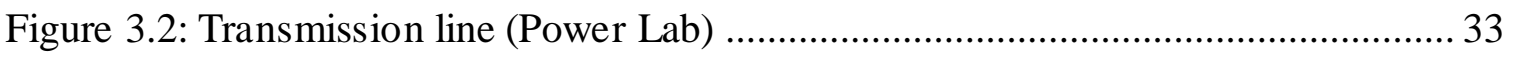

Figure 3.3: Schematic of a $\pi$ - line in the power lab ................................................... 33

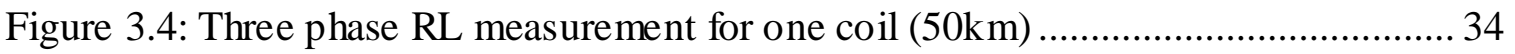

Figure 3.5: DC motor and synchronous generator .................................................. 37

Figure 3.6: Measurements and polynomial regression of the open-circuit curve and air-

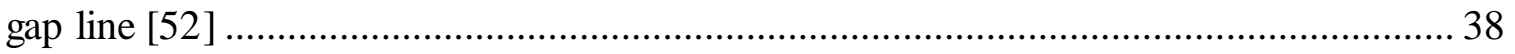

Figure 3.7: Clarke and Park Transformation [54] ....................................................... 45

Figure 3.8: Equivalent circuits of a three-phase synchronous machine, Park

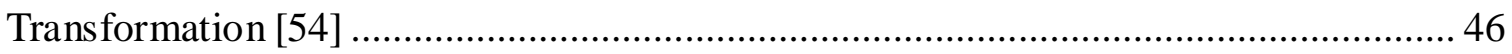

Figure 3.9: Conventional synchronous generator q-axis circuit model [54] ................... 47

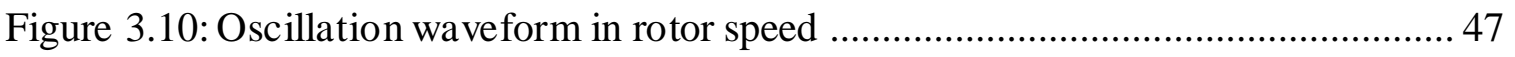

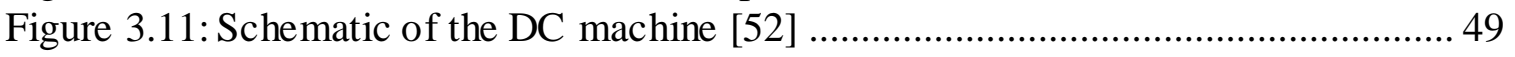

Figure 4.1: Validating the synchronous generator PU model......................................55

Figure 4.2: Synchronous generator PU model parameters [50] .................................... 55

Figure 4.3: SG Active Power in Pu model (pu) ........................................................ 56

Figure 4.4: Terminal voltage of SG Vab in PU model .............................................56

Figure 4.5: Synchronous generator SI Fundamental model........................................57

Figure 4.6: Synchronous Generator SI model parameters ............................................ 58

Figure 4.7: PU and SI Simulink model comparison test results .................................59

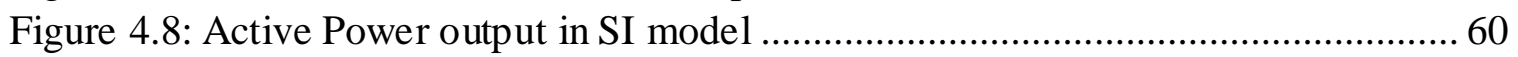

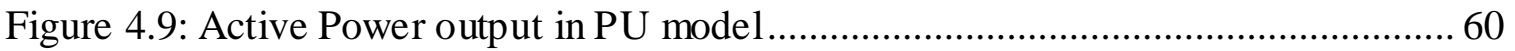

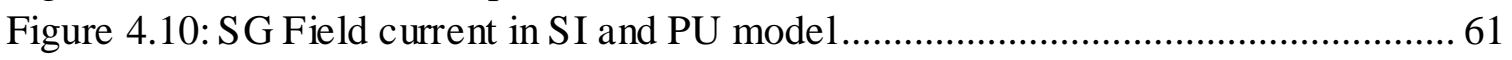

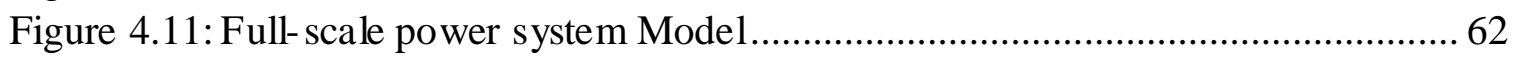

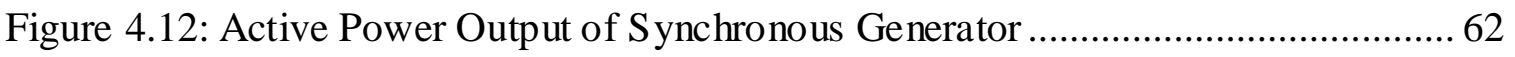

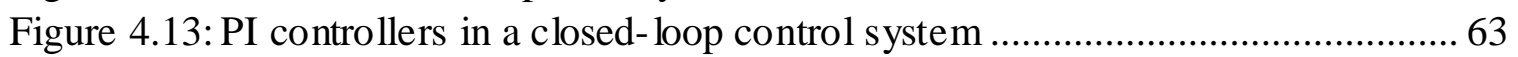

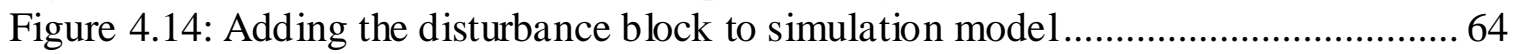

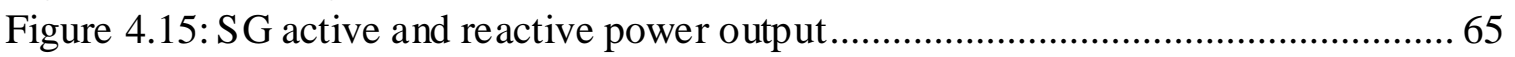

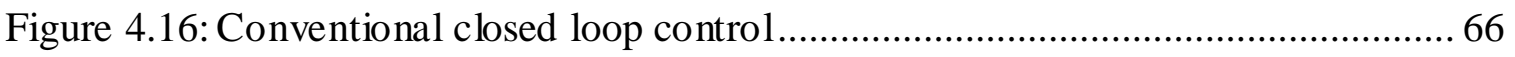

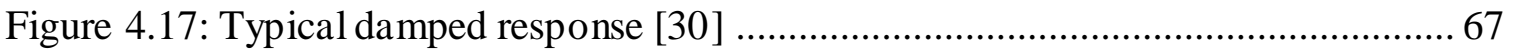


Figure 4.18: Synchronous generator active power output

Figure 4.19: Simulink model with dynamic rotating system and without transfer function block.

Figure 4.20: Synchronous generator active power output and dynamic rotating model $\mathrm{G}(\mathrm{s})$.

Figure 4.21: Simulink model with the disturbance block and without PI controllers ...... 70

Figure 4.22: SG active power output and dynamic rotating model G(s) with a disturbance

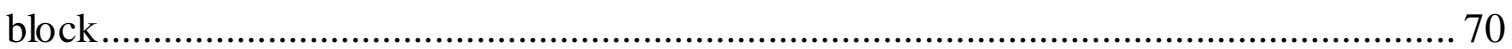

Figure 4.23: SG active and reactive power output with $18 \mathrm{~Hz}$ oscillation ........................ 71

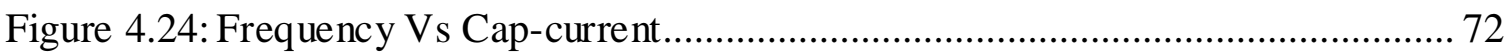

Figure 5.1: Experimental test rig design schematic ..................................................... 74

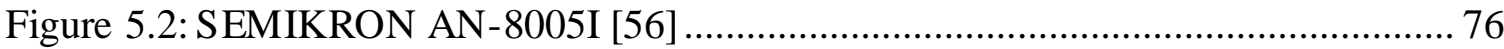

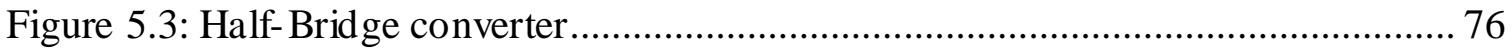

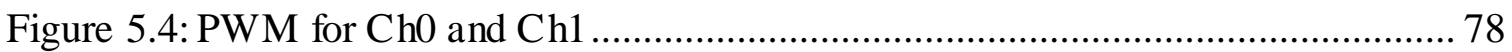

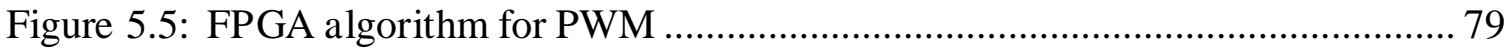

Figure 5.6: Pulse Width Modulation monitored by oscilloscope ..................................... 80

Figure 5.7: Armature current monitored by oscilloscope ................................................ 80

Figure 5.8: Real-Time control panel in Lab VIEW for current and power control ........... 82

Figure 5.9: Real-Time front panel control in Lab VIEW ............................................... 83

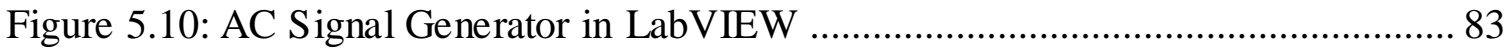

Figure 5.11: Protection logic circuit for LabVIEW FPGA ............................................. 84

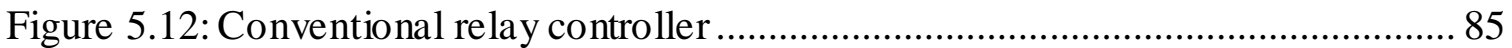

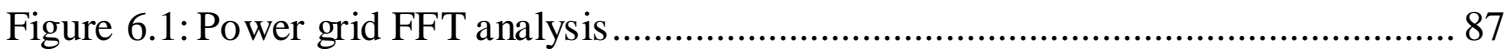

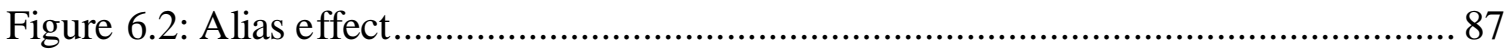

Figure 6.3: SSR test for 700uF compensated line …………….................................. 88

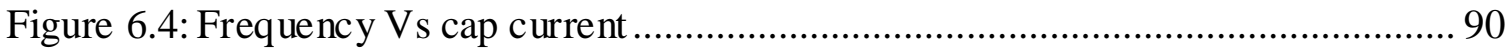

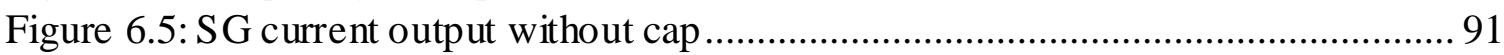

Figure 6.6: SG current output without cap (zoomed in) ………………………............ 91

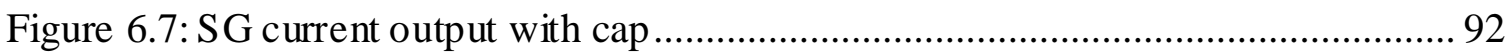

Figure 6.8: SG current output with cap (zoomed in) ……………………................... 92

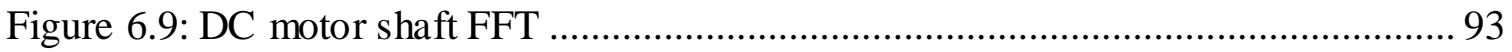

Figure 6.10:32 Hz oscillation on electrical side with $700 \mathrm{uF}$.......................................... 94

Figure $6.11: 32 \mathrm{~Hz}$ oscillation on electrical side with $700 \mathrm{uF}$ cap plus $28 \mathrm{~Hz}$ oscillation on

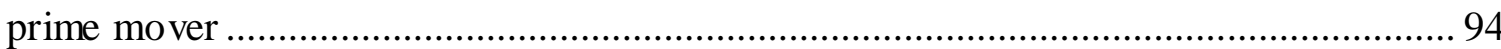

Figure 6.12:36 Hz oscillation on electrical side with $700 \mathrm{uF}$........................................ 95

Figure $6.13: 36 \mathrm{~Hz}$ oscillation on electrical side with $700 \mathrm{uF}$ cap plus $24 \mathrm{~Hz}$ oscillation on

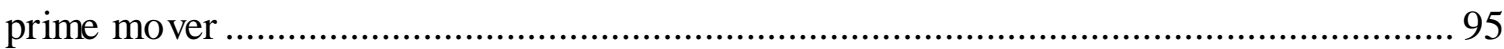

Figure 6.14: 40Hz oscillation on electrical side with $700 \mathrm{uF}$........................................ 96

Figure $6.15: 40 \mathrm{~Hz}$ oscillation on electrical side with $700 \mathrm{uF}$ cap plus $20 \mathrm{~Hz}$ oscillation on

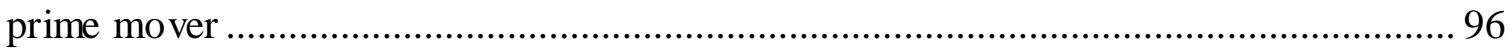

Figure 6.16: FFT results for $10-30 \mathrm{~Hz}$ frequency range with $700 \mathrm{uF}$ cap ......................... 98

Figure 6.17: FFT results for $10-27 \mathrm{~Hz}$ frequency range with $600 \mathrm{uF}$ cap ........................ 98

Figure 6.18: FFT results for $10-30 \mathrm{~Hz}$ frequency range with $500 \mathrm{uF}$ cap ........................ 99 
Figure 6.19: 700,600 and 500uF series compensated line 100 


\section{Chapter 1}

\section{Introduction}

The purpose of power system dynamic stability analysis is to study oscillation modes and their relationship with controllers' variables and parameters. Understanding this relationship allows engineers to identify instability sources and develop solutions which ensure reliable operation of the system for the small disturbances.

Turbine-generators have torsional natural frequencies due to physical properties of their long multi-element shafts. Power electronics devices such as series capacitors, HighVoltage Direct Currents (HVDC) line, Voltage Source Converters (VSCs), etc. in AC transmission networks tend to reduce damping of torsional vibrations of nearby turbine generators [6]. Series capacitors are extensively used as an effective means of increasing power transfer capability. This is due to partially compensating the reactance of the transmission lines. Moreover, they are used to improve transient and steady state stability in power systems. However, the application of series capacitors may lead to the phenomenon of sub-synchronous resonance (SSR). Under a disturbance, series capacitors may excite subsynchronous oscillations, when the electrical resonant frequency of the network is close to natural torsional mode frequency of a turbine-generator shaft [6]. Under such circumstances, the shaft will oscillate at this natural frequency.

This oscillation might grow to endurance limit in seconds resulting in shaft fatigue and possibly damage and failure. Therefore, there is a need to investigate and analyze SSR when planning inclusion of series capacitors for new or existing power system [7]. 


\subsection{Objective}

The objective of this thesis is to design a power system model to emulate SSR. The existence of SSR and its severity can be verified using simulation and analytical tools such as SIMULINK/MATLAB and EMPT-RV. Aside from the simulations, power system facilities are employed to emulate a real model of SSR. The software and hardware data combined, provides a comprehensive study. The power system lab is equipped with a synchronous generator with 10 s time constant, transmission line emulator with per-unit impedance equivalent to a $600 \mathrm{~km}$ line, and stiff grid.

This equipment replicates the behavior of a power system. In this thesis, a control method is designed and used to emulate disturbances on the mechanical shaft. A user interface and control are implemented in National Instrument's LabVIEW software, and a CompactRIO FPGA-based hardware system.

\subsection{Thesis Structure}

This thesis describes and illustrates the process by which the objectives of the research are obtained. Although the focus of the research is on the SRR, it is important to investigate various types of sub synchronous interaction to understand the importance of power system stability better.

Therefore, an extensive literature review of SSR and past research is provided. More specifically, the likely scenario of SSR and various types of sub-synchronous interaction. This detailed information is given in Chapter 2. The simulation model and system description are analyzed and explained at the beginning of Chapter 3. 
Chapter 4 describes the model results and control scheme including the effect of series compensation, and generator behavior under SSR condition. Model implementation in the power system lab is shown in Chapter 5, with the emphasis on the unique method to emulate the mechanical disturbances on the shaft. In addition, this chapter includes all results obtained for the experimental test rig and the power system behavior under the series compensation effect. Conclusions and future work that extends the scope of this research are expressed in chapter 6. 


\section{Chapter 2}

\section{Sub-synchronous Interactions}

Sub-synchronous oscillation $(<60 \mathrm{~Hz})$ in power systems can be amplified and sustained due to the physical interactions, which involve exchange of energy between two power facilities. Such phenomena is called Sub-synchronous Interactions. This chapter reviews causes, classifications and prior research on SSI. SSI is a family of interactions that can be categorized as follows [31]:

- Sub-synchronous Torsional Interactions (SSTI)

- Sub-synchronous Control interactions (SSCI)

- Sub-synchronous Resonance (SSR)

\subsection{Torsional Vibration and Resonance}

All rotating equipment experience a torsional load: the load for each rotating mass on the turbine shaft results in torque that can cause a vibration problem; each turbine has a unique load profile. A torsional vibration analysis considers how these combined loads interact with the crankshaft, motor, coupling, resulting in stress and vibration on the system. A turbine mass' coupling with a generator's shaft has a Torsional Natural Frequency (TNF) [1]. 
Resonance is the tendency of a system to oscillate with the greater amplitude at certain frequencies. Frequencies at which the response is maximized are known as a system's resonant frequencies. The shaft of rotating equipment has a natural resonant frequency. That resonant frequency is maybe below the actual operating speed of the equipment [3]. As the shaft is being accelerated from standstill to normal operating frequency, resonance can create a point at which the machine experiences more than its usual degree of vibration.

In this case, torque is driven by the generator's shaft and the acceleration proceeds smoothly from standstill to operating speed. However, there is a momentary 'blip' at the point when the instantaneous speed passes that resonant point. At this point, operators can control the rate of acceleration. Operators are aware of the resonant point and ensure that the machine is not allowed to settle at that speed. For example, in Figure 2.1 vibrations are minimal at 900 RPM and as the speed increases the system becomes resonant at 1200 RPM when speed is at TNF. At resonance, the vibration response is greatly amplified [1], [3].

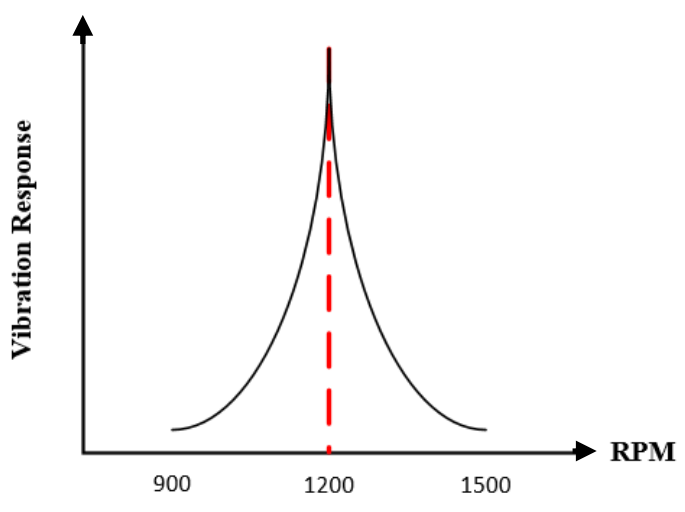

Figure 2.1: Illustration of the variation of torsional resonance with speed [15] 
Above the resonance frequency the vibration response is significantly reduced. The torsional analysis must accurately predict conditions and vibration problems otherwise, the result can become catastrophic such as destroying coupling or failure in the generator's shaft [1].

\subsection{Sub-synchronous Torsional Interactions (SSTI)}

Sub-synchronous torsional interaction (SSTI) caused by HVDC has been a well-known phenomenon since 1976, when sub-synchronous torsional interaction occurred between Square Butte HVDC and adjacent Milton Young turbine generator unit [37]. The HVDC systems may interact with the other dynamic devices in the power systems. The generator turbine torsional interactions with HVDC systems and interactions among multi-HVDC systems are some of the interaction phenomena [36].

Several factors are affecting the level of sub-synchronous interaction, but the main reason why HVDC reduces sub-synchronous damping is the control principle used to maintain power transmitted by HVDC around a single constant value. Constant power characteristics are obtained commonly using either constant current or constant power control as HVDC rectifier control mode. Another inherent characteristic of modern HVDC systems resulting decreased sub-synchronous damping is equidistant firing control used for the timing of valve firing. It was designed to replace equiangle firing control used in the very first HVDC schemes [38]. As equidistant firing control practically canceled the harmonic generation problem caused by the original equiangle firing control, equidistant 
firing control increased the deteriorating effect of HVDC on sub-synchronous damping [38].

The control system of HVDC is the component, which inherently causes interaction between HVDC and turbine generator. Particularly, parameters and structure of the rectifier current controller are conclusive regarding the level of the interaction, however other controllers may have an impact on it [38]. However, compared to the influence of the rectifier current controller their influence on interaction is minor [37]. As the control system, or above all the control principle of HVDC, is the cause of the interaction, the response of the control system on the critical torsional frequencies of certain unit can be affected by an additional control circuit [38]. This supplementary control called subsynchronous damping control is used to affect the transfer function of rectifier control. Thus, that control system related phase shift leading to growing sub-synchronous oscillation on certain natural frequency is cancelled [37], [38].

\subsection{Sub-synchronous Control Interactions (SSCI)}

Voltage Source Converters (VSC) are gaining widespread acceptance in interfacing renewable resources such as wind turbines, photovoltaic arrays, etc. [33]. Recent studies show that a VSC-based system may interact with a nearby synchronous machine through its incremental output impedance, and may reduce the damping at the torsional modes of the machine [33], [34]. In addition, studies reveal that there could be an interaction between the controllers of wind turbine-generator and a series compensated line. This interaction is called sub-synchronous Control Interactions (SSCI) [48]. The IEEE second benchmark (SBM) for SSR studies, shown in Figure 2.2 [35]. Such interactions depend on the VSC 
control mode (e.g. active and reactive power control, AC-voltage control, DC-voltage control, etc.), parameters of the control system, and physical parameters. Accordingly, the output impedance of a VSC may appear inductive or capacitive, which might shift the resonance frequencies of the network. On the other hand, the real part (resistive) of the output impedance of a VSC may induce a positive or negative resistance depending on the control system and control parameters of the VSC. These two effects directly influence the stability of a series-compensated system with a multi-mass generator [35].

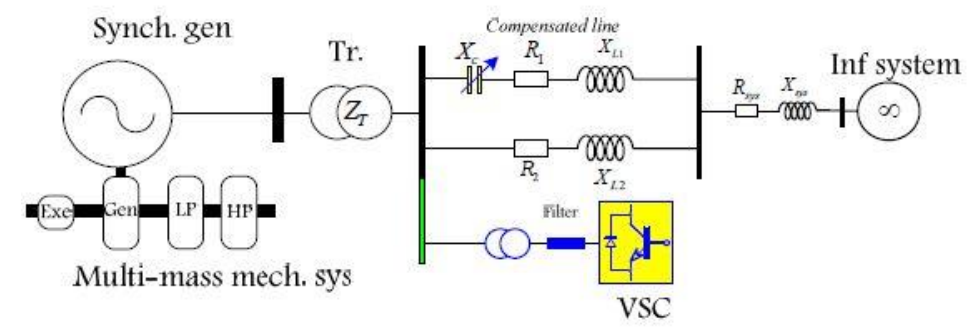

Figure 2.2: System under the study - IEEE SBM with VSC system [35]

\subsection{Sub-synchronous Resonance (SSR)}

Sub-synchronous Resonance (SSR) is a phenomenon in which the natural resonant frequency of the electrical system coincides with the resonant frequency of the turbine generator shaft such that there is a cyclic exchange of energy between the electrical system and the mechanical shaft [3].This exchange of energy results in torsional stress on the turbine generators shaft that can lead to severe damage. In extreme cases, the shaft can fracture. In 1970, and again in 1971, the Mohave generator in Nevada, USA experienced a growing vibration that eventually led to a fracture of the shaft between the rotating exciter 
and the generator [3]. Mohave is the only reported case of a shaft failure directly caused by SSR [3], [4]. The electrical torque of the generator can act stimulate the torsional vibration modes. Conversely, the torsional vibration changes the generator output voltage and excites the electrical oscillation at the fundamental $(50 \mathrm{~Hz}$ or $60 \mathrm{~Hz})$ complement frequency of the torsional vibration [2]. For instance, a $25 \mathrm{~Hz}$ torsional oscillation on a generator connected to a $60 \mathrm{~Hz}$ system will generate $35 \mathrm{~Hz}$ electrical oscillations. The generator's shaft couples the torsional vibration and the electrical oscillation for SSR interaction [6]. Figure 2.3 illustrates the schematic of mechanical and electrical side during in power system.

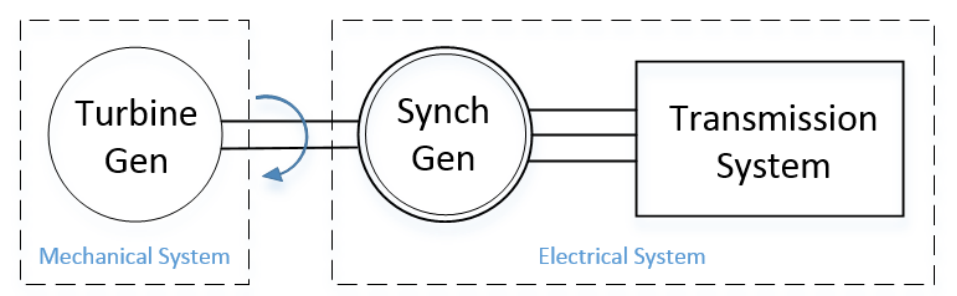

Figure 2.3: Mechanical and electrical system in power system

SSR involves a near exact match of the shaft resonances of a specific turbine generator and the electrical resonances of the series compensated transmission network. This condition typically requires the turbine-generator to be connected radial or nearly radial to a series compensated transmission line. 


\subsubsection{Sub-synchronous Resonance Likely Scenario}

The most likely scenario for SSI involves in the following cases:

\subsubsection{Multi Masses Shaft}

Turbine generators have natural mechanical resonant frequency that is in the order of 18$25 \mathrm{~Hz}$ [3]. The most likely candidates for this case are long shafts with multiple masses such as high and low-pressure turbine, generator, exciter, etc. The combinations of these masses result in natural resonant frequency and in most cases, a single shaft may have multiple resonance 'modes' or frequencies. The most common situation for SSR is a coalfired steam turbine generator because that structure tends to have a long, thin shaft with multiple masses and resonance modes [3].

There are no known published cases of SSR interaction between hydro generators and the electrical network. This is primarily due to the large inertia of the hydro generator with respect to the turbine (10 to 40 times higher). This results a very low mode shape, or torsional interaction factor, at the generator. A low mode shape means that the generator does not interact with the network at the torsional frequency [6]. However, it has been observed that hydro plants could face oscillations issue as well, particularly when they operate at their maximum capacity [15].

\subsubsection{Series Capacitors}

All electrical systems have an electrical resonant frequency. Typically, this frequency is much higher than the operating frequency of the system. However, resonant frequencies 
below synchronous frequency can be caused by the application of series capacitors [3]. Series capacitors have been widely used as an effective means of increasing power transfer capability of transmission system, and improving transient and steady state in a power system [3]. Series capacitors are used to introduce capacitive reactance into the transmission system which cancels the natural inductive reactance of transmission lines, to make transmission lines appear to be shorter than they are [7], [3]. Until 1971, it was believed that up to $70 \%$ series compensation could be used in any transmission line with little or no concern [16]. However, in 1971 it was shown that series capacitors can create an adverse interaction between the spring-mass mechanical system of the turbine generator and the series compensated electrical system [16].

Theoretically, the application of series capacitors may lead to the phenomenon of SSR [16]. Under a disturbance, series capacitors may excite SSR, when the electrical resonant frequency of the network is close to natural torsional mode frequency of turbine-generator shaft [6]. A likely scenario would be a coal-fired steam turbine generator that must transmit power over a long transmission line including series compensation. Therefore, there is a need to investigate and analyze SSR when power system comprising series capacitors for new or existing power system [3].

Figure 2.4 shows an example of a measured SSR instability during tests at the Wyodak generating plant when several lines were out of service [6]. This plot shows the torsional angle displacement at the turbine end of the shaft. A series capacitor was inserted at the start of the test, causing a growing torsional oscillation. Bypassing the series capacitor 128 seconds after the start of the test removed the unstable SSR conditions and the torsional oscillations decay [6]. 


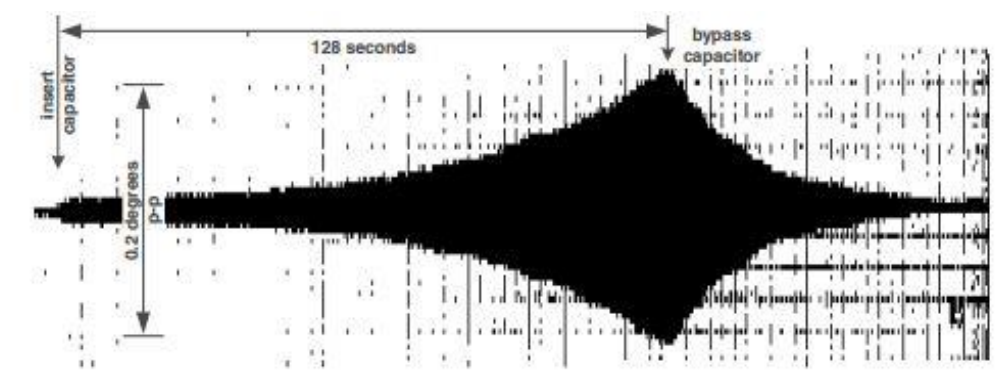

Figure 2.4: Sub-synchronous Resonance - Torsional Angle Displacement [6]

Series compensation in the line, results in excitation of sub-synchronous currents at an electrical frequency $f_{\text {er }}$ given by [39], [40]:

$$
f_{e r}=f_{0} \sqrt{\frac{X_{c}}{X_{N}}}
$$

Where, $X_{C}$ is the reactance of the series capacitor, $X_{N}$ is the reactance of the line including that of the generator and transformer, and $f_{0}$ is the nominal frequency of the power system. Typically, $X_{c}$ can be up-to $60-70 \%$ of $X_{N}$. Hence, $f_{e r}<f_{0}$ the sub-synchronous currents result in rotor torques and currents at the complementary frequency $f_{r}$ [39], [40].

$$
f_{r}=f_{0}-f_{e r}
$$

These rotor currents result in sub-synchronous armature voltage components that may enhance sub-synchronous armature currents to produce SSR [39], [40]. 


\subsubsection{Short Circuit}

In some cases, the coincidence of both electrical and mechanical resonance is not sufficient. Thus, a stimulus is needed to trigger the interchange of electrical and mechanical energy between the transmission system and the turbine generator shaft. The most common stimulus is a single-line to ground short circuit [3]. In this case, fault clearing time has a significant effect on the magnitude of torque's oscillation [16]. Sub-synchronous resonance is addressed in three categories: induction generator effect, torsional interaction and torque amplification. SSR is due to the interaction of a series capacitor with turbine-generator. The first two categories are caused by a steady state disturbance, while the third is caused by transient disturbances.

There are three methods to analyze SSR: frequency scanning, eigenvalue analysis and the time domain simulation [7], [8], [9]. Frequency scanning is used to study induction generator effects [7], [10]. The eigenvalue analysis identify the frequencies of subsynchronous oscillations and damping of each frequency from state space model of the entire system [4], [7]. This analysis is regarded as a sound measurement of the proper operation of SSR [11]. Time domain simulation is performed in different types of programs such as EMTP (Electromagnetic Transient Program). These studies provide vital information regarding peak shaft that is to be expected when a certain level of series compensation is applied [7], [12].

\subsubsection{Sub-synchronous Resonance Classifications}

Sub-synchronous resonance is addressed in three categories [7]: 
1. Torque amplification

2. Induction generator effect

3. Torsional interaction

\subsubsection{Torque Amplification}

Series capacitors tend to amplify the shaft stress during major network transient events above the stress level that would exist without the series capacitors. Transient torque or torque amplification (TA) becomes a concern only when the series compensated transmission line and the mechanical shaft resonances of a specific turbine-generator are closely aligned [2]. If SSR stability studies show this alignment, studies should be performed to evaluate the transient torque on the turbine-generator shaft and the resulting loss of life of the shaft. The critical measure of the transient torque is the magnitude of the shaft vibration excited during each network transient event and the fatigue on the turbine generator shaft. The following figure shows an example of SSR transient torque amplification. This example depicts a system with $70 \%$ and $60 \%$ series compensation [6].
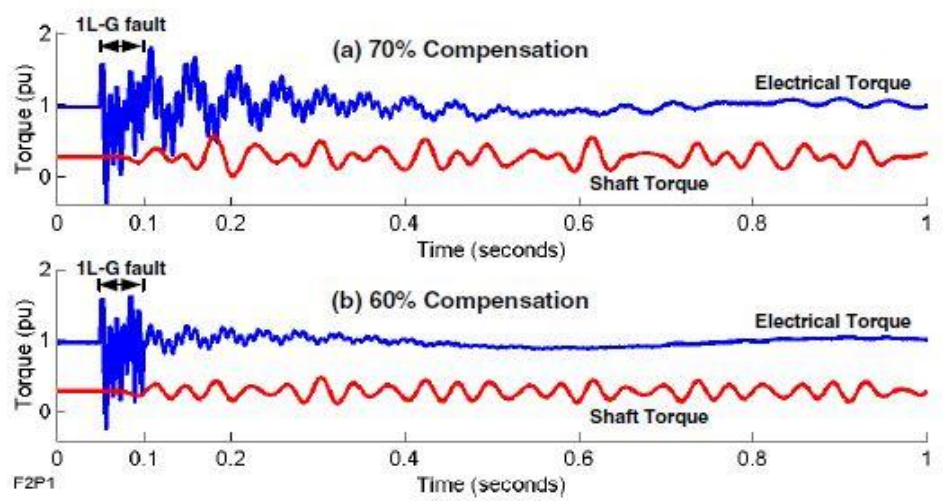

Figure 2.5: Sub-synchronous Resonance - Transient Torque Amplification [6] 
In Figure 2.5, the electrical torque and High-Pressure and Intermediate-Pressure shaft torque are shown in per unit on the generator base. The peak-to-peak torque on the HP-IP shaft with $70 \%$ series compensation is double of that with $60 \%$ compensation. This is due to the alignment of the electrical resonance of the electrical network with the torsional resonant frequency with $70 \%$ series compensation. With $60 \%$ series compensation, the electrical system resonance is shifted sufficiently to avoid transient torque amplification.

Although there is no record of severe damage due to transient torque amplification, the anticipation of this problem has led to several system designs and operating criteria that limit the amount of cumulative stress the turbine-generator would be exposed to through highly compensated lines after a system fault clearance. A similar type of shaft torque amplification can occur with automatic high speed reclosing of transmission lines. Reclosing, particularly when the fault still exists, can result in an increase in the torsional oscillations which have not decayed sufficiently from the first fault clearing [6].

\subsubsection{Induction Generator Effect}

Induction generator effect involves only electric system dynamics. Generator armature currents at sub-synchronous frequency $\left(f_{\text {er }}\right)$ produce a component of rotating MMF in the armature air gap of angular velocity $2 \pi f_{e r}$ [40], [41]. This MMF interacts with the main field air gap MMF to produce torques at sub-synchronous frequency $\left(f_{0} \pm f_{\text {er }}\right)$. If the generator rotor torsional mode frequency $\left(f_{n}\right)$ is different from the sub-synchronous torque frequency $\left(f_{0}-f_{e r}\right)$ then relatively little torsional interaction takes place [40], [41]. However, because the rotor circuits are rotating faster than the rotating mmf, the resistance of the sub-synchronous current viewed from the armature terminal is negative. This is due to the induction machine theory. 
When this negative resistance exceeds the sum of the armature and network resistance at the resonant frequency $\left(f_{e r}\right)$, the armature currents can be sustained or grow. This phenomenon is called the induction generator effect [40], [41]. Wind farms comprising squirrel cage induction generators are also susceptible to the induction generator effect. As the rotating MMF produced by the sub-synchronous frequency armature currents moves at speed $\omega_{s}$, which is slower than the speed of the rotor $\omega_{r}$, the resistance of the rotor (at the sub-synchronous frequency viewed from the armature terminals) is negative as the slip 's' of the induction generator is negative. The slip is defined as:

$$
s=\frac{\omega_{s}-\omega_{r}}{\omega_{s}}
$$

When self-excitation starts in a network, sub-synchronous electrical currents tend to increase rapidly [39]. SSR may reveal itself in the form of overvoltage as induction generator effect (IGE) in series compensated system [5], [9]. Therefore, there is always a possibility of SSR due to IGE even in hydro generators. [5], [9] stated that the IGE effect is only concerned when:

1. The magnitude of the equivalent rotor resistance viewed from the stator side of the generator is greater than the summation of the resistance of transformer and transmission line [5], [14]. Or,

2. The summation of the resistance of transformer and transmission line is less than the equivalent rotor resistance viewed from the stator side of the generator. In practical condition both these are possible but needs to be taken care to avoid the IGE during planning a new generating station with existing transmission line or new transmission line with existing generating station [5], [14]. 


\subsubsection{Torsional Interaction}

As explained previously, when the natural resonant frequency of the electrical system coincides with the resonant frequency of the turbine generator shaft, there is a cyclic exchange of energy between the electrical system and the mechanical shaft. This exchange of energy results in torsional stress on the turbine generators shaft that can lead to severe damage. In extreme cases, the shaft can fracture [3].

For the discussion of torsional interaction (TI) Figure 2.6 shows a simple system, consisting of a turbine-generator connected to a single series compensated transmission line. The turbine-generator has two masses connected by a shaft. The two masses act as a torsional spring. There are damping elements between the two masses, and each mass has a damping element [16].

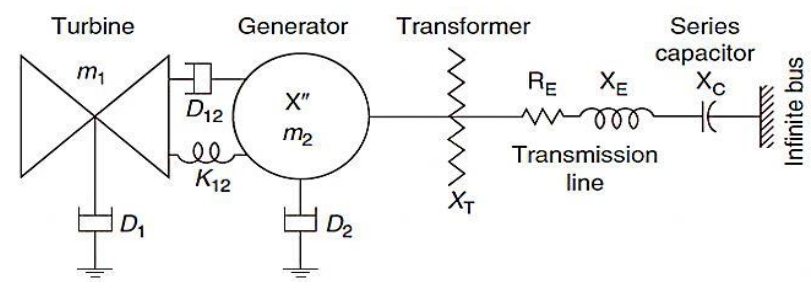

Figure 2.6: A simple power system network [16]

The mechanical spring-mass system has a single natural frequency $f_{n}$ and the electrical system has a single resonant frequency $f_{e r}$. The electrical grid including several series compensated lines may result in numerous resonance frequencies $f_{\text {er } 1}, f_{\text {er } 2}, f_{\text {er } 3}$, etc. Besides, the turbine-generator with several masses connected by shafts, resulting in several torsional natural frequencies $f_{n 1}, f_{n 2}, f_{n 3}$, etc. [16]. For all the power system disturbances, 
in generator output at frequency $f_{\text {er }}$ there is an armature current flow. A rotating magnetic field is produced at an angular electrical speed of $2 \pi f e r$ due to the positive sequence component of these currents. [16]. Inside the rotor winding currents are induced due to the relative speed of this rotating field. The armature magnetic field, rotating at an angular frequency of fer, interacts with the rotor's dc field. Rotating at an angular frequency of fo, develops an electromagnetic torque component in the generator rotor at an angular frequency of fo-fer. This torque component contributes to torsional interaction [16].

\subsubsection{Sub-synchronous Resonance Analysis Techniques}

In power systems there are several techniques available for the study of sub-synchronous resonance. The most common methods are [7]:

- Frequency scanning

- Eigenvalue analysis

- Transient torque analys is

\subsubsection{Frequency Scanning}

The frequency scanning method is used for a preliminary analysis of sub-synchronous resonance. It provides the driving point impedance determination over the frequency range of interest as viewed from the neutral bus of the generator [49]. The equivalent reactance and resistance are computed by looking into the network from a point of the stator winding. Frequency scanning can provide information regarding the possible problems with 
torsional interaction and transient torques [24], [41], [43]. They also are relatively inexpensive for systems with 100 to 150 buses. Therefore, the frequency scanning technique is cost effective and easy to screen out those system conditions that are potentially hazardous from an SSR standpoint [13].

\subsubsection{Eigenvalue Analysis}

Eigenvalue analysis is extensively utilized for the study of torsional interaction and induction generator effect. This analysis is studied through the linearized model of the power system. The basic procedure of the eigenvalue analysis encompasses [9], [24], [45], [46]:

(a) Development of a positive sequence model of the power system

(b) Modeling of generator electrical circuits

(c) Modeling of turbine-generator spring mass system

(d) Calculation of eigenvalues of the interconnected systems

(e) Real component of eigenvalues corresponding to the sub-synchronous modes of the turbine-generator spring mass system indicates the severity of torsional interaction

(f) Real component of eigenvalues corresponding only to electrical system resonant frequencies reveals the severity of the induction generator effects problem

The real part of the eigenvalue is a direct measure of the negative or positive damping for each mode [9], [24], [45], [46]. 


\subsubsection{Transient Torque Analysis}

To determine the potential for SSR torque amplification, electromagnetic transient analysis is performed. This analysis finds the peak transient shaft torque that is to be expected when a fault or equipment switch takes place in a series compensated line [4], [9], [24], [41]. SSR analysis can be carried out through a comprehensive eigenvalue analysis. The eigenvalue analysis is then reasonably validated through the electromagnetic transient simulation such as PSCAD or EMTP-RV software.

\subsubsection{Sub-synchronous Resonance Analysis in Alberta}

Series compensation is proposed for some of the new $240 \mathrm{kV}$ lines in the southern region in Alberta [31]. SSR is a concern in series compensated networks. The series capacitor can result in an electrical resonance in the sub-synchronous frequency range $(0-60 \mathrm{~Hz})$. The shaft system of a gas turbine or thermal unit can contain numerous turbines, generators, and mechanical exciters masses. This results in a fixed set of mechanical frequencies of oscillation, often in the sub-synchronous range. SSR is a direct concern if the frequencies of the electrical resonances correlate with the mechanical modes of oscillation. Typically, the worst cases result when there is a direct radial path between the generator and the serie $\mathrm{s}$ capacitor. In this case, a high degree of torsional interaction occurs, resulting in shaft damage due to undamped oscillations. Harmonic impedance scans were performed to compute the electrical impedance as seen from the generator [31]. Resonance in the sub-

synchronous frequency region will result in an "impedance dip" - i.e. a variation in the 
impedance at the resonant frequency. The size of the impedance dip is an approximate indicator of the likelihood for SSR [31].

\subsubsection{Thermal Power Plant Concerns in Alberta}

Due to interacting with the series capacitor banks, the Sheerness, Carseland and Cavalier power plants are considered for potential SSR [31]. As seen from behind each generator, impedance frequency scans of the electrical network were performed to determine the resonant frequencies of the electrical network under the base case and contingency conditions. Contingencies were selected up to Category $\mathrm{C}$ which place the generator more radially connected to the nearby series capacitor banks.

The harmonic impedance studies indicate that the new series capacitor will not have an adverse impact on the SSR performance of these generators, up to Category C contingency/outage conditions. Torsional stress relays detect undamped or growing subsynchronous oscillations and trip units if the oscillations get too large. These relays could be utilized at nearby units as a precaution for SSR impacts [31].

\subsubsection{Wind Farm Concerns}

Wind farms can be affected by nearby series compensation lines. It is suggested that when a large number of wind turbines are aggregated, the SSR issue might become more prominent [31]. The SSR is effected by specific type of wind farm model. According to SSR experts consulted by the AESO, some studies have indicated that doubly fed wind 
turbines demonstrated low-frequency control instabilities and control interactions, whereas a full converter model appeared to function well in these conditions [31]. Frequency scans of the electrical network were performed for the wind farms at Peigan, Goose Lake, and Vulcan substation. The scans are as seen from behind an equivalent inductance approximating the wind farm generator impedance and transformer reactances to determine the resonant frequencies of the electrical network.

This study is performed under base case and contingency conditions [31]. Again, contingencies were selected up to Category $\mathrm{C}$ which places the generator more radially connected to the nearby series capacitor banks [31]. In Figure 2.7, Top: wind turbine (or aggregated wind farm) radially connected to series-compensated transmission system. Bottom: principle of SSR formation: an SSR might be triggered if the resonance frequency of the wind turbine matches the resonance frequency of the network [32].

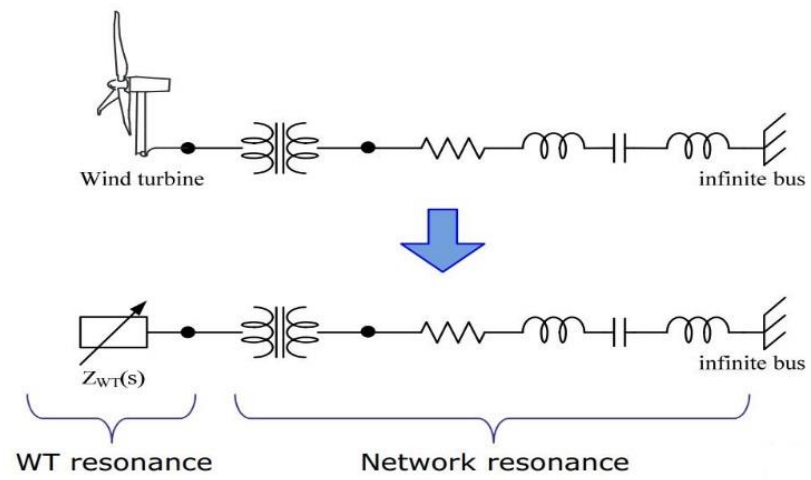

Figure 2.7: Wind turbine connected to series-compensated transmission system [32]

Possible mitigation to avoid the SSR impacts on wind farms associated with series capacitors may include modifications to wind controls, if accommodated by the manufacturer. The AESO will not be directly involved in manufacturer negotiations for 
wind turbine control modifications [31]. Other mitigation options include the use of SSR bypass filters across each series capacitor bank or power electronic alternatives such as thyristor controlled series capacitors [31]. To protect wind farms from SSR oscillations, a relay has recently been developed by ERL phase power technologies [74]. This relay is used to detect the oscillation of frequency band between $5-25 \mathrm{~Hz}$ [47].

\subsection{Nature of Electromechanical Oscillations}

Electrical power systems are complex, due to consisting of a vast number of dynamic devices such as synchronous machines and loads. They have the potential to be exposed to sudden small disturbances (and quite frequently to large disturbances) in generation, load, and transmission network configuration. The appearance of low-frequency oscillations in some part or between parts of the interconnected power system is a usual phenomenon. In general, these oscillations occur in interconnected power systems when the synchronous generators swinging against each other. Since the phenomenon involves mechanical oscillations of the rotor and oscillations of the generated electrical power, these oscillations are called electromechanical oscillations.

Oscillations can lead to fatigue of machine shafts, and excessive wear of mechanical actuators of machine controllers. [17]. Furthermore, their presence may increase the risk of system breakdown. Therefore, it is desirable that oscillations are well damped for a range of possible power system operating conditions [17 [17]. The occurrence of poorly damped low frequency electromechanical oscillations in electric power systems have constituted the main stability problem during the last decades. Problems with these oscillations are of 
major concern for system control and operation security analysis. These low frequency oscillations (up to $2 \mathrm{~Hz}$ ) are associated mainly with electromechanical torque imbalances at synchronous generators, producing tie-line oscillatory power exchanges [18]. Excitation systems with fast response times and a large gain provide an excessive benefit to the transient stability. However, they can also reduce small signal stability like damping torque.

Power system stabilizer (PSS) control plays a significant role by damping generator rotor angle swings, which are in a broad range of frequencies in the power system [19]. These range from low frequency or intertie modes (typically $0.1-1.0 \mathrm{~Hz}$ ), to local modes (typically $1-2 \mathrm{~Hz}$ ), to intra-plant modes (about $2-3 \mathrm{~Hz}$ ) [19]. The low frequency modes, called intertie or inter-area modes. They are caused by coherent groups of generators swinging against other groups in the interconnected system. These modes occur in all interconnected systems and the damping is a function of unit loading factors and tie line strength [19]. Heavy system loads and weak ties due to line outages can result in poorly damped intertie modes. PSS control provides significant improvements in intertie mode damping, by applying stabilizers to most units that participate in power swing modes. PSS performance is frequently evaluated from the damping of the "local mode," the generator swinging against the rest of the power system. This mode is usually occur at frequencies between 1 and 3 Hertz. Lighter loading and stronger system ties tend to give higher local mode frequencies, and heavier loading and weaker ties have a tendency to give lower local mode frequencies.

PSS must be designed in a way to provide remarkable performance over a wide range of system conditions, which may result from different operating conditions such as varying 
load levels and lines out-of-service [19]. In power systems, oscillations are classified by the system components and their effects. Some of the major system collapses attributed to oscillations are described below [20].

Electromechanical oscillations are of the following types:

- Intra-plant mode oscillations

- Local plant mode oscillations

- Inter-area mode oscillations

- Control mode oscillations

- Torsional modes between rotating plant

\subsubsection{Intra-plant Mode Oscillations}

In the same power generation site, machines oscillate against each other at 2.0 to $3.0 \mathrm{~Hz}$ depending on the reactance connecting and unit ratings [20]. This oscillation is termed as intra-plant because the oscillations manifest themselves within the generation plant complex. The rest of the system is unaffected [20].

\subsubsection{Local plant Mode Oscillations}

In local mode, one generator swings against the rest of the system at 1.0 to $2.0 \mathrm{~Hz}$. The variation in speed of a generator is shown in Figure 2.8 [20]. The impact of the oscillation is localized to the line connecting it to the grid and the generator. The rest of the system is normally modeled as a constant voltage source whose frequency is assumed to remain 
constant. This is known as the single-machine-infinite-bus (SMIB) model [21]. The frequency and damping vary with machine output and the infinite bus voltage and the impedance between the machine terminals. The oscillation may be removed with a single or dual input PSS. This input provides modulation of the voltage reference of the Automatic Voltage Regulator (AVR) with proper gain and phase compensation circuit [21].

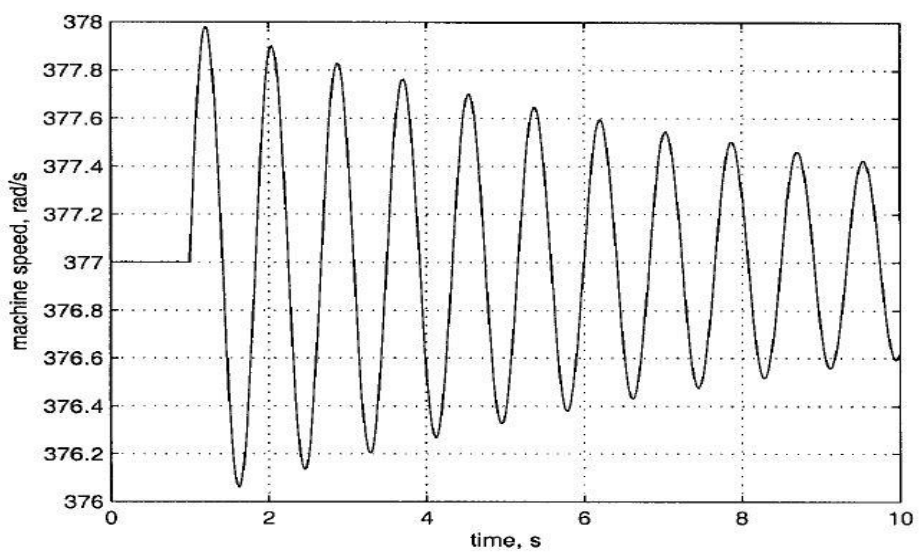

Figure 2.8: A typical example of local oscillation [21]

\subsubsection{Inter-area Mode Oscillations}

Power system oscillations usually contain multiple frequency components (modes), which are determined by generator inertia, transmission line impedance, governor and excitation control, etc.[25]. For generators close to each other (in the same area), the electric link between generators are relatively strong. The oscillations between these generators tend to be at relatively higher frequencies. In the mean-time, generators in the same area can also oscillate against generators in the neighboring areas. This is called inter-area oscillation and the frequency is called inter-area modes [21]. 


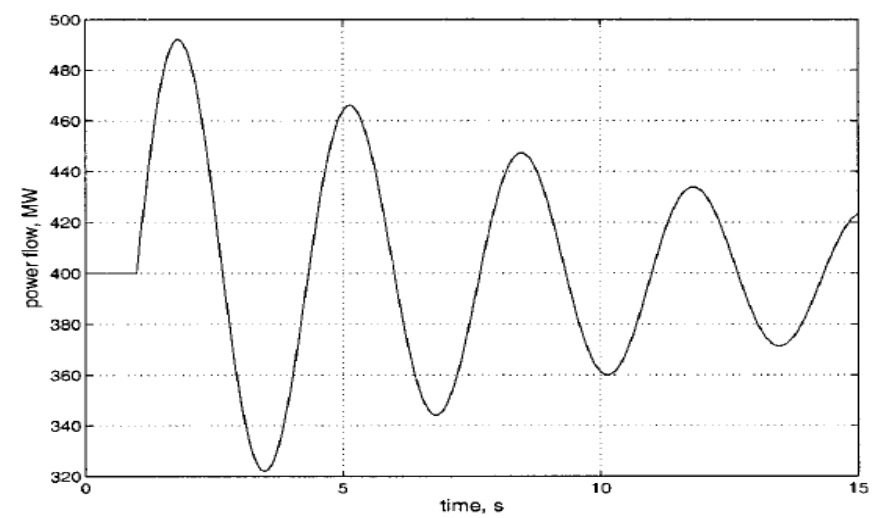

Figure 2.9: A typical example of inter-area oscillation [21]

This phenomenon is considered and observed over a large part of the electrical network. In inter-area mode, two coherent group of generators swinging against each other at $1 \mathrm{~Hz}$ or less. The large variation in tie-line power is shown in Figure 2.8 as an example [21]. The oscillation frequency is roughly $0.3 \mathrm{~Hz}$. This complex phenomenon impacts on many parts of the system with highly non-linear dynamic behavior [21]. The damping behaviour of the inter-area mode is influenced by the tie-line strength and the power flow through the interconnection. In addition, the behaviour is dictated by the nature of the loads, the interaction of loads with the dynamics of generators and their associated controls. The operation of the power system with the presence of a lightly damped inter-area mode is complicated [26].

\subsubsection{Control Mode Oscillations}

These oscillations are related with poorly tuned exciters, generators, HVDC converters, governors, and Static Voltage Compensator (SVC) controls. Excitation systems and load 
can interact through control modes [21]. Transformer tap-changing controls can also interact in a complex manner with non-linear loads giving rise to voltage oscillations [23].

\subsubsection{Torsional mode oscillations}

These modes are associated with a turbine generator shaft system in the frequency range of 10-46 Hz. A typical oscillation is shown in Figure 2.10 [21].

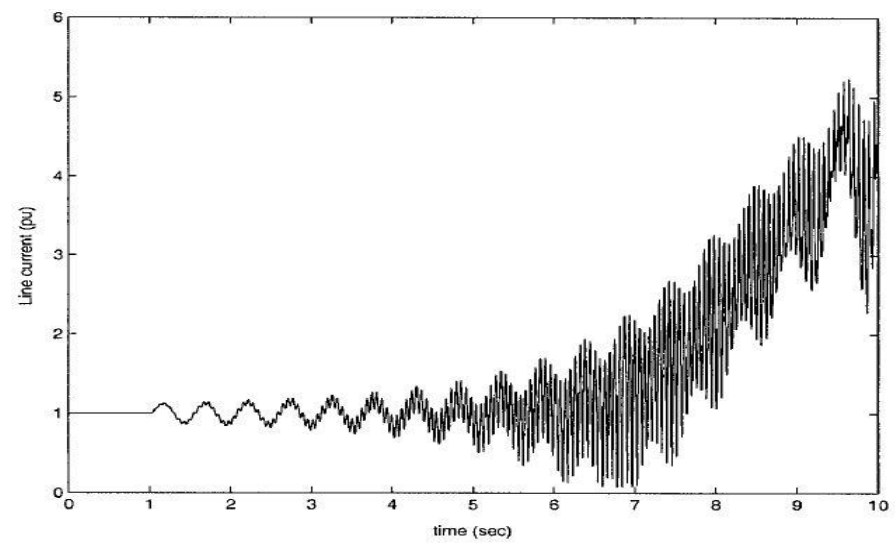

Figure 2.10: A typical example of torsional mode oscillation [21]

Generally, these modes are excited when a multi-stage turbine generator is connected to the grid system through a series compensated line [24]. A mechanical torsional mode of the shaft system interacts with the series capacitor at the natural frequency of the electrical network. The shaft resonance appears when network natural frequency equals synchronous frequency minus torsional frequency [50]. 


\subsection{Role of Oscillations in Power Blackouts}

Inter-area oscillations have led to many system separations but few wide-scale blackouts [25-26]. The incidents include:

- Detroit Edison (DE-Ontario Hydro (OH)-Hydro Quebec (HQ) (1960s, 1985)

- Finland-Sweden-Norway-Denmark (1960s)

- Saskatchewan-Manitoba Hydro-Western Ontario (1966)

- Italy-Yugos lavia-Austria (1971-1974)

- Western Electric Coordinating Council (WECC) $(1964,1996)$

- Mid-continent area power pool (MAPP) $(197$ 1,1972)

- $\quad$ South East Australia (1975

- $\quad$ Scotland-England (1978)

- Western Australia $(1982,1983)$

- Taiwan (1985)

- Ghana-Ivory Coast (1985)

- Southern Brazil (1975-1980,1984)

\subsubsection{Oscillations in the WECC system}

Power transfer capability has been improved in Western Electricity Coordinating Council (WECC) by stability considerations for 40 years because of the long distance between power sources and load centers. Oscillations have resulted in system instability and separation on several occasions. They were caused by weak mitigations and insufficient damping. The oscillations role in this power system has influenced the system planning, 
operation and design strategy. Insufficient damping turned out to be the major constraint when in 1964, the Northwest United States and Southwest United States were interconnected through the Colorado River Storage Project [50].

In less than a year of interconnected operation, there were at least a hundred tie-line separations due to system oscillations frequency, voltage and, power. In 1965, the problem was solved by modifications to one of the hydro-unit governors [27]. The frequency of oscillation and the amount of damping varies with system operating conditions. Reliable operation is one of the significant role in power system and it requires an advanced oscillation damping control strategy that can improve the stability and reliability. It is compulsory to have analysis techniques and comprehensive modeling of all the components that may interact to produce oscillations [20]. 


\section{Chapter 3}

\section{Lab Grid Connected Power System Model}

After studying the definition and influence of SSR in power systems, a model is proposed to emulate SSR in the power research laboratory at $\mathrm{U}$ of $\mathrm{C}$. The project began by modeling the SSR in the Matlab/Simulink and using the toolbox SimPowerSystems to model the dynamic rotating system to add a control desired response. In order to simulate the power system model in the Simulink, real parameters of the Synchronous Generator, DC Motor and Transmission Line in the ENA lab are required. The simulation model process is outlined in phases as follows:

- Transmission Line Parameters Measurement

- Synchronous Generator Parameters Measurement

- DC Motor Parameters Measurement

Grid connected power systems typically consist of a prime mover or a DC motor, synchronous or induction generator, transmission line and stiff grid. The generator is connected to the prime mover through the shaft allowing it to transform the mechanical energy into electrical energy. The Figure 3.1 shows the typical power system model in the power lab that will be applied for this thesis and the experiment test rig. 


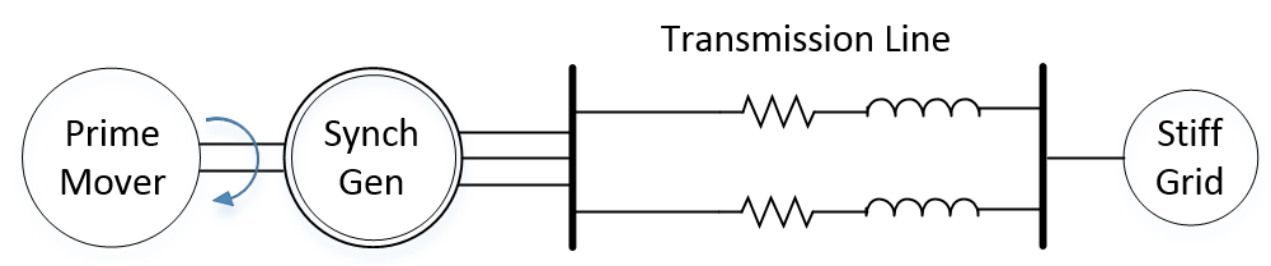

Figure 3.1: Grid connected power system model in ENA power lab

\subsection{Transmission Line Parameters Measurement}

To provide the precise results and analysis, the transmission line parameters are measured accurately. The transmission line has 6 stands and each stand includes $6 \pi$-sections as seen in the Figure 3.2. Each pole has two $\pi$-sections and each $\pi$-section represents $50 \mathrm{~km}$. To measure resistance, inductance and capacitance of the $\pi$-section 3-phase Variable Voltage Supply is used. Current is injected via autotransformer and the voltage across the resistance is measured for each $\pi$-section. The FLUKE93 power meter is employed to monitor active and reactive power in each experiment. The same process was undertaken for each phase to calculate the precise value. Figure 3.3 shows the schematic of the pi-line. 


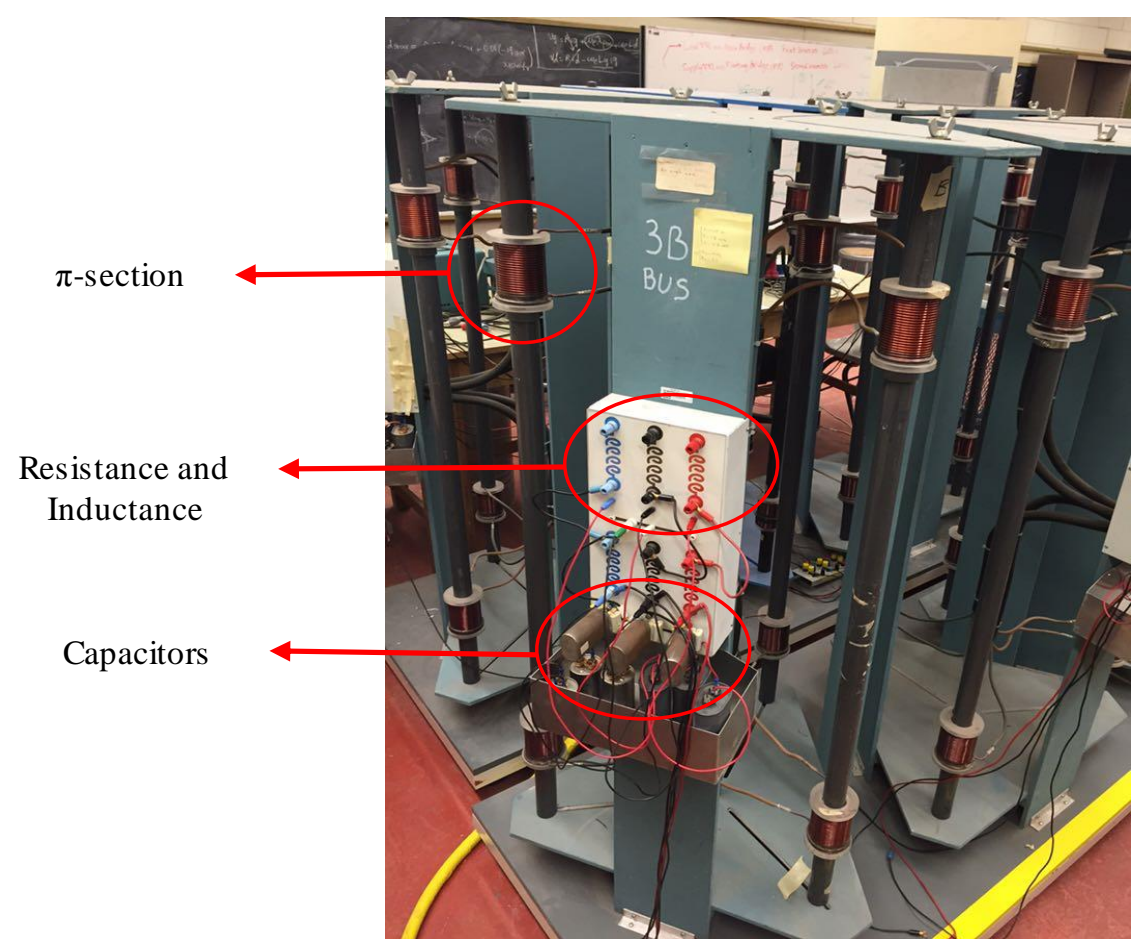

Figure 3.2: Transmission line (Power Lab)

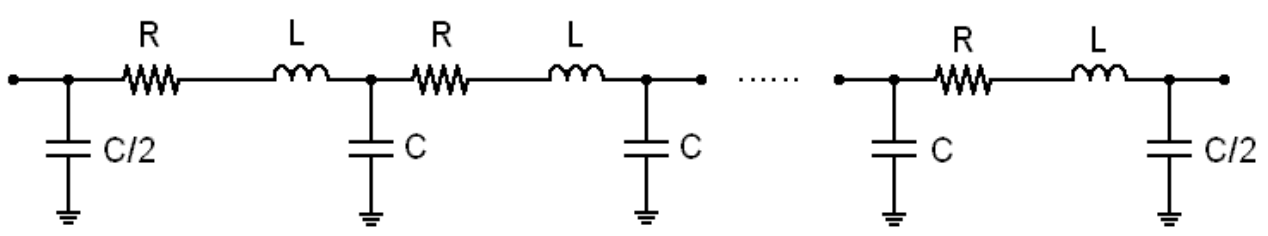

Figure 3.3: Schematic of a $\pi$-line in the power lab

\subsubsection{Inductance Measurements}

The Power Analyzer PA2200 series is used to measure the RL parameters. The readings for one $\pi$-section is depicted by the table and figure below. 


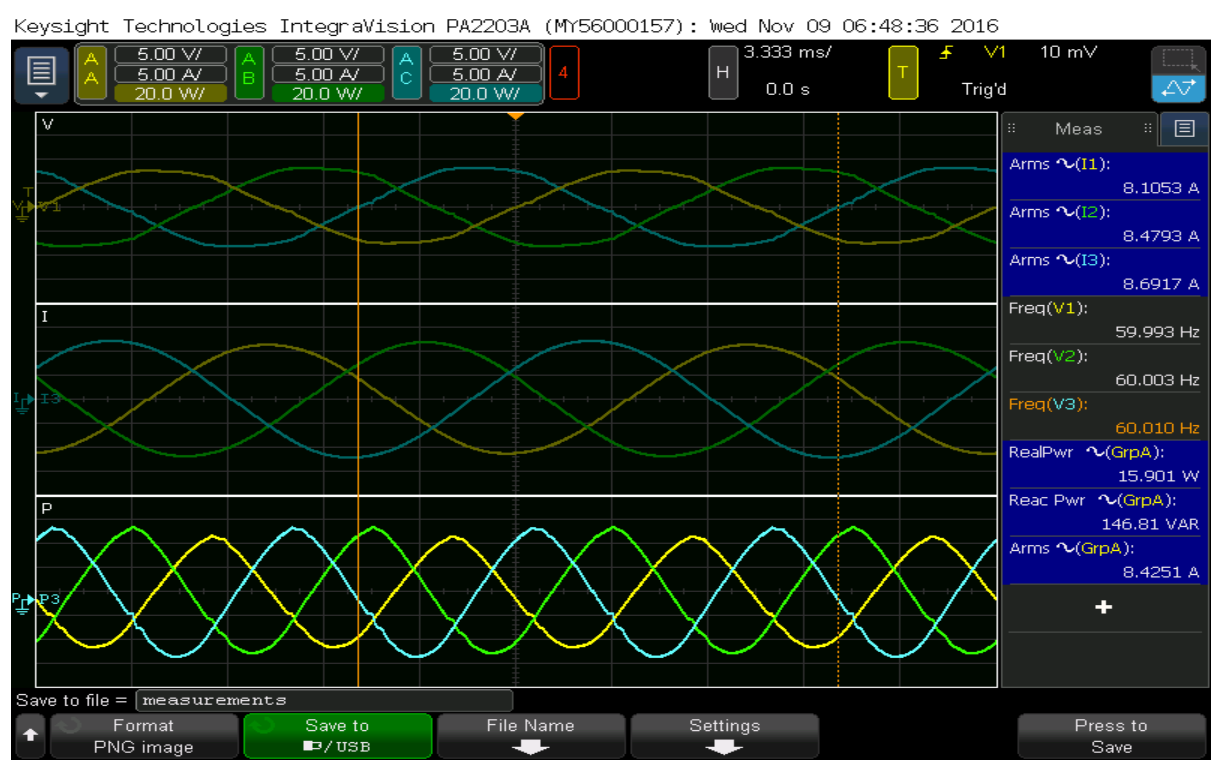

Figure 3.4: Three phase RL measurement for one coil (50km)

\section{\begin{tabular}{l|l|l|l} 
3-Phase & $\mathrm{I}=8.4251 \mathrm{~A}$ & $\mathrm{P}=15.901 \mathrm{~W}$ & $\mathrm{Q}=146.81 \mathrm{VAR}$
\end{tabular}}

Table 3.1: Three phase RL measurement for one coil

$$
\begin{gathered}
Q=3 X I^{2} \\
X=\frac{146.8}{8.425^{2} * 3}=0.689 \Omega \\
0.689=120 \pi L
\end{gathered}
$$


Readings for $6 \pi$-section are shown in the table below. Rated current of the line is 8.3A.

\begin{tabular}{|l|l|l|l|l|l|}
\hline 1 $^{\text {st }}$ Measurement & $\mathrm{I}=6 \mathrm{~A}$ & $\mathrm{~V}=45.7 \mathrm{~V}$ & $\mathrm{P}=0.08 \mathrm{KW}$ & $\mathrm{Q}=0.46 \mathrm{KVAR}$ & $\mathrm{Pf}=0.17$ \\
\hline $\mathbf{2}^{\text {nd }}$ Measurement & $\mathrm{I}=8.28 \mathrm{~A}$ & $\mathrm{~V}=63 \mathrm{~V}$ & $\mathrm{P}=0.15 \mathrm{KW}$ & $\mathrm{Q}=0.89 \mathrm{KVAR}$ & $\mathrm{Pf}=0.17$ \\
\hline $\mathbf{3}^{\text {rd }}$ Measurement & $\mathrm{I}=8.34 \mathrm{~A}$ & $\mathrm{~V}=63 \mathrm{~V}$ & $\mathrm{P}=0.16 \mathrm{KW}$ & $\mathrm{Q}=0.89 \mathrm{KVAR}$ & $\mathrm{Pf}=0.18$ \\
\hline
\end{tabular}

Table 3.2: Reading's data for $6 \pi-$ section

$$
\begin{gathered}
Q=3 X I^{2} \\
X=\frac{0.89 * 10^{3}}{8.28^{2} * 3}=4.33 \Omega \\
4.33=120 \pi L
\end{gathered}
$$

For $6 \pi$-section:

$$
L=0.0114 H
$$

For $1 \pi$-section:

$$
L=1.9 \mathrm{mH}
$$

The $\mathrm{L}$ value for $300 \mathrm{Km}$ is slightly larger than $50 \mathrm{~km}$ due to the losses on the line.

\subsubsection{Resistance Measurements}

In order to calculate resistance per $\pi$-section, the HP 34401A Ohm meter is used. This device injects current and measures voltage across resistance as well as calculates $\mathrm{R}$. 


$$
R=0.0315 \Omega
$$

\subsubsection{Capacitance}

The capacitance is $15 \mu \mathrm{F}$.

For each $\pi$-section the RLC parameters are:

\begin{tabular}{|c|c|c|}
\hline $\boldsymbol{L}$ & $\boldsymbol{C}$ & $\boldsymbol{R}$ \\
\hline $1.8 \mathrm{mH}$ & $15 \mu F$ & $0.0315 \Omega$ \\
\hline
\end{tabular}

Table 3.3: $\pi$-section parameters

The measured parameters are quite precise compared to the results from previous student's thesis [52].

\subsection{Synchronous Generator Parameters Measurements}

To simulate and study power disturbances such as SSR, accurate data on generator is important. In this experiment, the majority of the parameters are taken from [52]. Figure 3.5 shows DC motor and synchronous generator in the power lab. 


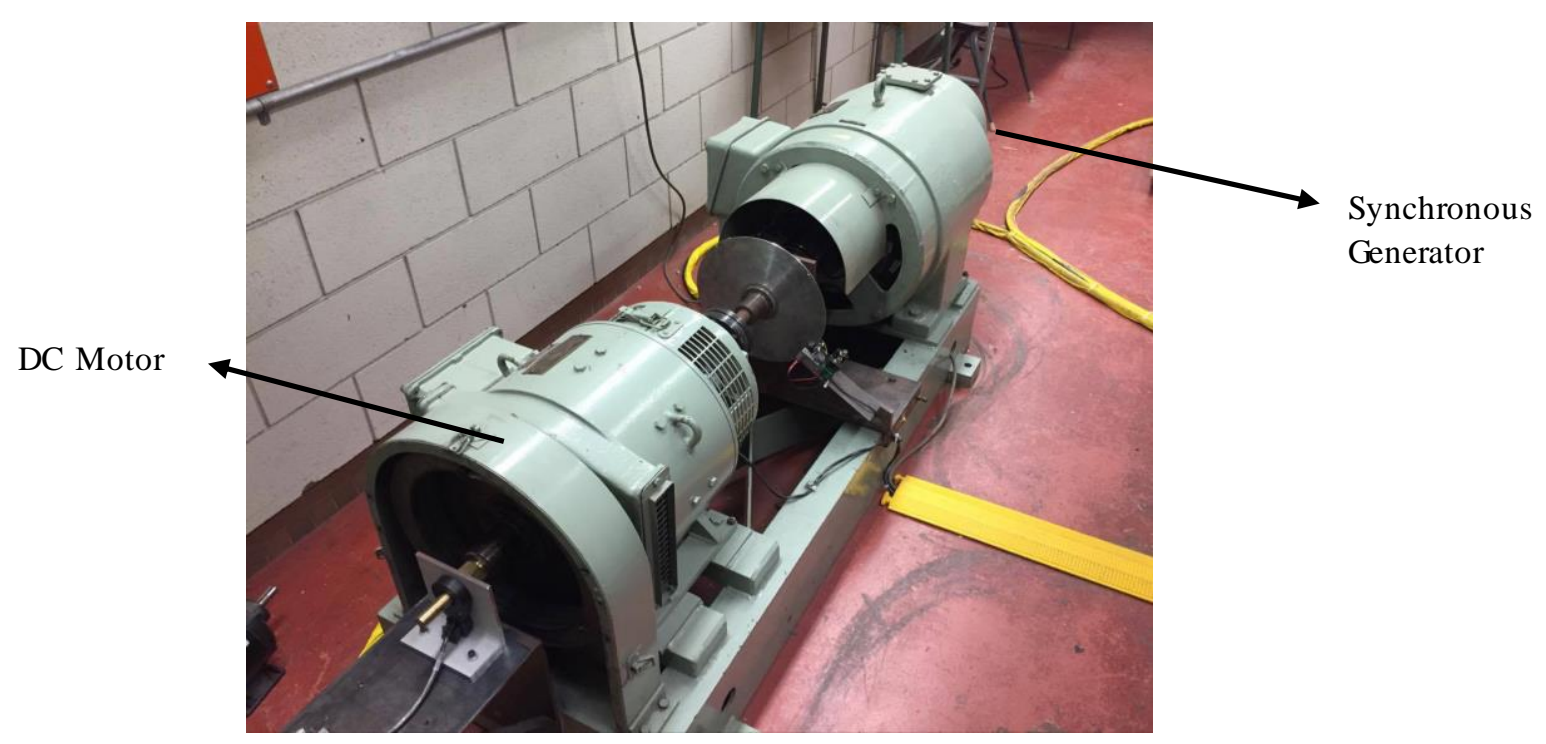

Figure 3.5: DC motor and synchronous generator

Parameters in PU of the Single Machine Infinite Bus System are given in APPENDIX A. The stator base value used in simulink are given in APPENDIX A. They are derived from the MATLABISIMULINK help option. Base values can be computed for stator and rotor windings when the parameters are specified in PU. Further, the Stator/Field transformation ratio and the field parameters referred to the stator can be calculated from the actual field parameters.

By using the open-circuit curve test from [52], the nominal field current Ifn with noload at rated voltage $220 \mathrm{~V}$ can be calculated in ENA lab. 


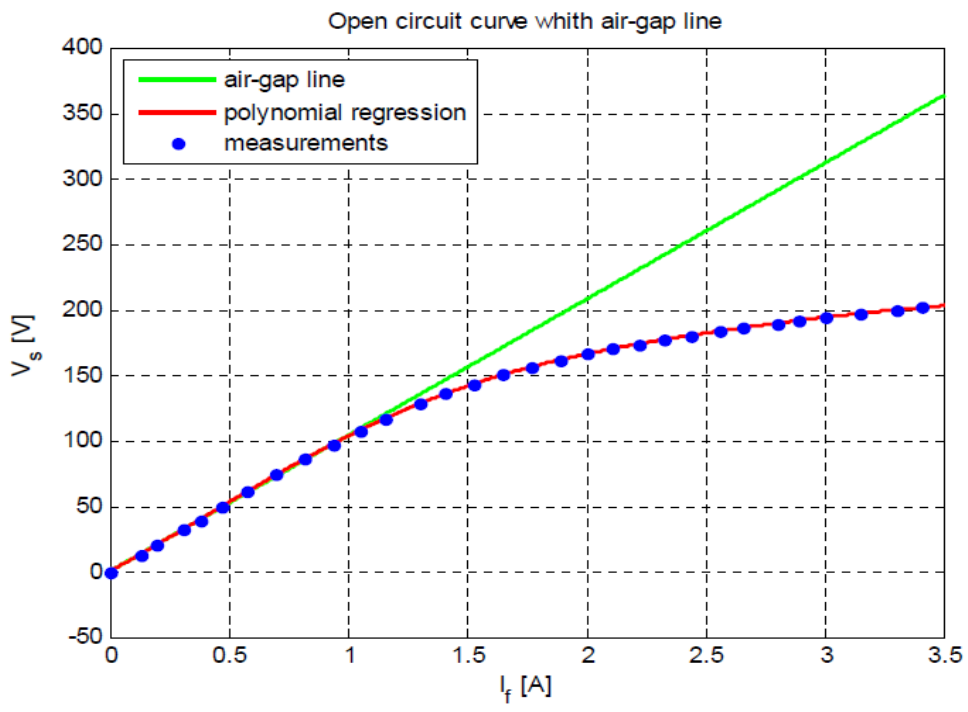

Figure 3.6: Measurements and polynomial regression of the open-circuit curve and air-gap line [52]

The SG parameters are as follows [52]:

$P_{n}=3 K V A \quad$ Three-phase nominal power

$V_{n}=220 \mathrm{~V} \quad$ Nominal line-to-line voltage (Vrms)

$f_{n}=60 \mathrm{~Hz} \quad$ Nominal frequency

$I_{f n}=1.28 \mathrm{~A} \quad$ Nominal field current producing nominal stator voltage at no load.

The base parameters for SI model can be calculated by using stator base value equations given in APPENDIX A.

$$
Z_{\text {sbase }}=\frac{V_{n}^{2}}{P_{n}}=\frac{220^{2}}{3000}=16.13 \Omega
$$




$$
\begin{gathered}
I_{\text {sbase }}=\frac{P_{n} \sqrt{2}}{V_{n} \sqrt{3}}=11.13 \mathrm{~A} \\
V_{\text {sbase }}=\frac{V_{n} \sqrt{2}}{\sqrt{3}}=179.63 \mathrm{~V} \\
\omega_{\text {base }}=2 \pi f=377 \frac{\mathrm{rad}}{\mathrm{s}}=1800 \mathrm{rpm} \\
L_{\text {sbase }}=\frac{Z_{\text {sbase }}}{\omega_{\text {base }}}=0.04 \mathrm{H}
\end{gathered}
$$

The power SM_fundamental example in Matlab/Simulink illustrates the use of the Synchronous Machine SI and PU Fundamental block. The model Properties/PreLoad Fen callback in MATLAB shows how to calculate RL rotor parameters referred to the stator, transformation ratio, and nominal field voltage and current. The following equations below is extracted from PreLoad Fen callback section. Stator parameters in PU follow as below [44]:

Stator resistance per phase $(\mathrm{pu})$ :

$$
R_{s_{-} p u}=\frac{R_{s}}{Z_{\text {sbase }}}
$$

Stator leakage inductance $(\mathrm{pu})$ :

$$
L_{l \_p u}=\frac{L_{l}}{L_{\text {sbase }}}
$$


Direct-axis magnetizing inductance (pu)

$$
L_{m d_{\_} p u}=\frac{L_{m d}}{L_{\text {sbase }}}
$$

Quadrature-axis magnetizing inductance (pu)

$$
L_{m q \_p u}=\frac{L_{m q}}{L_{\text {sbase }}}
$$

Field base values are depicted below [44]:

Base field current (A):

$$
I_{\text {fbase }}=I_{f n} * L_{m d_{p u}}
$$

Base field voltage (V):

$$
V_{\text {fbase }}=\frac{P_{n}}{I_{\text {fbase }}}
$$

Base field impedance $(\Omega)$ :

$$
Z_{\text {fbase }}=\frac{V_{\text {fbase }}}{I_{\text {fbase }}}
$$


Base field inductance $(\mathrm{H})$ :

$$
L_{\text {fbase }}=\frac{Z_{\text {fbase }}}{\omega_{\text {sbase }}}
$$

Transformation ratio [44]:

$$
\frac{N_{s}}{N_{f}}=\frac{2}{3} \frac{I_{\text {fbase }}}{I_{\text {sbase }}}
$$

The stator parameters are calculated and show below [44]. All PU parameters are extracted from [52].

Stator resistance:

$$
R_{S}=R_{S_{-} p u} * Z_{\text {sbase }}=0.0026 * 16.13=0.0419 \Omega
$$

Stator leakage inductance:

$$
L_{l}=L_{l \_p u} * L_{\text {sbase }}=0.071 * 0.04=2.84 \mathrm{mH}
$$

$\mathrm{d}$-axis and q-axis magnetizing inductances: 


$$
L_{m q}=L_{m d}=l_{m q \_p u} * l_{\text {sbase }}=1.129 * 0.04=0.045 \mathrm{H}
$$

Note: The PreLoad Fcn callback section uses Zfbase to find Rf which makes the reactive power-output constantly negative in the model and is not a desirable result. The value for $\mathrm{Rf}$ is calculated below and it is a large number which is not acceptable. The Rf is referred to stator.

$$
R_{f}=R_{f_{-} p u} * Z_{\text {fbase }}=0.000747 * 688.113=0.514 \Omega
$$

However, the Matlab help option shows Rf is calculated based on Zsbase instead of Zfbase and the new calculation makes the reactive power output accurate.

$$
\begin{gathered}
R_{f}=R_{f_{p u}} * Z_{\text {sbase }}=0.000747 * 16.13=0.012 \Omega \\
I_{\text {fbase }}=I_{f n} * L_{m d_{p u}}=1.28 * 1.129=1.445 \mathrm{~A} \\
V_{\text {fbase }}=\frac{P_{n}}{I_{\text {fbase }}}=\frac{3000}{1.445}=2075.95 \mathrm{~V} \\
Z_{\text {fbase }}=\frac{V_{\text {fbase }}}{I_{\text {fbase }}}=\frac{2075.95}{1.445}=1436.64 \Omega
\end{gathered}
$$

d-axis and q-axis damper resistance:

$$
R_{k d}=R_{k q}=R_{k d_{\_} p u} * Z_{\text {sbase }}=0.0083 * 16.13=0.133 \Omega
$$


Field leakage inductance:

$$
L_{l f d}=L_{l f d \_p u} * L_{\text {sbase }}=0.14 * 0.04=5.6 \mathrm{mH}
$$

Damper leakage inductance:

$$
L_{l k d}=L_{l k d \_p u} * L_{\text {sbase }}=0.12 * 0.04=4.8 \mathrm{mH}
$$

The machine inertia constant $\mathrm{H}$ is given in appendix $\mathrm{A}$ [52]. $\mathrm{P}$ is number of pole $\mathrm{P}=4$.

$$
\begin{aligned}
& \omega_{m}=\frac{4 * p i * f}{P}=188.49 \\
& J=\frac{2 * H * P_{n}}{\omega_{m}^{2}}=0.8 \mathrm{~kg} \cdot \mathrm{m}^{2}
\end{aligned}
$$

The field parameters that are used in the Synchronous Machine SI Fundamental block are the field resistance and leakage inductance referred to the stator ( $\mathrm{Rf}^{\prime}, \mathrm{Llfd}$ ').

If the nominal field current ifn is known, the transformation ratio $\mathrm{Ns} / \mathrm{Nf}$ is calculated using the same equation as for the stator/field transformation ratio.

When the values referred to the stator are known [50], the actual field resistance Rf (seen from the rotor) is easy to calculate. Therefore, the real Vf for the SI model simulation can be found. 
Field resistance referred to the stator:

$$
R_{f^{\prime}}=0.00747
$$

Field resistance $\mathrm{Rf}$ (seen from the rotor):

$$
R_{f^{\prime}}=\frac{3}{2} \boldsymbol{R}_{\boldsymbol{f}}\left(\frac{N_{s}}{N_{f}}\right)^{2}
$$

Transformation ratio:

$$
\frac{N_{s}}{N_{f}}=\frac{2}{3} \frac{I_{\text {fbase }}}{I_{\text {sbase }}}=0.086
$$

The actual field resistance $\mathrm{Rf}$ (seen from the rotor)

$$
\boldsymbol{R}_{\boldsymbol{f}}=1.073 \Omega
$$

The actual field voltage (seen from the rotor):

$$
V_{f}=R_{f} * I_{f}=1.373 \mathrm{~V}
$$




\subsubsection{Synchronous Generator Dynamic Model}

Due to the complexity of synchronous machine analysis, mathematical transformations are often used to decouple variables and to solve equations involving time varying quantities. This is done by referring all variables to a common frame of reference.

Among the various transformation methods available, the well-known are [54]:

- Clarke Transformation

- Park Transformation

\subsubsection{Clarke Transformation}

This transformation converts balanced three-phase quantities into balanced two-phase quadrature quantities.

\subsubsection{Park Transformation}

This transformation converts vectors in balanced two-phase orthogonal stationary system into orthogonal rotating reference frame.

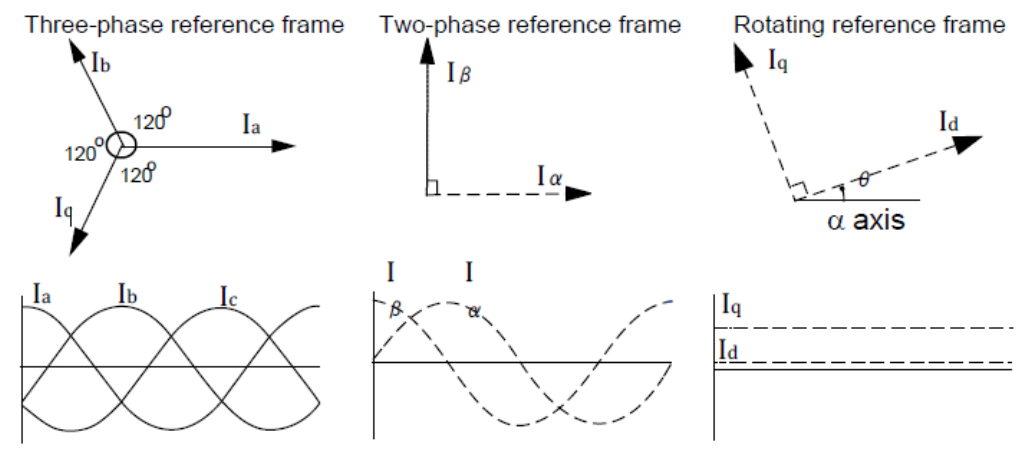

Figure 3.7: Clarke and Park Transformation [54] 
Equivalent circuits of a three-phase synchronous machine with the reference frame fixed in rotor are following by [54]:
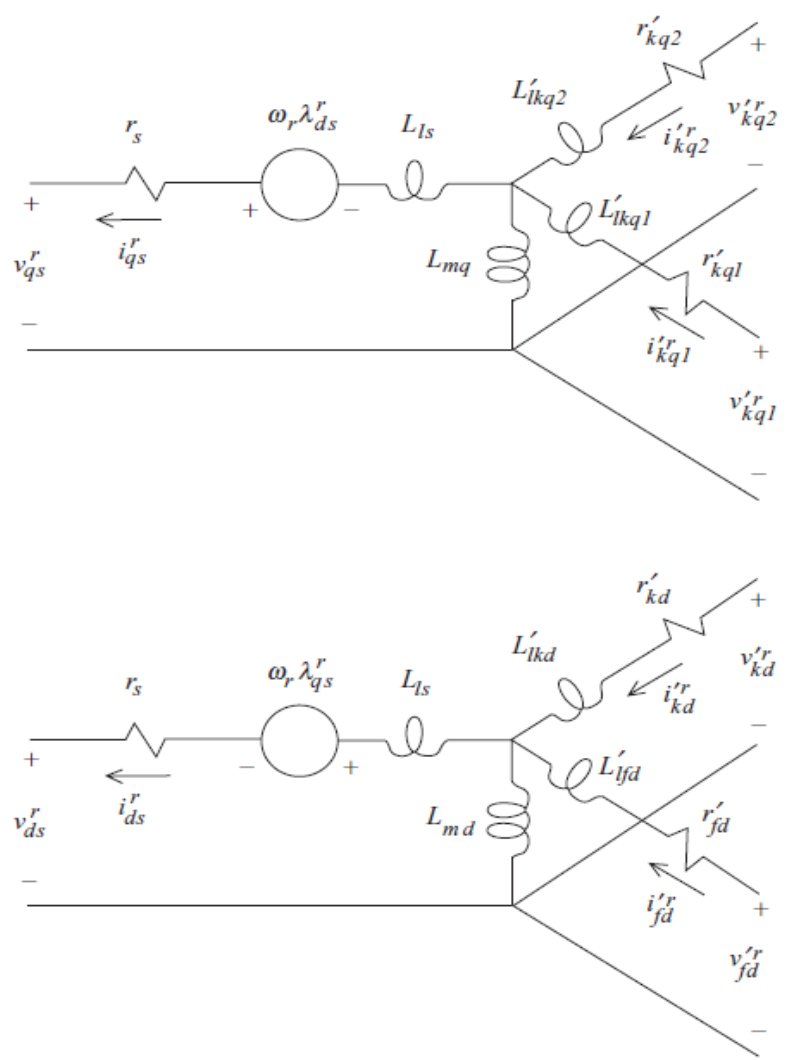

Figure 3.8: Equivalent circuits of a three-phase synchronous machine, Park Transformation [54]

Simplification [54]:

1) Almost always, $V_{k d}=V_{k q 1}=V_{k q 2}=0$

2) In steady state damper currents $\left(i_{k d}=i_{k q 1}=i_{k q 2}=0\right)$

3) No harmonics is assumed on the field current

After simplification, the circuit for $\mathrm{q}$-axis is demonstrated by the following figure below: 


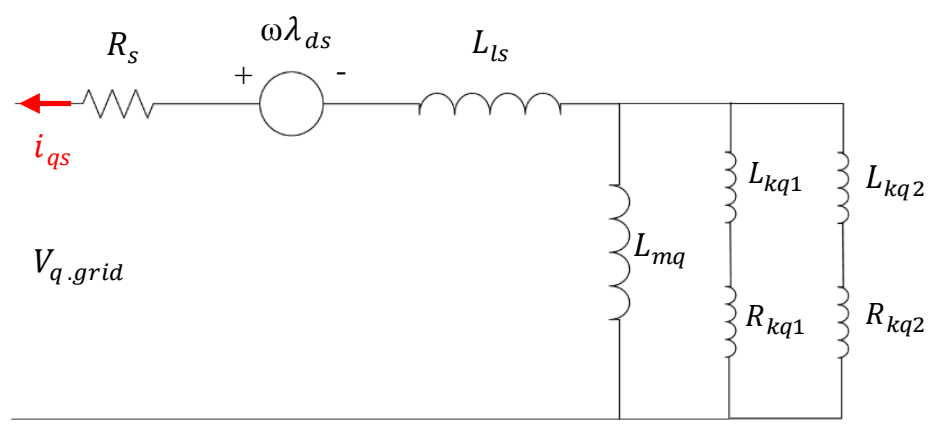

Figure 3.9: Conventional synchronous generator q-axis circuit model [54]

$$
V_{q . g r i d}=R_{s} i_{q}+L_{l s} \frac{d i_{q}}{d t}+\omega_{r} \lambda_{d}+R_{k q} i_{q}+L_{k q} \frac{d i_{q}}{d t}
$$

$\omega_{r}$

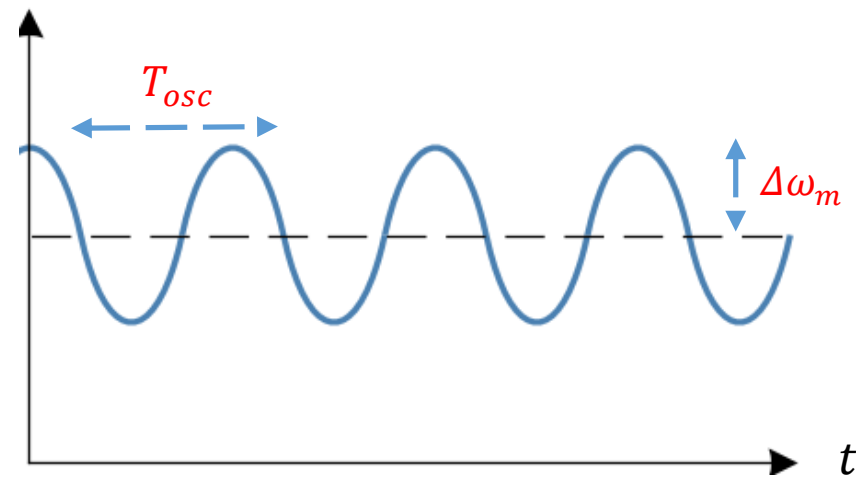

$\omega_{m . a v e}=1800\left(\frac{2 \pi}{60}\right)$

Figure 3.10: Oscillation waveform in rotor speed

$$
\begin{gathered}
\omega=\omega_{\text {m.ave }}+\Delta \omega_{m} \cdot \cos \left(\omega_{o s c} t\right) \\
f_{o s c}=\frac{1}{T_{o s c}} \\
\omega_{o s c}=\frac{2 \pi}{T_{o s c}}
\end{gathered}
$$


By simplifying the circuit:

- $L_{m q}$ is too big, therefore no harmonics flow through that inductance

- $V_{\text {q.grid }}$ is zero, therefore no harmonics flow through that inductance

Replacing equation (3.45) into equation (3.44):

$$
0=R i_{q h}+L \frac{d i_{q h}}{d t}+\Delta \omega \cos \left(\omega_{o s c} t\right) \lambda_{d}+R_{k q} i_{q h}+L_{k q} \frac{d i_{q h}}{d t}
$$

Equation for $\mathrm{d}$ and q-axis:

$$
\left[\begin{array}{l}
0 \\
0
\end{array}\right]=\left[\begin{array}{c}
\Delta \omega \cos \left(\omega_{o s c} t\right) \lambda_{d} \\
-\Delta \omega \cos \left(\omega_{o s c} t\right) \lambda_{q}
\end{array}\right]+\left[\begin{array}{ll}
R & 0 \\
0 & R
\end{array}\right]\left[\begin{array}{l}
i_{q h} \\
i_{d h}
\end{array}\right]+\left[\begin{array}{cc}
L & 0 \\
0 & L
\end{array}\right]\left[\begin{array}{c}
\frac{d i_{q h}}{d t} \\
\frac{d i_{d h}}{d t}
\end{array}\right]
$$

The equation below is the final dynamic response of the synchronous generator.

$$
\left[\begin{array}{l}
0 \\
0
\end{array}\right]=\left[\begin{array}{c}
\Delta \omega \lambda_{d} e^{j\left(\omega_{e}-\omega_{o s c}\right) t} \\
-\Delta \omega \lambda_{q} e^{j\left(\omega_{e}-\omega_{o s c}\right) t}
\end{array}\right]+\left[\begin{array}{cc}
R+j \omega L & 0 \\
0 & R+j \omega L
\end{array}\right]\left[\begin{array}{c}
i_{q h} e^{j\left(\omega_{e}-\omega_{o s c}\right) t} \\
i_{d h e^{j\left(\omega_{e}-\omega_{o s c}\right) t}}
\end{array}\right]
$$

If transmission line parameters are added to the synchronous generator, the final model is shown by the following equation (3.51):

$$
\left[\begin{array}{l}
0 \\
0
\end{array}\right]=\left[\begin{array}{c}
\Delta \omega \lambda_{d}+(R+j \omega L) i_{q h} \\
-\Delta \omega \lambda_{q}+(R+j \omega L) i_{d h}
\end{array}\right]\left[\begin{array}{c}
e^{j \phi_{i}} \\
e^{j \phi_{i}}
\end{array}\right]+\left[\begin{array}{cc}
R_{L}+j \omega L_{l}+\frac{1}{j \omega C_{L}} & 0 \\
0 & R+j \omega L_{l}+\frac{1}{j \omega C_{L}}
\end{array}\right]\left[\begin{array}{l}
i_{q h} e^{j \phi_{i}} \\
i_{d h} e^{j \phi_{i}}
\end{array}\right]
$$

Transmission Line Parameters 


\subsection{Motor Parameters Measurements}

The DC machine in the ENA lab is used as a prime mover. This motor is a relatively complex DC motor. The Figure below represents the schematic of the DC motor in ENA lab.

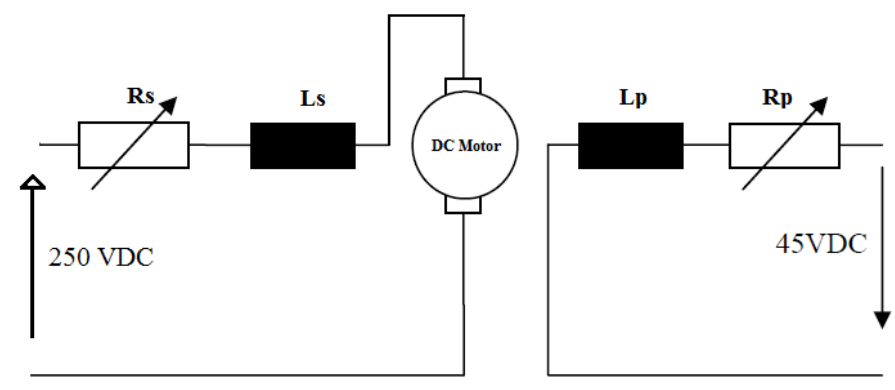

Figure 3.11: Schematic of the DC machine [52]

The current can be changed by series winding with the variable resistance $\mathrm{R}_{\mathrm{s}}$ or in the shunt winding with the resistance $R_{p}$. Channing the current in series and shunt winding can lead to power variation on the output of the DC motor [52].

To simulate the DC motor in the Simulink the $\mathrm{Ra}, \mathrm{La}, \mathrm{Km}, \mathrm{J}$ and $\mathrm{B}$ need to be calculated. In the simulation Permanent Magnet is chosen as the field type. The $\mathrm{Ra}$ is calculated below using parameters from [53]:

$$
\begin{gathered}
Z_{\text {sbase }}=\frac{V_{\text {base }}^{2}}{P_{n}}=\frac{220^{2}}{2.4 * 10^{3}}=20.166 \Omega \\
R_{a}=R_{\text {a.pu }} * Z_{\text {sbase }}=0.11 * 20.166=2.21 \Omega
\end{gathered}
$$


Since the $2.21 \mathrm{ohm}$ is not acceptable and it is fairly large for this DC motor, a new Ra needs to be calculated.

\subsubsection{Armature Resistance (Ra):}

In larger practical machines $\varphi$ is also influenced by $I_{a}, \varphi=\varphi\left(I_{f}, I_{a}\right)$. In order to find Ra, the test is simplified by setting $I_{f}$ to zero $(\omega=0)$, therefore $E_{a}=0$. Applied $V_{t}$ and measured $I_{a}$.

$V_{t}=181.2 \mathrm{~V}, E_{a}=0, I_{a}=11.5 \mathrm{~A}$

$$
V_{t}=E_{a}+R_{a} \cdot I_{a}
$$

Therefore,

$$
R_{a}=0.86 \Omega
$$

\subsubsection{Armature Inductance (La):}

$$
X_{a}=120 \pi L_{a}
$$

From [53]:

$$
\begin{gathered}
X_{a(p u)}=0.3 \\
L_{a(p u)}=\frac{0.3}{120 \pi}=7.95 * 10^{-4} \\
L_{a}=L_{a(p u)} \cdot L_{s(\text { base })}=16 \mathrm{mH}
\end{gathered}
$$

\subsubsection{Torque Constant $(\mathrm{Km})$ :}

$$
\tau=k . \varphi \cdot I_{a}
$$




$$
\varphi=\varphi\left(I_{f}\right)
$$

If it is linear $\tau=k \cdot I_{f} \cdot I_{a}$, then

$$
\begin{aligned}
& \tau=k \cdot\left(I_{f}\right) \cdot I_{a} \\
& E=k \cdot I_{f} \cdot \omega_{m}
\end{aligned}
$$

Therefore

$$
\begin{gathered}
E=k_{m} \cdot\left(I_{f}\right) \cdot \omega_{m} \\
P=E_{A} I_{A}=V_{T} I_{A}-I_{A}^{2} R_{A}
\end{gathered}
$$

$V_{T}=180, P=3000$. From equation (3.64):

$$
0.86 I_{A}^{2}-180 I_{A}+3000=0
$$

Therefore

$$
\begin{gathered}
I_{A}=18.25 A \\
E_{A}=V_{T}-I_{A} R_{A}
\end{gathered}
$$

From equation (3.66)

$$
E_{A}=163.3 \mathrm{~V}
$$

$E_{A}=163.3 \mathrm{~V} @ 1800 \mathrm{rpm}$ 


$$
k_{m}=\frac{E}{\omega_{m}}=\frac{163.3}{1800\left(\frac{2 \pi}{60}\right)}=0.86 \mathrm{~N} \cdot \mathrm{m} / \mathrm{A}
$$

\subsubsection{Inertia (J):}

The inertia of Synchronous Generator from equation (3.38) is calculated and because the DC motor and SG are on the same shaft, the $\mathrm{J}$ equally divided for both mass. The inertia for DC motor is $0.4 \mathrm{~kg} . \mathrm{m}^{2}$.

\subsubsection{Friction (B):}

Based on similar models the friction can be estimated approximately 0.005 N.m.s.

\subsubsection{Initial Field Current:}

To calculate the initial field current, different types of measurements can be done by following the procedures below:

1. Synchronizing the SG output to the grid

2. Set P output and Q output to zero

3. Disconnect the DC machine

4. Measure Ea (If) as If changes 
The results are as follows:

\begin{tabular}{|c|c|}
\hline Voltage Terminal (Vt) & Field Current (If) \\
\hline $\mathbf{1 8 8 . 8}$ & $\mathbf{3 A}$ \\
\hline 181.2 & 2.8 \\
\hline 171.3 & 2.6 \\
\hline 162.7 & 2.4 \\
\hline 151 & 2.2 \\
\hline 138.7 & 2 \\
\hline
\end{tabular}

Table 3.4: Intial field current test

$\mathrm{Ea}=188.8$ and intial field current $\mathrm{If}=3 \mathrm{~A}$ are chosen. The calcuation is based on $\mathrm{If}=3 \mathrm{~A}$. 


\section{Chapter 4}

\section{Simulation}

\subsection{Validating Synchronous Generator Model}

The synchronous generator simulation model is outlined in phases as follows:

- Synchronous generator PU model

- Synchronous generator SI model

- PU and SI Simulink Model Comparison

\subsubsection{Synchronous Generator PU Model:}

To validate the synchronous generator PU model results, a generator is tested as a single machine connected to a $\pi$-line and stiff grid. All the parameters are used in this test are extracted from [50], [52]. 


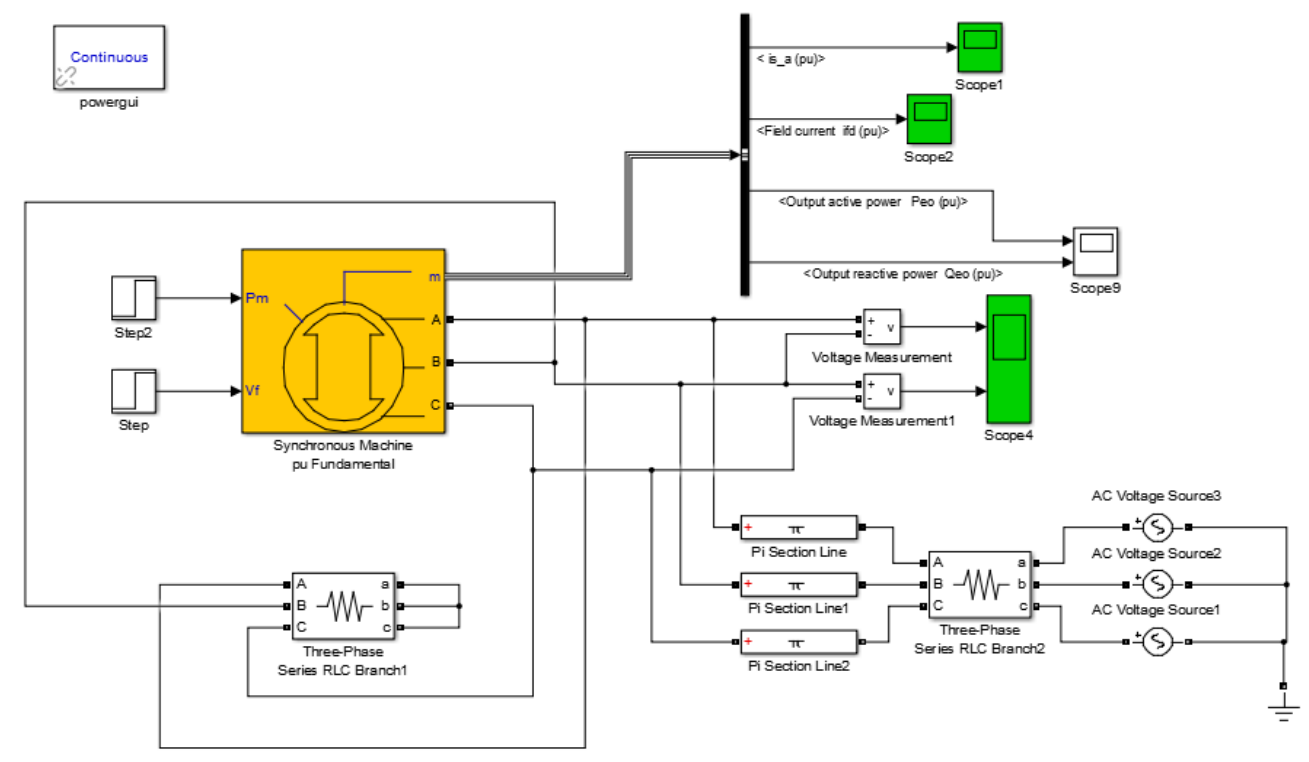

Figure 4.1: Validating the synchronous generator PU model

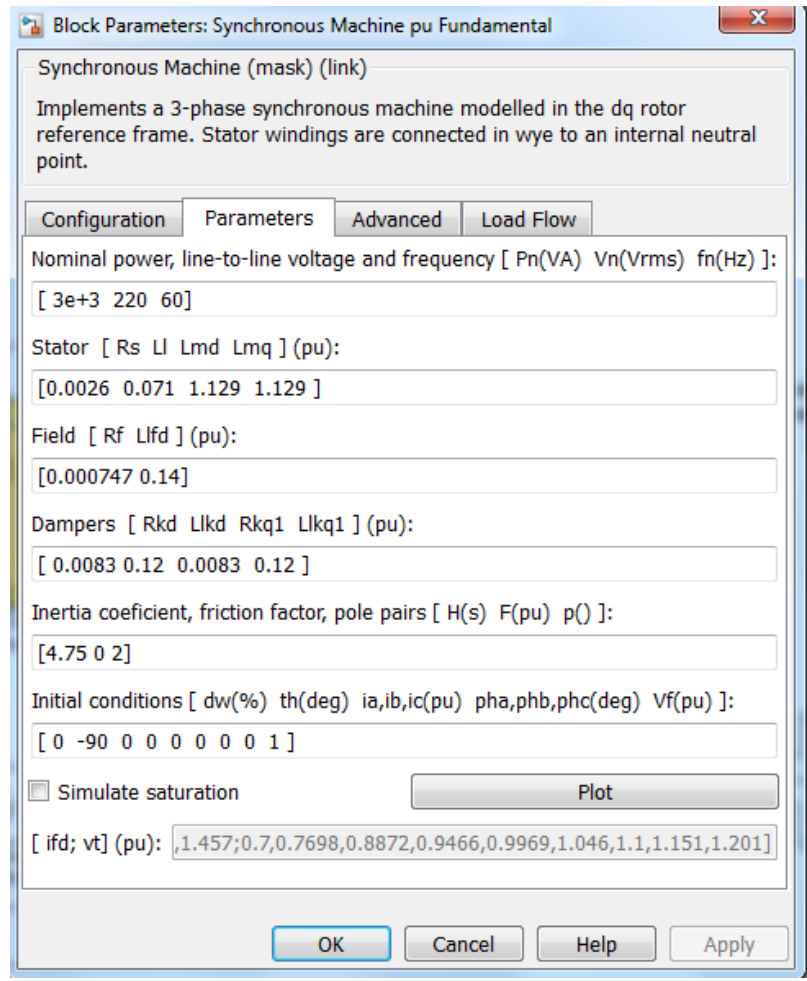

Figure 4.2: Synchronous generator PU model parameters [50] 
In the simulation, step function was used as a power input. In order to validate SG behavior, $\mathrm{P}=0.33$ at $2 \mathrm{sec}$ is applied. As shown below, the power reaches out to 0.33 after $2 \mathrm{sec}$. The results are as expected. The rotor type is salient pole.

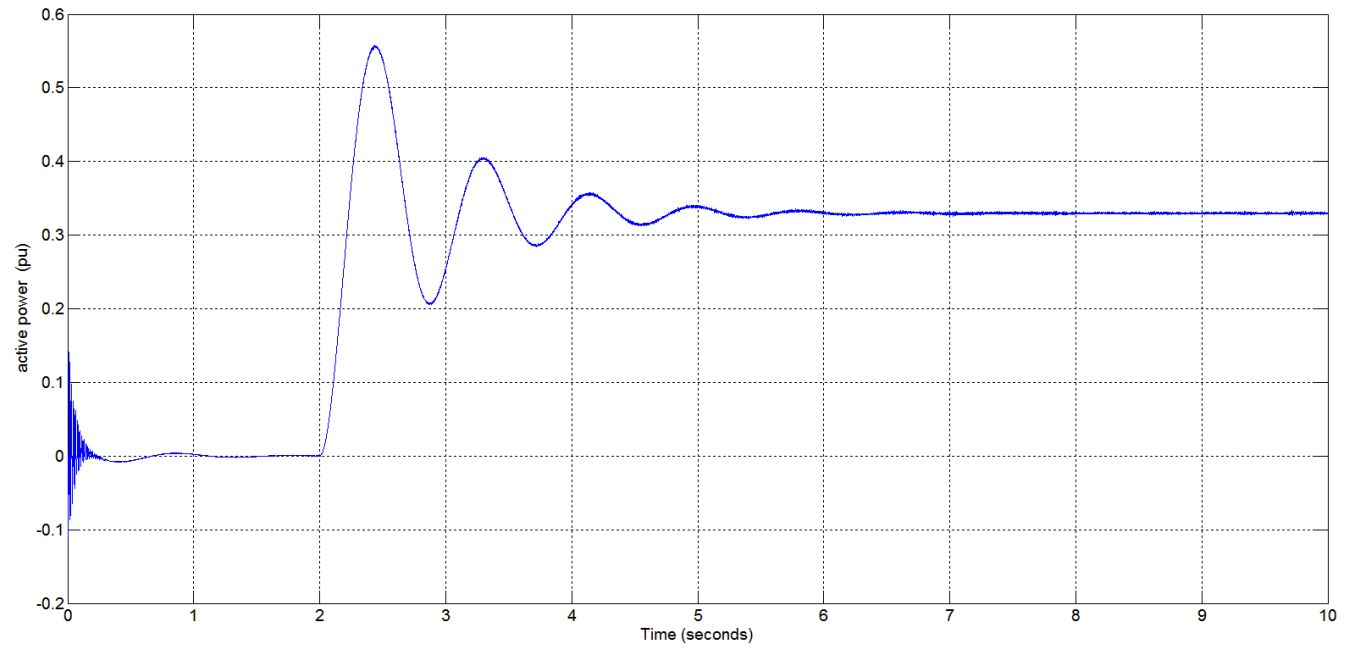

Figure 4.3: SG Active Power in Pu model (pu)

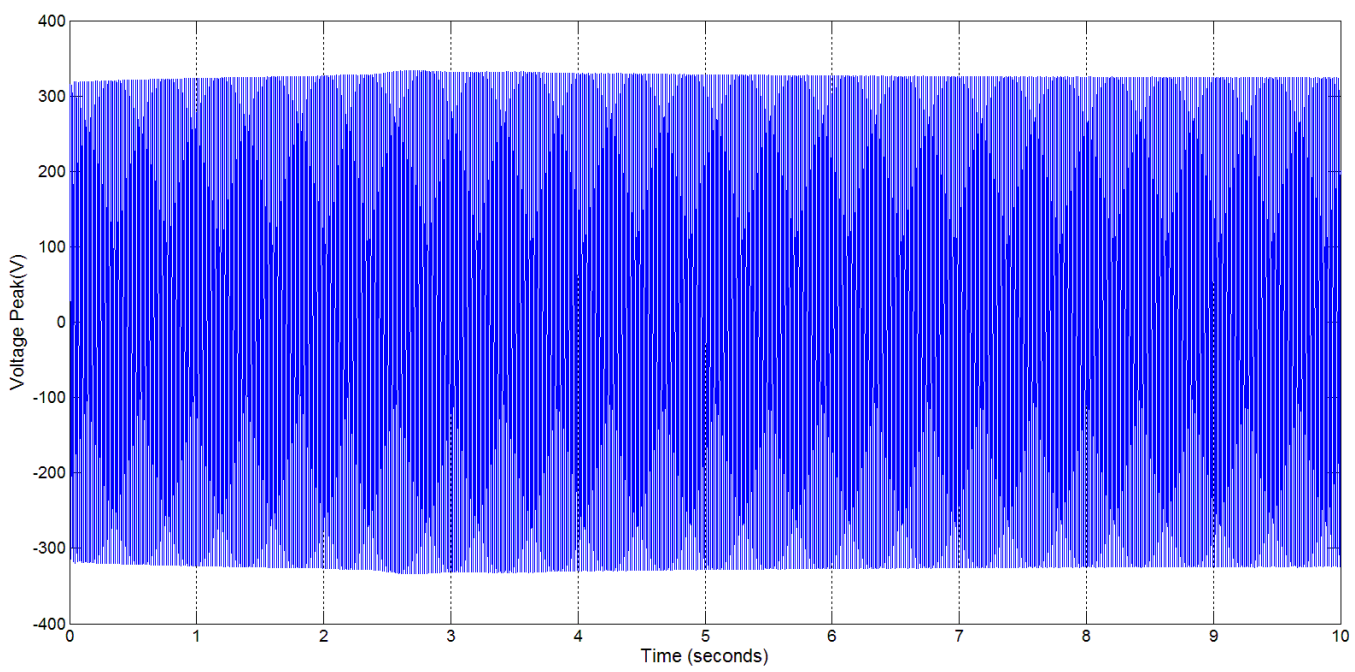

Figure 4.4: Terminal voltage of SG Vab in PU model 
Note: The output voltage of the Synchronous Generator PU model is a real number and they are not in PU.

\subsubsection{Synchronous Generator SI Model:}

From Chapter 3 parameters are calculated and used to simulated synchronous generator SI model. All the conversion from PU to SI model is given in Chapter 3. Parameters for SI model simulation are shown in Figure 4.6.

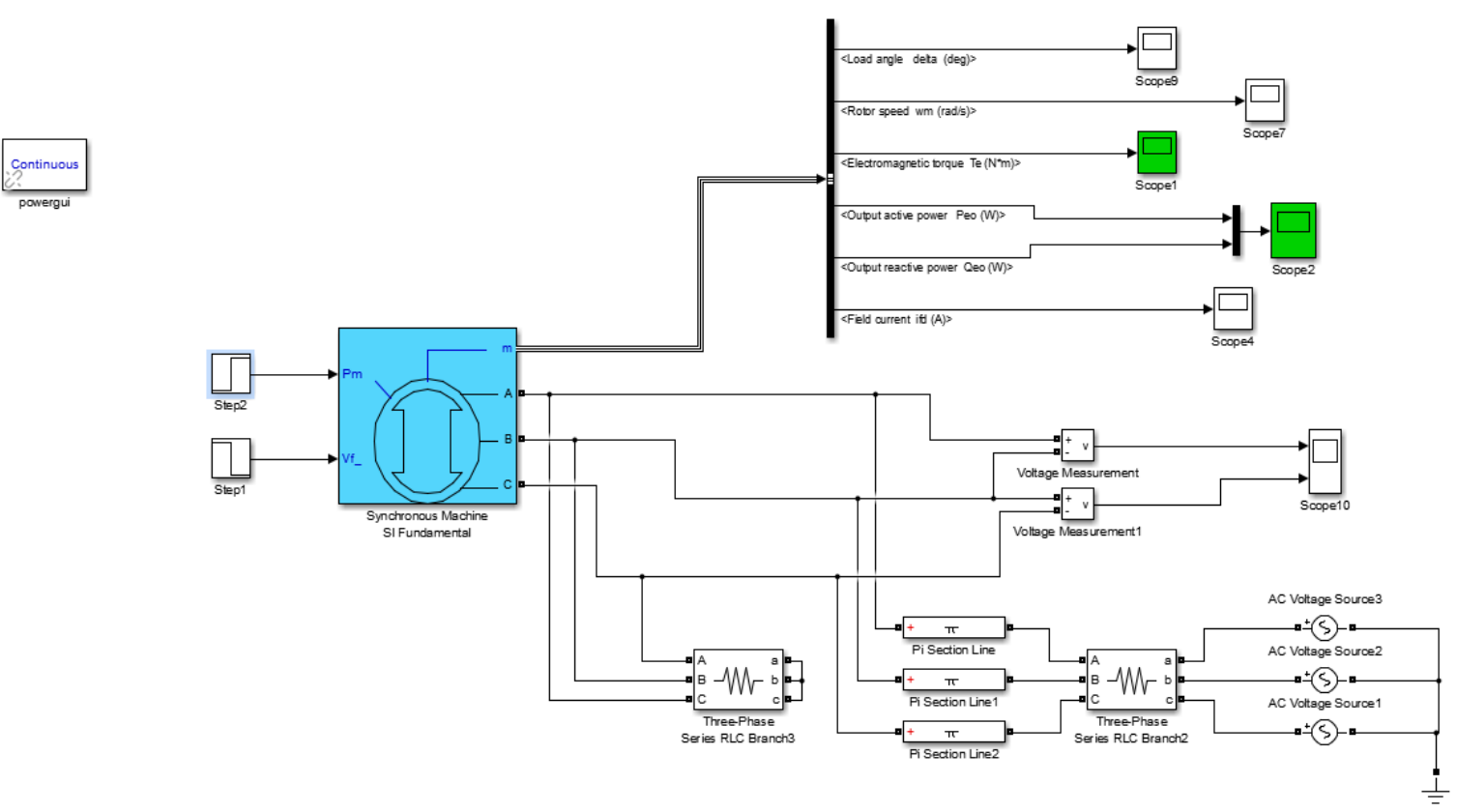

Figure 4.5: Synchronous generator SI Fundamental model 


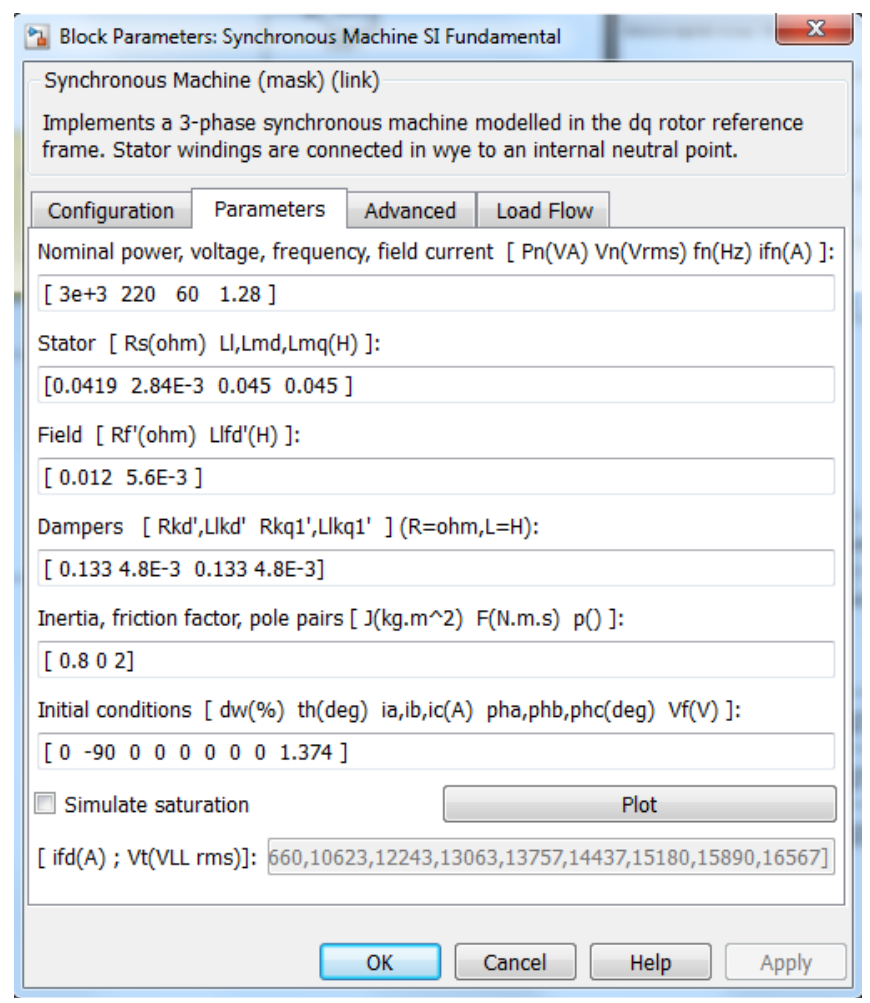

Figure 4.6: Synchronous Generator SI model parameters 


\subsubsection{PU and SI Simulink Model Comparison}

After all the required parameters are calculated, the SI model result can be gained and compared to the PU model. The step function is used as the input of active power and field voltage in both the SI and PU model. In order to illustrate a precise comparison between the two models, both PU and SI model are simulated in a single Simulink file. The purpose of this comparison is to validate the new parameters for SI model which will be used in the power lab.

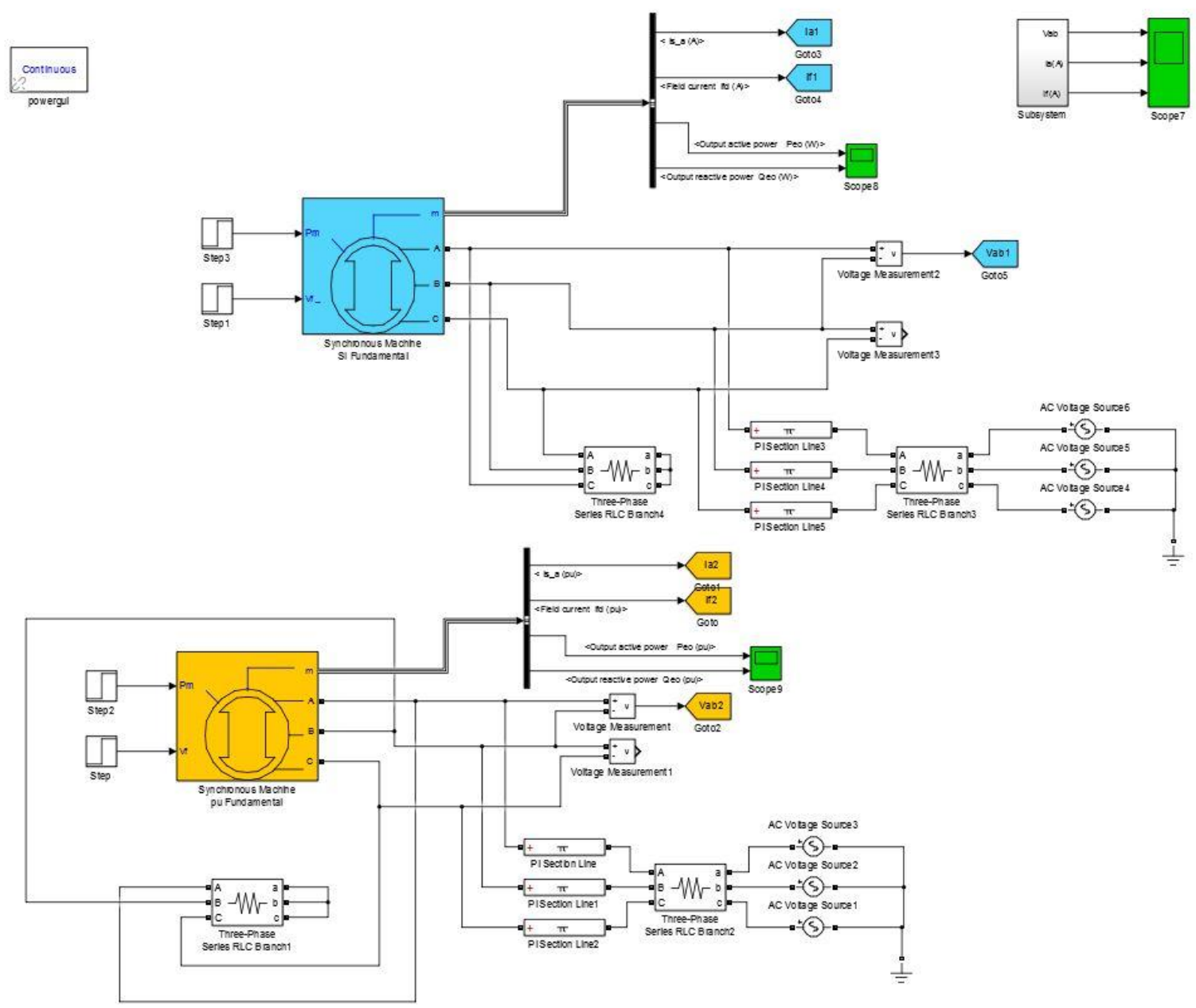

Figure 4.7: PU and SI Simulink model comparison test results 
At $\mathrm{t}=2 \mathrm{~s}, 1000 \mathrm{w}$ and 0.33 are applied to the input power of SI and PU model respectively $(\mathrm{S}=3 \mathrm{KVA}$ ). And the comparison results are shown by the following figures:

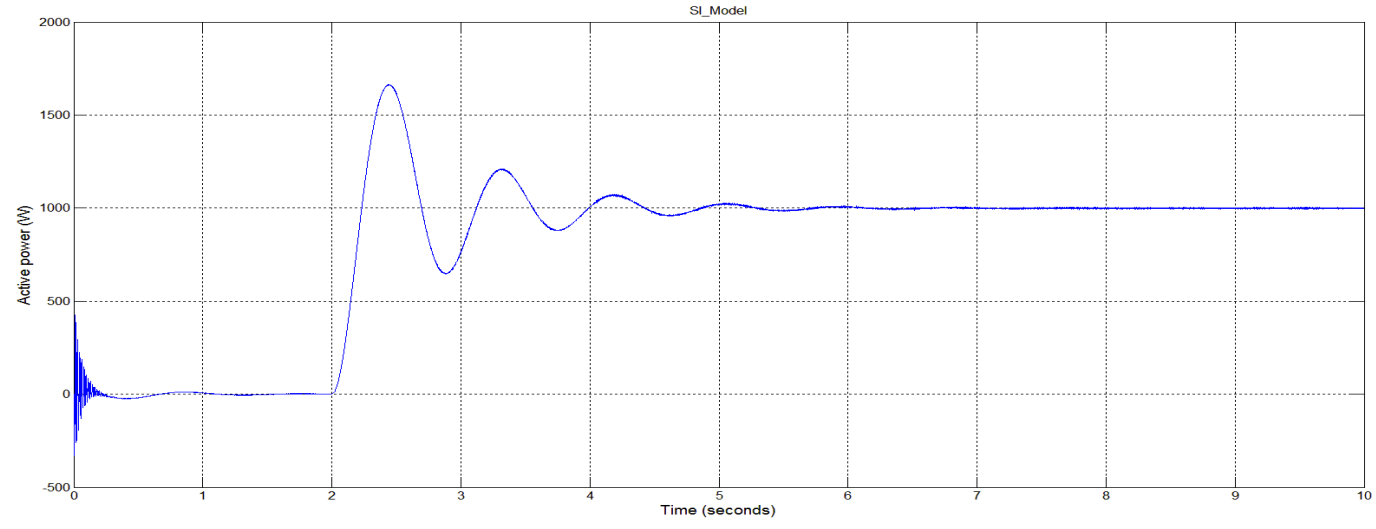

Figure 4.8: Active Power output in SI model

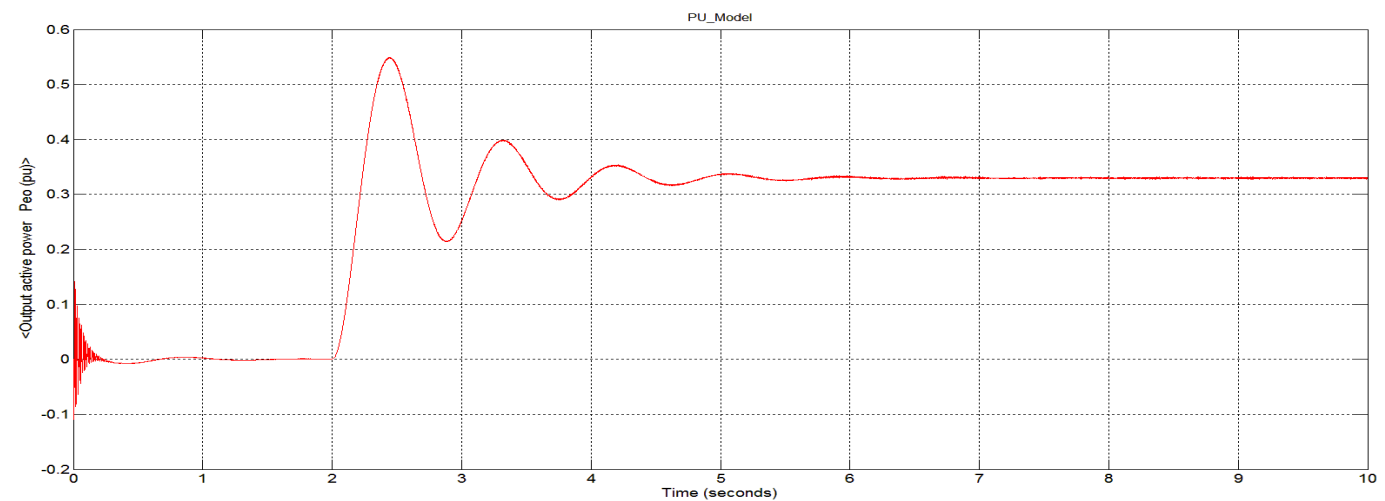

Figure 4.9: Active Power output in PU model 


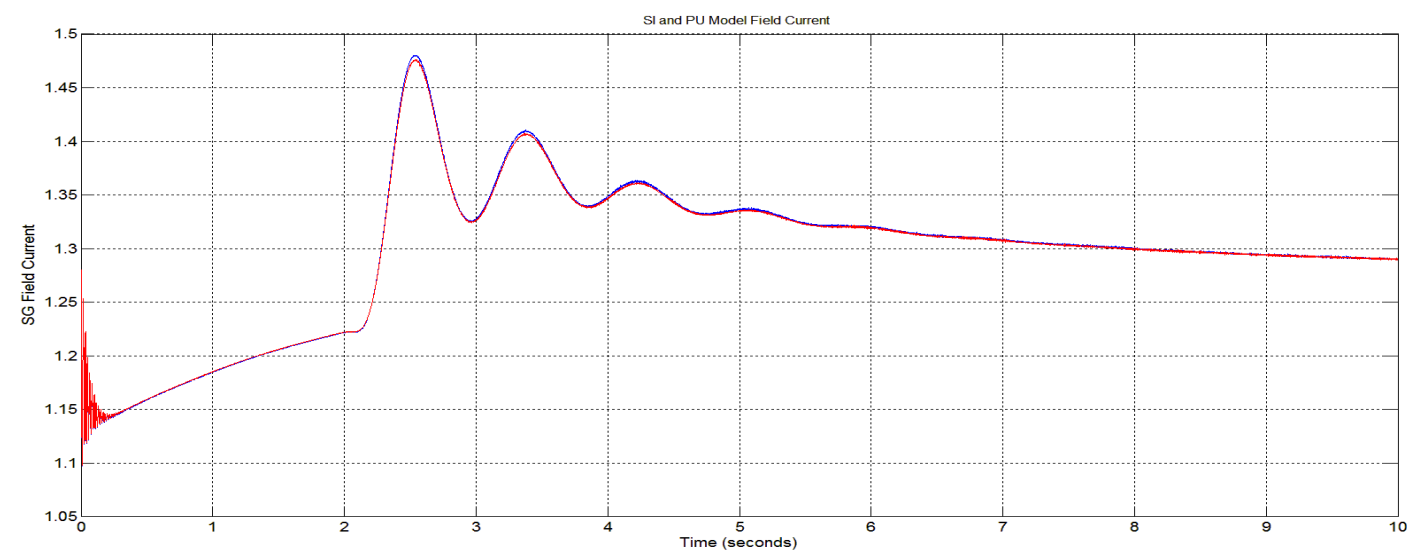

Figure 4.10: SG Field current in SI and PU model

As a result, it can be confirmed that the SI model outputs are identical to the PU model. Therefore, the SI block parameters are valid for the next phase of experiment.

\subsection{Designing Power and Current Control}

After all the parameters measurements for the DC motor and SG, the next step is connecting the DC motor to the SG, $\pi$-line and the grid. In order to build a power control in the model, a control loop which brings two PI controllers to the model needs to be designed. As depicted below, the output of first PI controller is a current which is a desired current and injected to the second PI controller. Eventually, the second PI controller output is a voltage which runs the Half-Bridge converter (between 0 to $1 \mathrm{~V}$ ). In the simulation average-model based VSC is chosen for the universal bridge, to reduce the simulation time and simplify the process. 


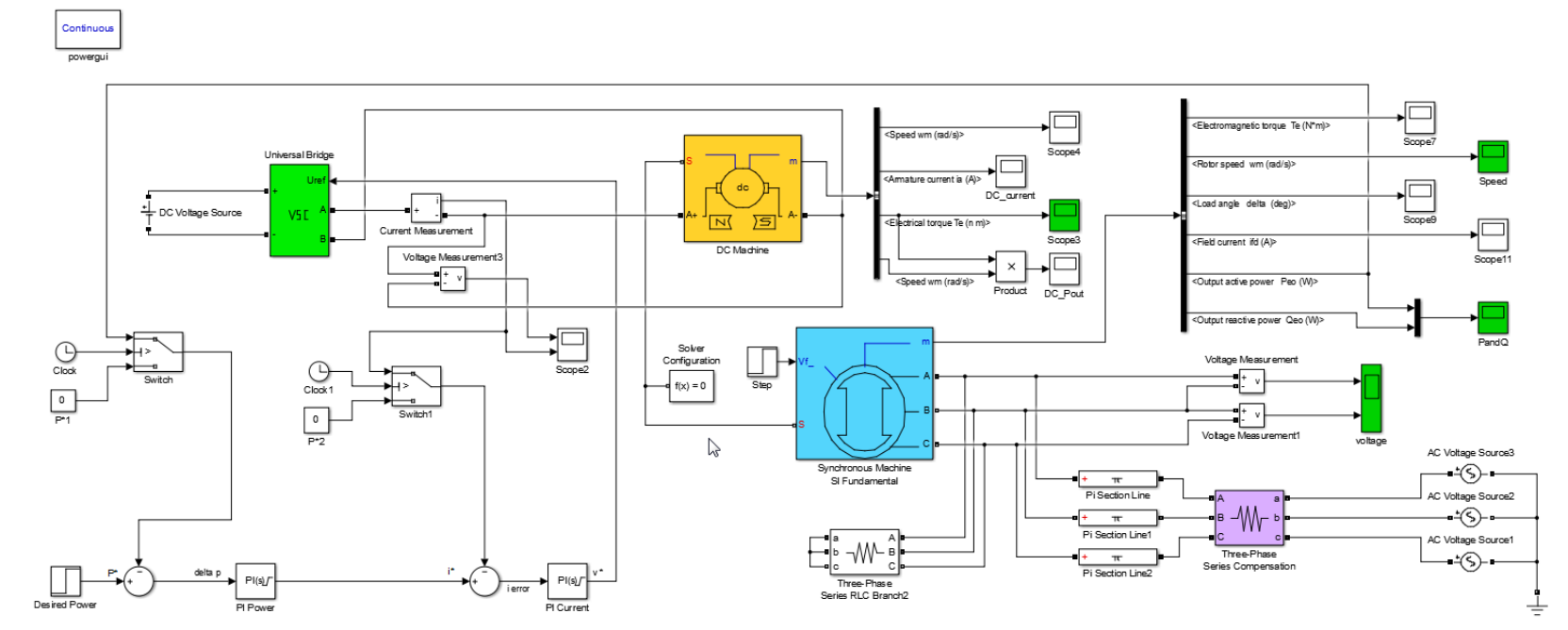

Figure 4.11: Full-scale power system Model

The PI controllers are tuned and the correct value for $\mathrm{Kp}$ and $\mathrm{Ki}$ is found which will be used in the ENA lab control model. In this test a step function is applied at $t=1$ sec to generate $1000 \mathrm{~W}$. As shown below, the PI controllers are perfectly tuned and the power reaches to $1000 \mathrm{~W}$ after $3 \mathrm{sec}$.

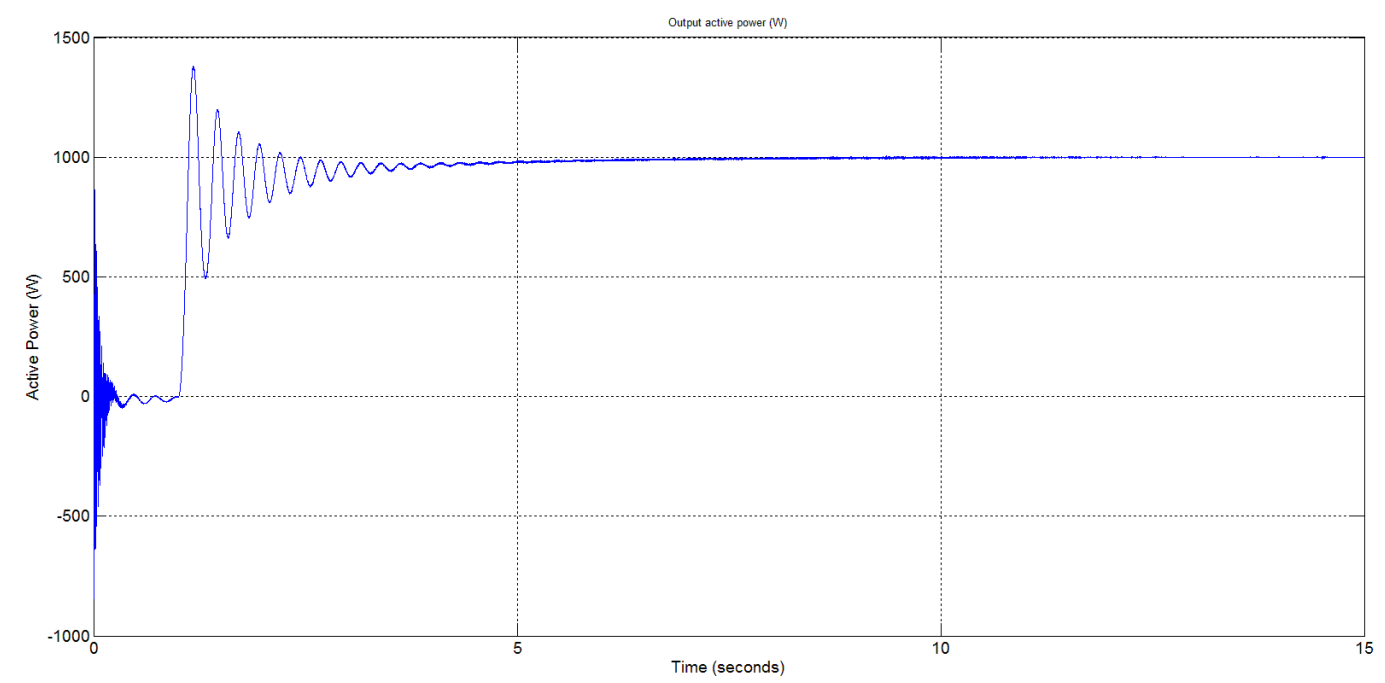

Figure 4.12: Active Power Output of Synchronous Generator 


\subsubsection{PI Controllers Parameters}

The conventional closed-loop control is depicted in the figure below.

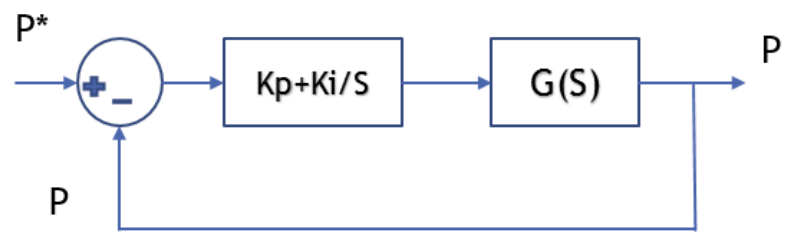

Figure 4.13: PI controllers in a closed-loop control system

Power PI controller parameters in simulation

$\mathrm{Kp}=0.066, \mathrm{Ki}=0.033$

Upper saturation limit=1.15, Lower saturation limit=-1.15

Current PI controller parameters in simulation

$\mathrm{Kp}=0.6, \mathrm{Ki}=35$

Upper saturation limit=20, Lower saturation limit $=-20$

\subsection{Designing a Transfer Function with a Controlled Desired Response}

After completing the power control model, a Transfer Function block is designed to create oscillation to the mechanical shaft. Equation (4.1) demonstrates the Transfer Function block. Assume $\mathrm{u}(\mathrm{t})$ is the input and $\mathrm{y}(\mathrm{t})$ is the output to a second-order system with transfer function [42]: 


$$
\begin{gathered}
H(s)=\frac{Y(s)}{U(s)}=\frac{\omega_{n}^{2}}{S^{2}+2 \zeta \omega_{n}+\omega_{n}^{2}} \\
\omega_{n}=2 \pi f_{e}
\end{gathered}
$$

$f_{e}=$ Frequency oscillation

$\zeta=$ Damping ratio

Assume the prime mover needs to experience $18 \mathrm{~Hz}$ oscillation, the Transfer Function would be:

$$
H(s)=\frac{(2 \pi 18)^{2}}{S^{2}+2 * 0.0001 *(2 \pi 18)+(2 \pi 18)^{2}}
$$

A tiny damping ratio is chosen to make the system oscillated rather than damping it out. The TF block is added into the Simulink to create the oscillation.

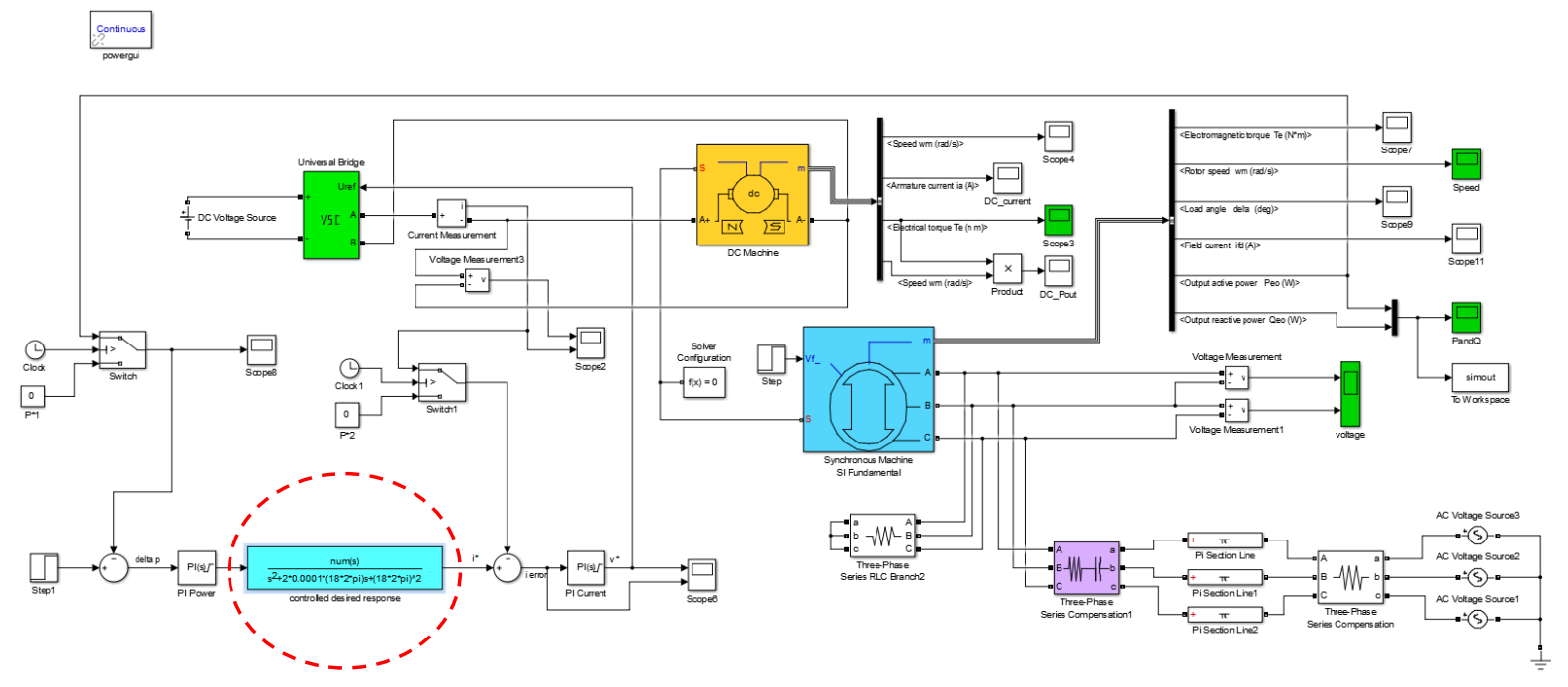

Figure 4.14: Adding the disturbance block to simulation model 
The output of SG is depicted below. As it shown in Figure 4.14, active power does not carry any oscillations. Because the PI controllers damp out the oscillation. Therefore, the dynamic of the rotating system needs to be investigated.

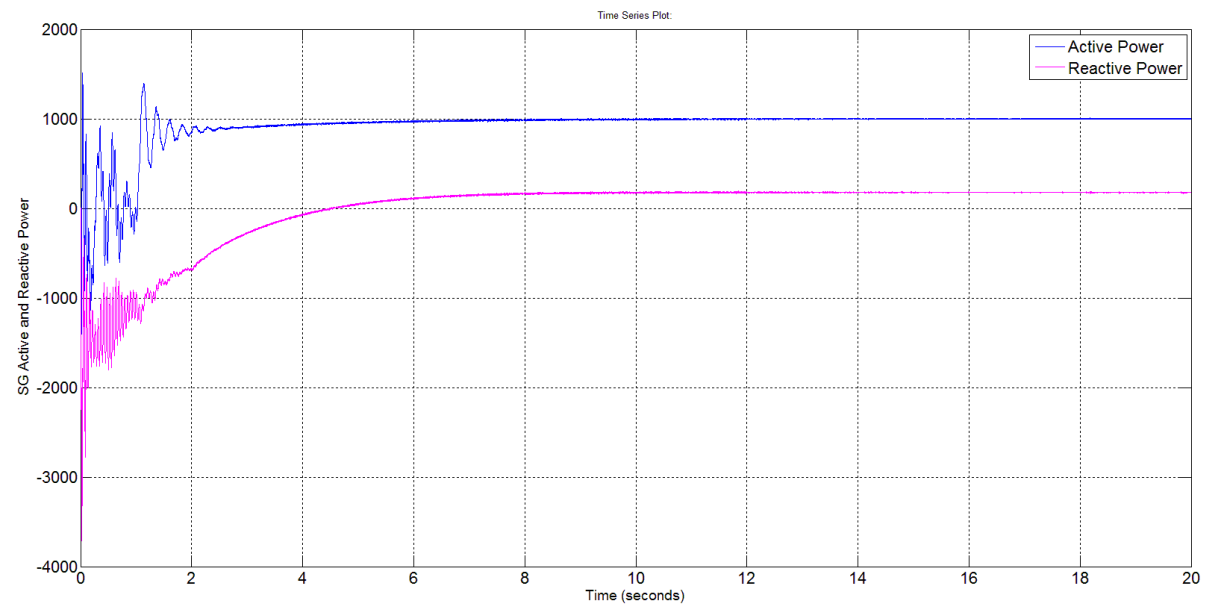

Figure 4.15: SG active and reactive power output

Emulating mechanical dynamics that result in resonance is outlined in two phases:

- Identify transient response at generator

- Add controlled desired response

\subsection{Identify Transient Response at Generator}

By using the equations and system model from [30], transient response of the rotating system can be identified. 


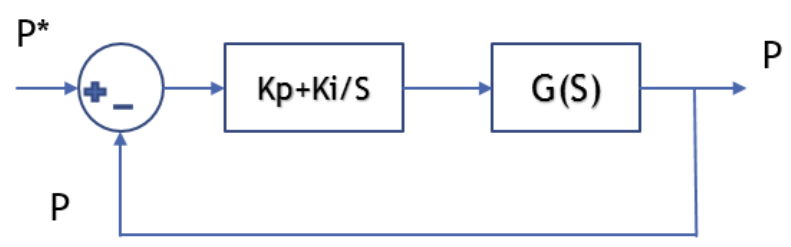

Figure 4.16: Conventional closed loop control

$$
\begin{gathered}
G(S)=\frac{K}{\frac{s^{2}}{\omega_{0}^{2}}+\frac{2 \zeta s}{\omega_{0}}+1} \\
\omega_{d}=\omega_{0} \sqrt{1-\zeta^{2}}
\end{gathered}
$$

$\boldsymbol{\omega}_{\mathbf{d}}$ Damped frequency of free oscillation

$\boldsymbol{\omega}_{0}$ Un-damped natural frequency

$\zeta$ Damping co-efficient

$$
\ln \left(\frac{a_{1}-a_{0}}{a_{2}-a_{0}}\right)=\frac{2 \pi \zeta}{\sqrt{1-\zeta^{2}}}
$$




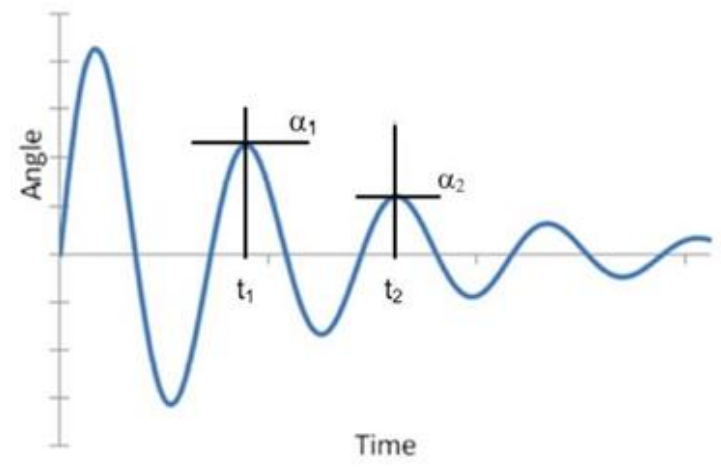

Figure 4.17: Typical damped response [30]

From Figure 4.16 it is clear that:

$$
\omega_{d}=\frac{2 \pi}{t_{2}-t_{1}}
$$

Assume the figure below is the active power output of the synchronous generator.

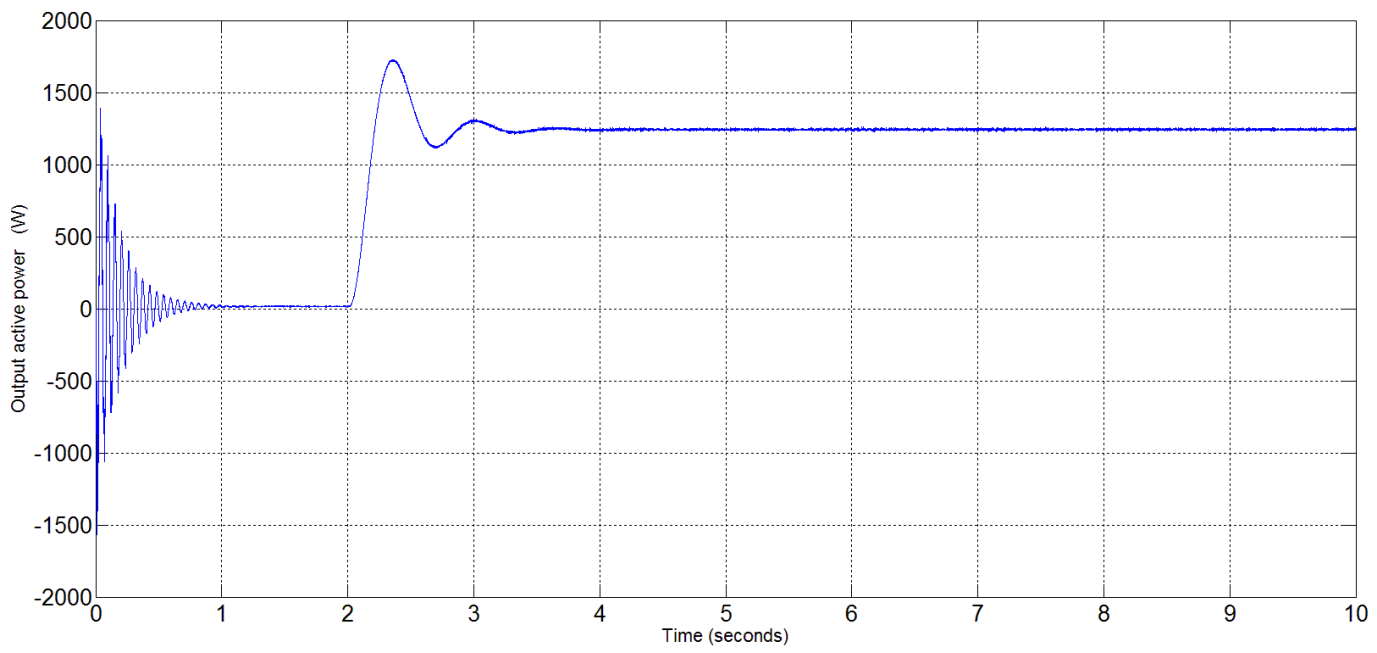

Figure 4.18: Synchronous generator active power output 
Therefore, the rotating system model $\mathrm{G}(\mathrm{s})$ for SG output would be:

$$
G(s)=\frac{41300}{\frac{s^{2}}{10.5^{2}}+\frac{2 * 0.31 s}{10.5}+1}
$$

To validate the dynamic rotating system, the $\mathrm{G}(\mathrm{s})$ is added to the Simulink model and compared to the actual SG output.

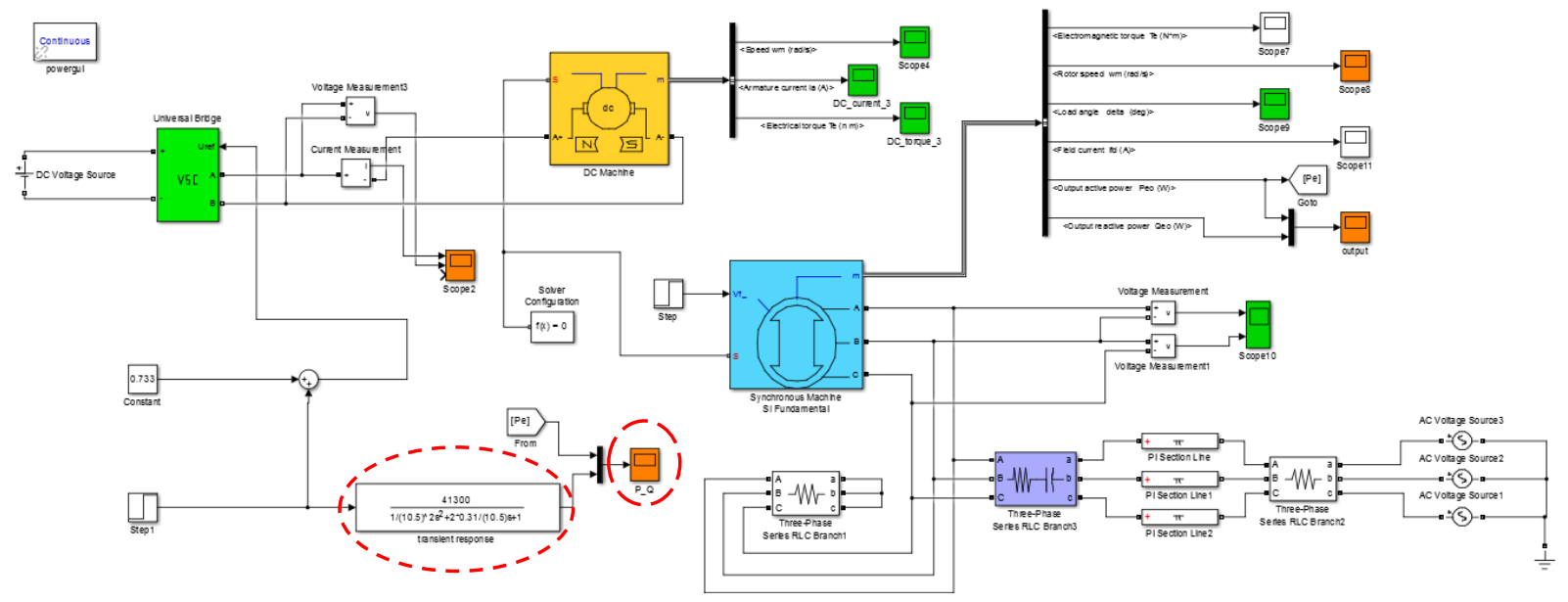

Figure 4.19: Simulink model with dynamic rotating system and without transfer function block

The P_Q scope shows the dynamic rotating model G(s) compared with the actual SG output. As it is depicted below, the blue line is the synchronous generator active power output and the red line is the dynamic rotating model. This graph shows they are identical and validates the dynamic model of the synchronous generator. 


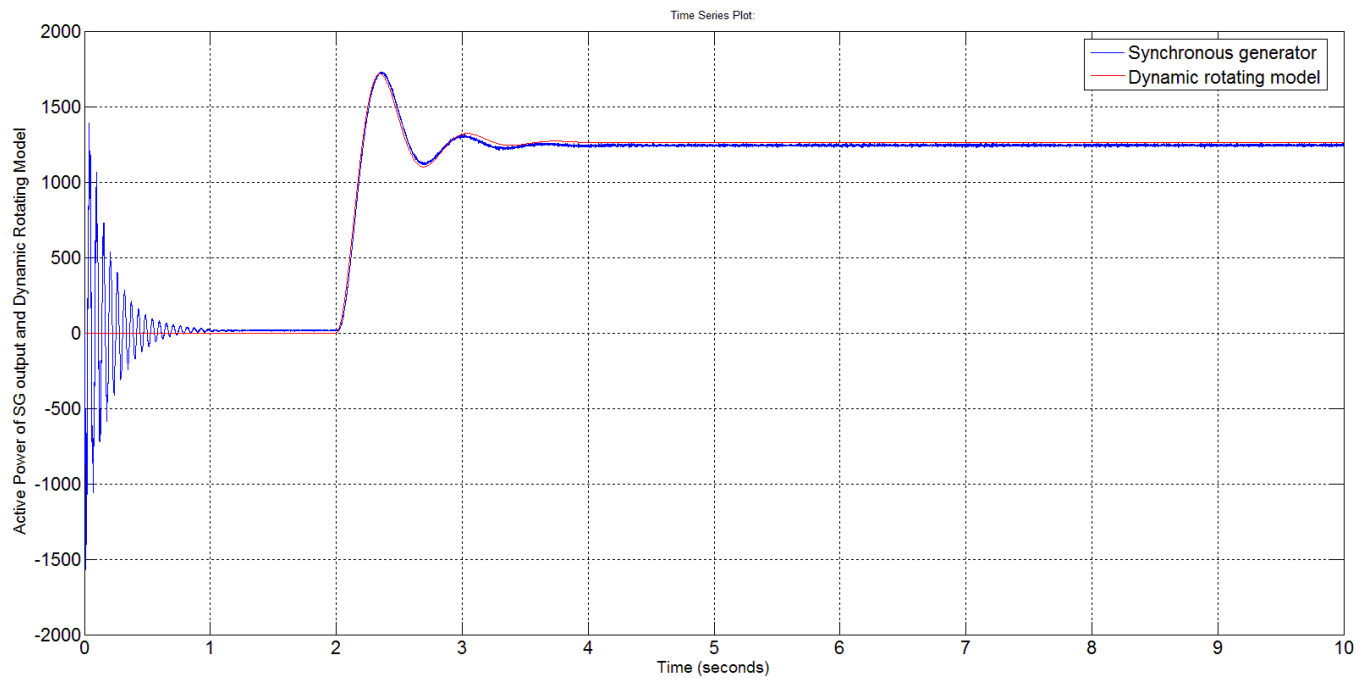

Figure 4.20: Synchronous generator active power output and dynamic rotating model G(s)

In the simulation average-model based VSC is selected for the universal bridge, and an average-model type of voltage source converter is used to represent the power-electronic switches. Unlike the other power electronic devices, this model uses the reference signals representing the average voltages generated at the $\mathrm{ABC}$ terminals of the bridge (uref varies between 0 to 1 ). The output of PI current control is 0.733 which feeds uref.

\subsection{Adding Controlled Desired Response}

After identifying the dynamic model of the synchronous generator, the Transfer Function equation (4.3) is added to the Simulink model. This TF cancels out the original response of the system and add a control desired response. Moreover, it brings an advantage of creating oscillations with a desired frequency. 


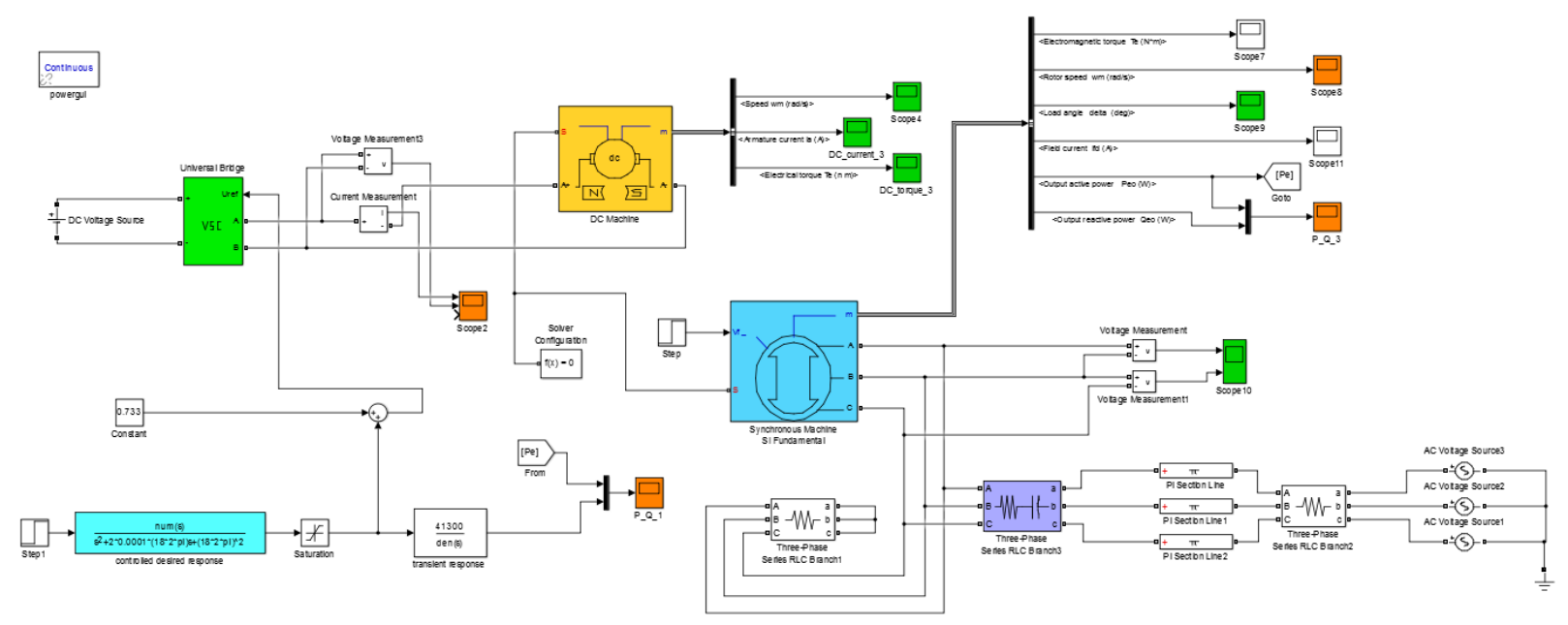

Figure 4.21: Simulink model with the disturbance block and without PI controllers

The Figure 4.21 and 4.22 show the result of synchronous generator output without PI controllers and the active power carries $18 \mathrm{~Hz}$ oscillation. As a result, the transfer function block creates an oscillation with a desired frequency.

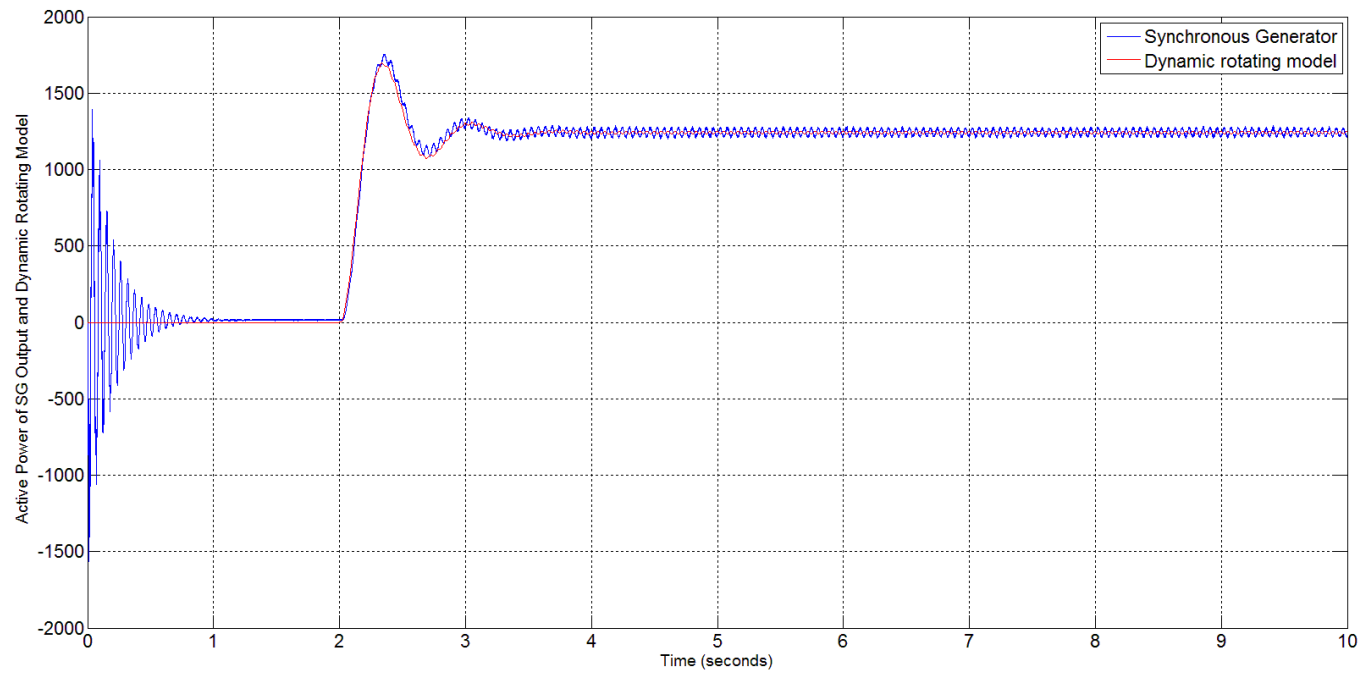

Figure 4.22: SG active power output and dynamic rotating model G(s) with a disturbance block 


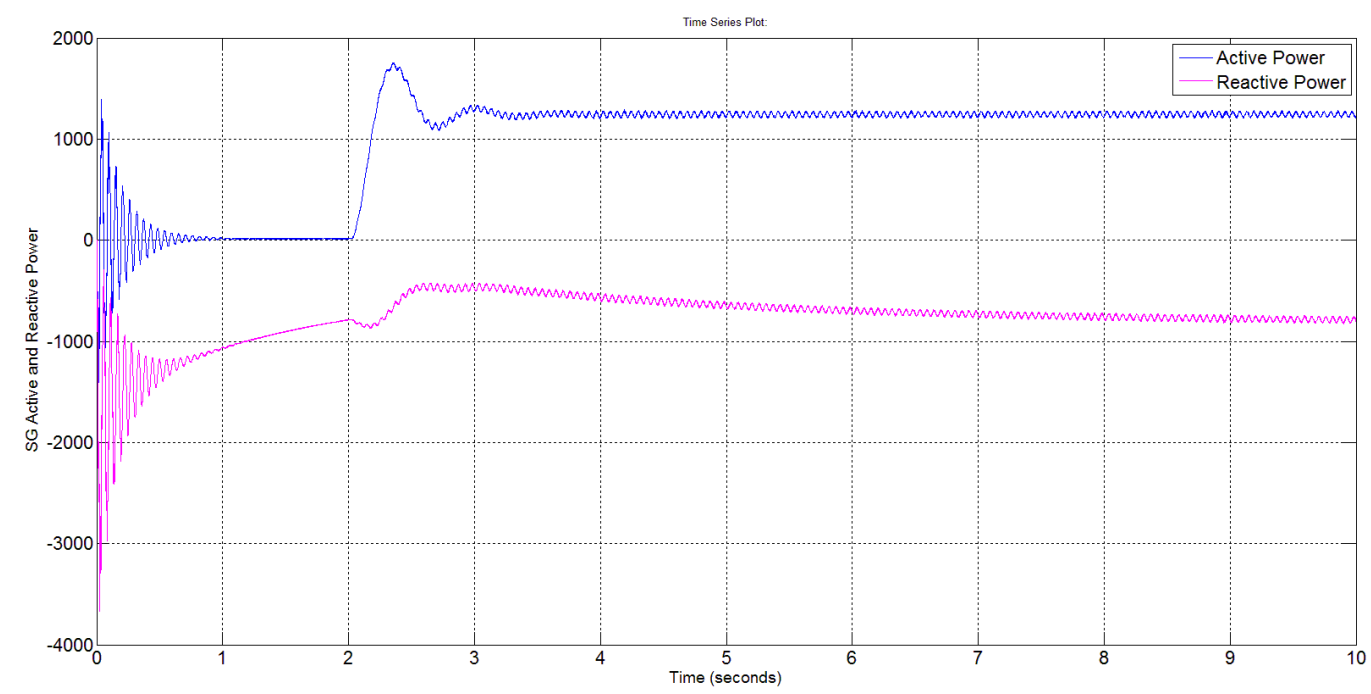

Figure 4.23: Figure 4.22: SG active and reactive power output with $18 \mathrm{~Hz}$ oscillation

The transfer function block brings the advantage of oscillating mechanical shaft with a different range of frequency.

The electrical torque of the generator can act as a stimulus to excite the torsional vibration modes. Conversely, the torsional vibration changes the generator output voltage and excites the electrical oscillation at the fundamental $(50 \mathrm{~Hz}$ or $60 \mathrm{~Hz})$ complement frequency of the torsional vibration. For instance, a $25 \mathrm{~Hz}$ torsional oscillation on a generator connected to a $60 \mathrm{~Hz}$ system will generate $35 \mathrm{~Hz}$ electrical oscillations. The generator's shaft couples the torsional vibration and the electrical oscillation for SSR interaction [6]. 


\subsection{Series Capacitors}

To find a specific resonance frequency at the electrical side, the frequency equation below is used:

$$
f=\frac{1}{2 \pi \sqrt{L C}}
$$

$L_{\text {Line }}=1.8 \mathrm{mH} * 12=21.6 \mathrm{mH}$ Total inductance for 12 pi-sections

As an example the resonance frequency on the transmission line for $700 \mathrm{uF}$ capacitors would be:

$$
f=\frac{1}{2 \pi \sqrt{21.6 \times 10^{-3} \times 700 \times 10^{-6}}} \approx 41 \mathrm{~Hz}
$$

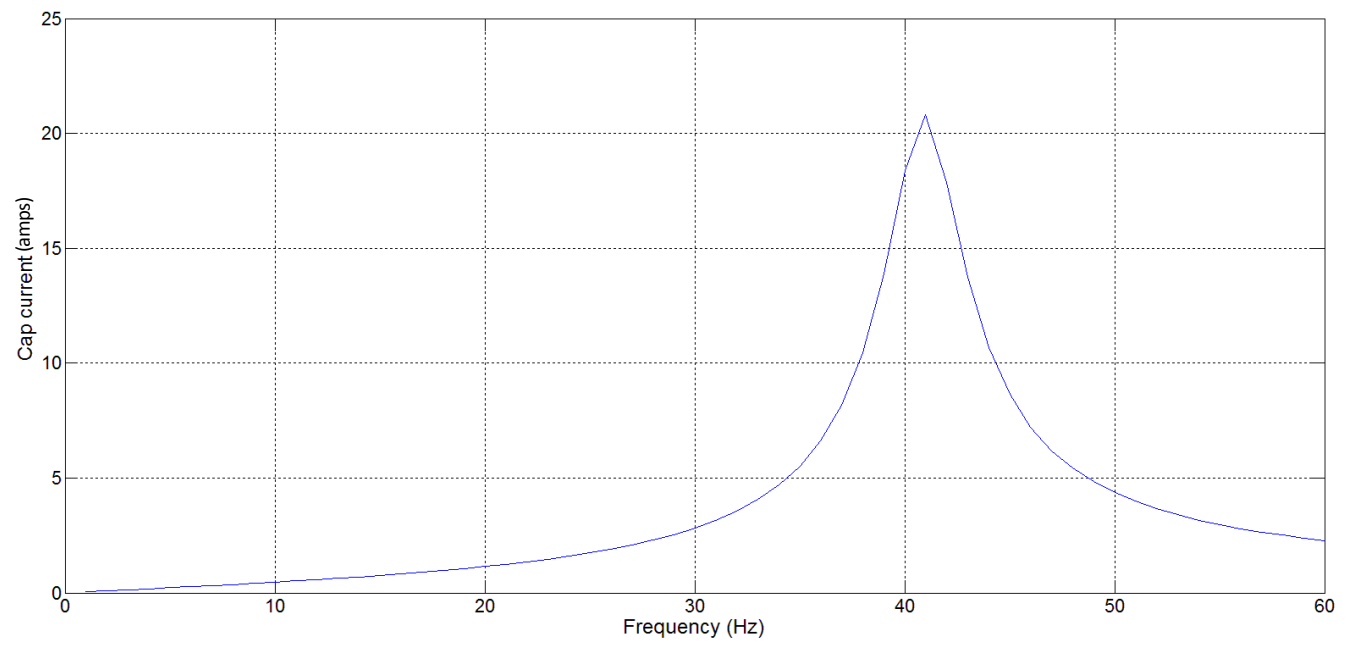

Figure 4.24: Frequency Vs Cap-current 
The $C_{\text {series }}=700 \mu F$ brings $35 \mathrm{~Hz}$ resonance frequency on the electrical side. By setting the transfer function frequency to $25 \mathrm{~Hz}$, the interaction between the mechanical and the electrical side should be clearly observable. 


\section{Chapter 5}

\section{Experimental Design}

\subsection{Introduction}

The design and experimental verification of the proposed power system model are presented in this chapter. The experimental test rig is shown in Figure 5.1 in which LabVIEW and National Instruments are employed to provide Real-Time power and current control and emulate oscillation on mechanical shaft. The DC motor is connected to the DC supply with a controllable current. The generator is connected to the DC motor through the shaft allowing it to transform the mechanical energy into electrical energy. The generator supplied desired power to the grid via power loop control.

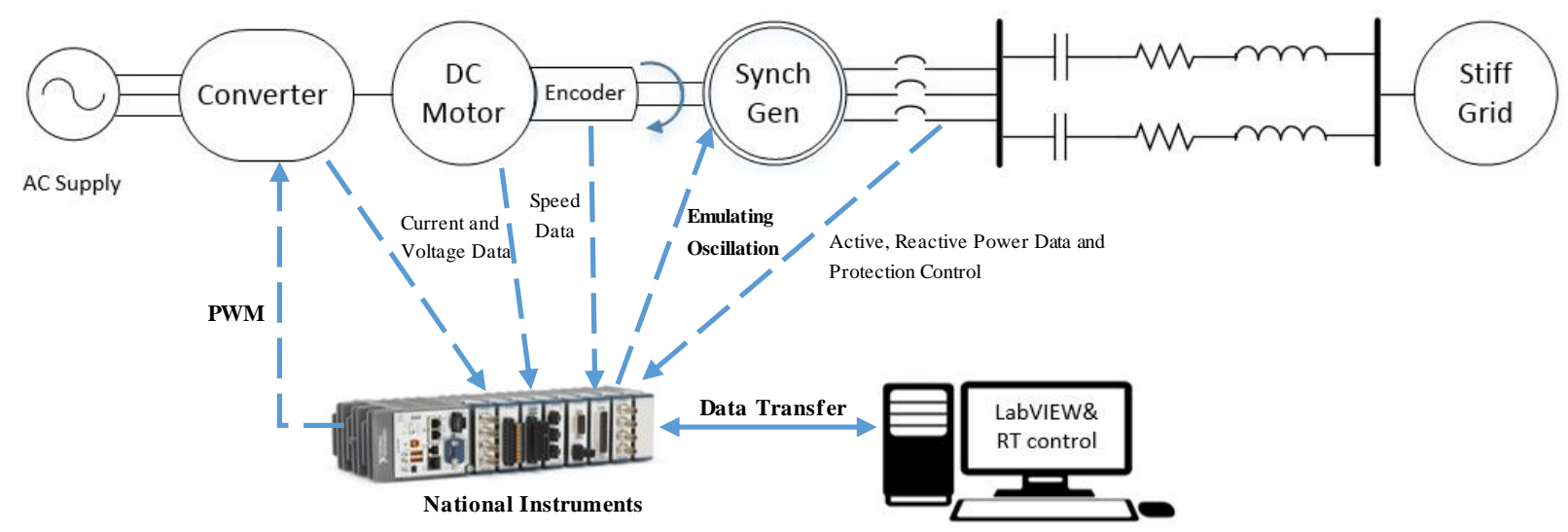

Figure 5.1: Experimental test rig design schematic 


\subsection{National Instruments}

By using the NI platform, a tailored user-defined system can be built to face the experiments need with flexible and reprogrammable I/O capabilities. To implement all the controls for the power system model, LabVIEW and National Instrument are employed to create an embedded system. NI chassis cRIO-9038 comes with dual core CPU and programmable FPGAs that are used to calculate and measure data at a sample rate up to $25 \mathrm{~ns}$ and send them to real-time and host interface. In this project more than 7 different NI modules are used to control and monitor power, reactive power, power factor, voltage, current, motor speed and relays protection.

\subsection{Motor Control and Drive}

A DC motor is a rotary electrical machines that converts direct current electrical energy into mechanical energy. To control the DC motor speed and transfer power to SG through the mechanical shaft, there is a need to design and build a current control for DC motor.

\subsubsection{Half-Bridge Converter}

The first step is designing a current control for the DC motor. SEMIKRON AN-8005I is employed as a half-bridge converter to convert 3-phase AC to DC for the DC motor supply. A Pulse Width Modulation (PWM) technique controls the half-bridge converter and provides the advantage of having full control on the DC motor operation speed. 


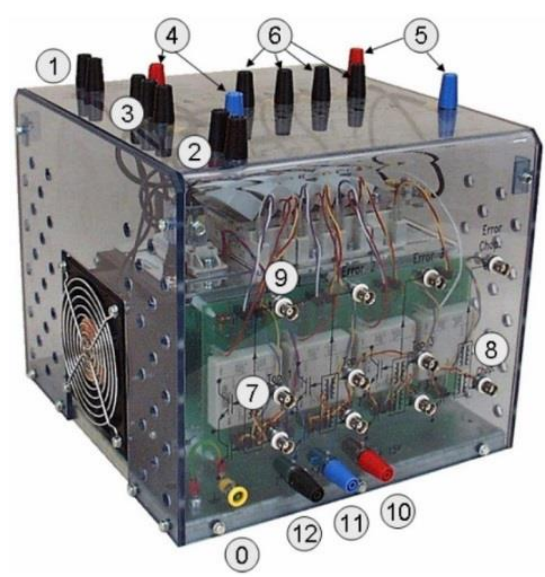

Figure 5.2: SEMIKRON AN-8005I [56]

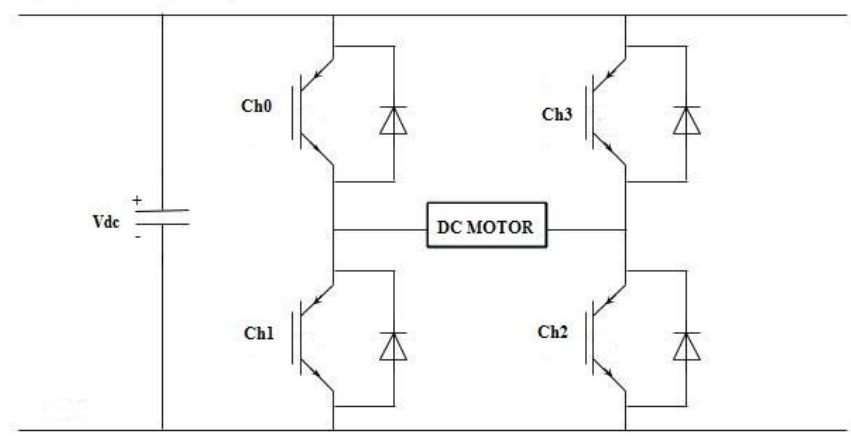

Figure 5.3: Half-Bridge converter

\subsubsection{Pulse Width Modulation}

A Pulse Width Modulation (PWM) is a method that generates an analog signal using a digital source. A PWM signal involves two main components that define its behavior: frequency and duty cycle. The amount of time that the signal is in a high state (on) as a percentage is described by duty cycle. The frequency determines PWM switches between high and low states. By switching between on and off state at a fast adequate rate, the output 
will appear as a constant voltage to provide power to the devices [29]. PWM signals are used to control the wide range of applications such as DC motor and pump, valve and etc. In this test PWM is used to control DC motor speed operation.

\subsubsection{FPGA Based PWM Implemented in LabVIEW}

The figure shown below depicts the PWM technique, which is sent to the converter by NI9474 module through BNC cables. Each BNC cable controls one of the IGBTs for a halfbridge converter.

NT=Ticks per PWM cycle

$\mathrm{N}=$ Tick count

$\mathrm{Nd}=$ Delay

Non=ON time 


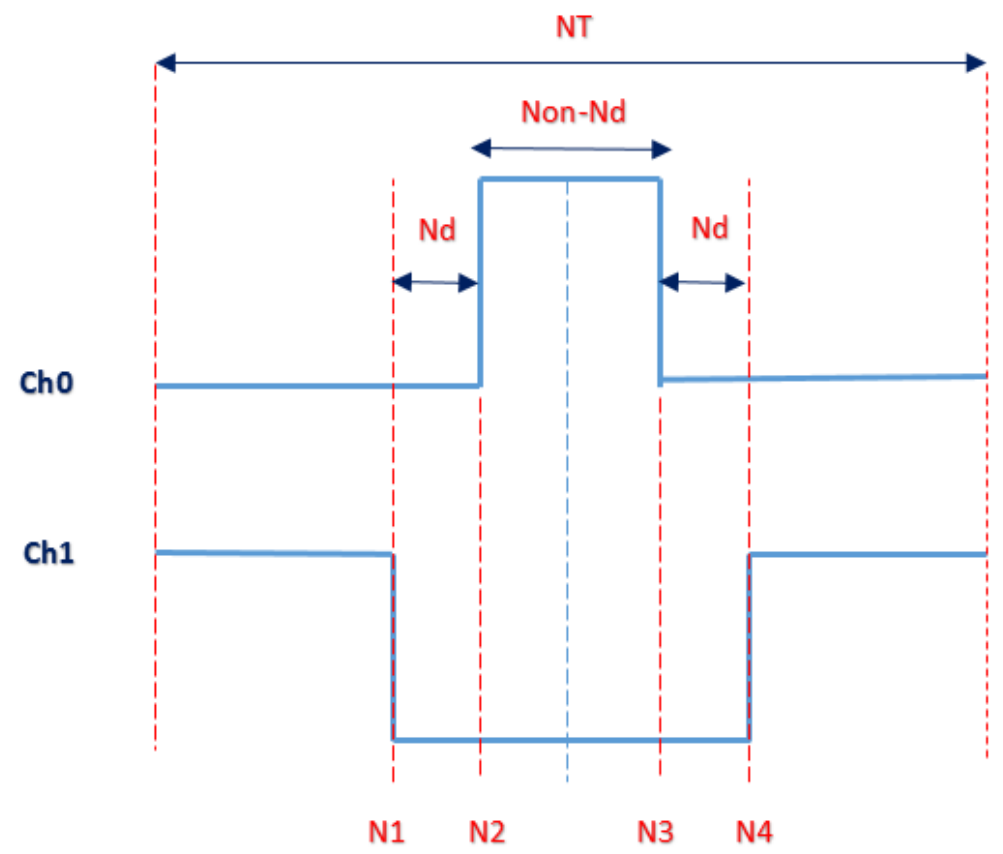

Figure 5.4: $\mathrm{PWM}$ for $\mathrm{Ch} 0$ and $\mathrm{Ch} 1$

$$
\begin{gathered}
N_{1}=\frac{N_{T}}{2}-\left(\frac{N_{\text {on }}+N_{d}}{2}\right) \\
N_{2}=\frac{N_{T}}{2}-\left(\frac{N_{\text {on }}-N_{d}}{2}\right) \\
N_{4}=N_{T}-N_{1} \\
N_{3}=N_{T}-N_{2}
\end{gathered}
$$

\begin{tabular}{|c|c|c|c|c|c|}
\hline & $\boldsymbol{N} \leq \boldsymbol{N}_{\mathbf{1}}$ & $\boldsymbol{N}_{\mathbf{1}}<\boldsymbol{N} \leq \boldsymbol{N}_{\mathbf{2}}$ & $\boldsymbol{N}_{\mathbf{2}}<\boldsymbol{N} \leq \boldsymbol{N}_{\mathbf{3}}$ & $\boldsymbol{N}_{\mathbf{3}}<\boldsymbol{N} \leq \boldsymbol{N}_{\mathbf{4}}$ & $\boldsymbol{N}>\boldsymbol{N}_{\mathbf{4}}$ \\
\hline Ch0, Ch2 & 0 & 0 & 1 & 0 & 0 \\
\hline Ch1, Ch3 & 1 & 0 & 0 & 0 & 1 \\
\hline
\end{tabular}

Table 5.1: The sequence of PWM for each channel 
From the Table 5.1 the algorithm in LabVIEW is represented by the following equations:

For Channel 1 and Channel 3

$$
N \leq N_{1} \text { OR } N>N_{4}
$$

For Channel 0 and Channel 2

$$
\operatorname{NOT} N \leq N_{2} \text { OR } N_{3}<N
$$

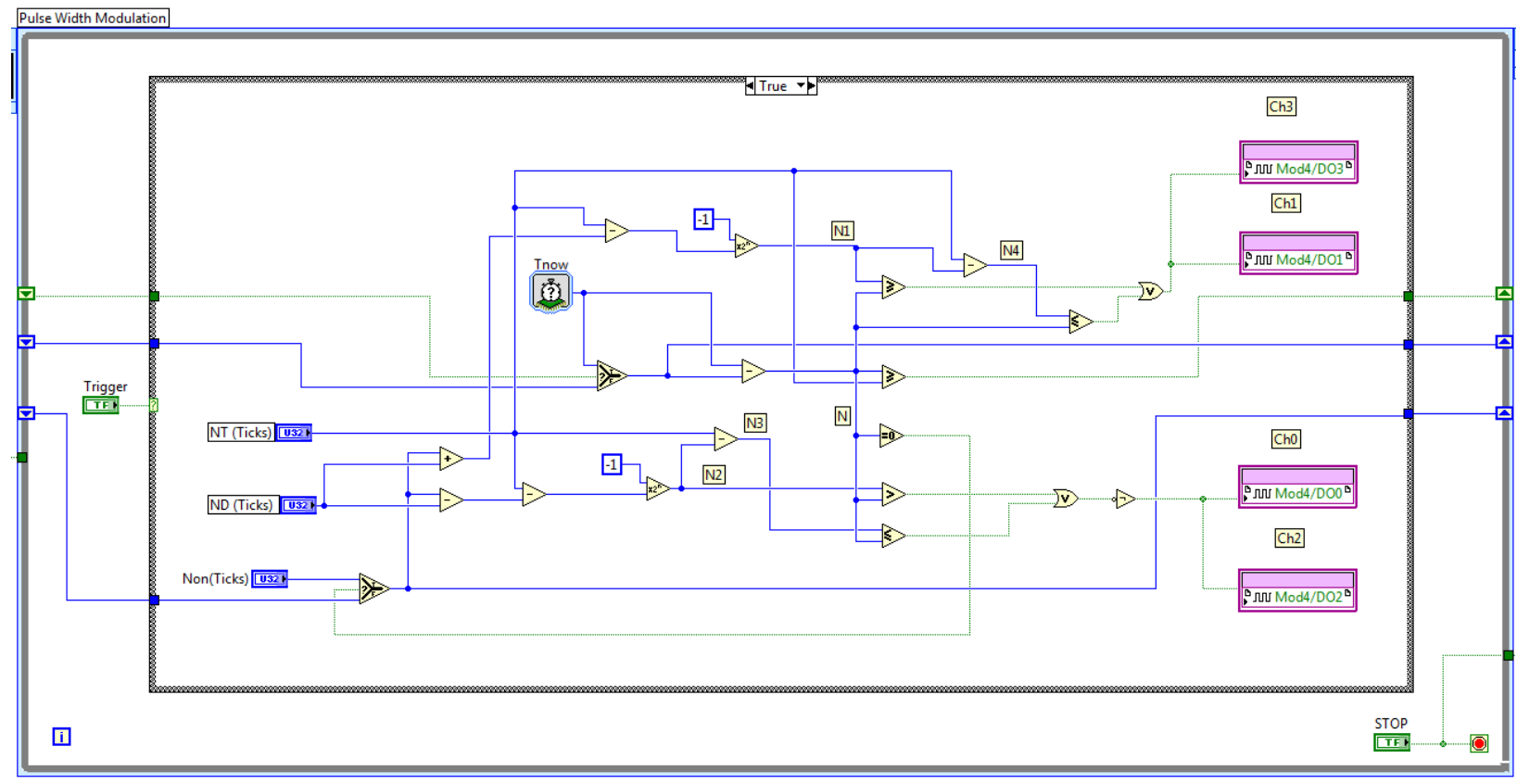

Figure 5.5: FPGA algorithm for PWM

The relation between Non and Vdc and Vref is:

$$
N_{o n}=\left(\frac{V_{r e f}}{V_{d c}}+1\right) * \frac{N_{T}}{2}
$$


Assume NT=10000 and ND=200 tick, the Non varies from 400 to 9600 (each tick is 25 Nano Second equal to $40000 \mathrm{KHz}$ ). By changing the Vref, the Non and the DC motor speed can be controlled. The Vref is the output of the second PI controller which is used in SIMULINK for power loop control. The figures below are taken from MDO3014 oscilloscope from the port $6 \mathrm{pf}$ Semikron. The armature current is measured by current probe TCP2020 and used as a current feedback for the second PI controller.

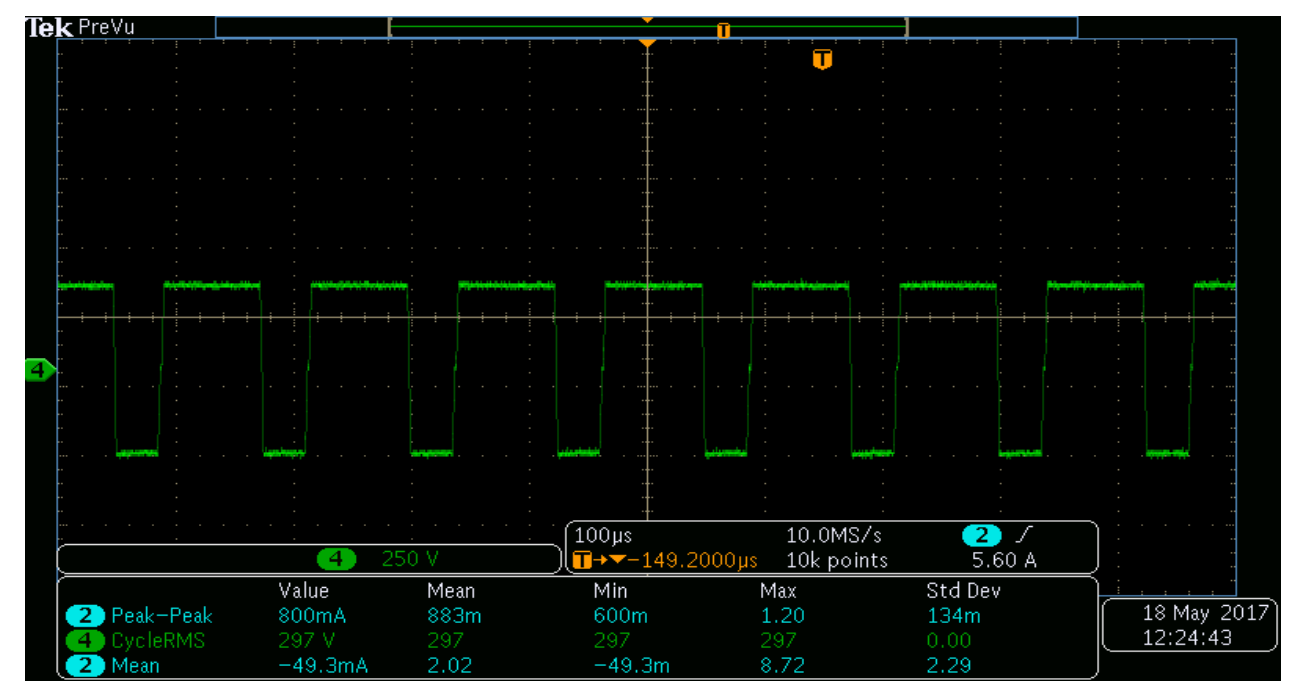

Figure 5.6: Pulse Width Modulation monitored by oscilloscope

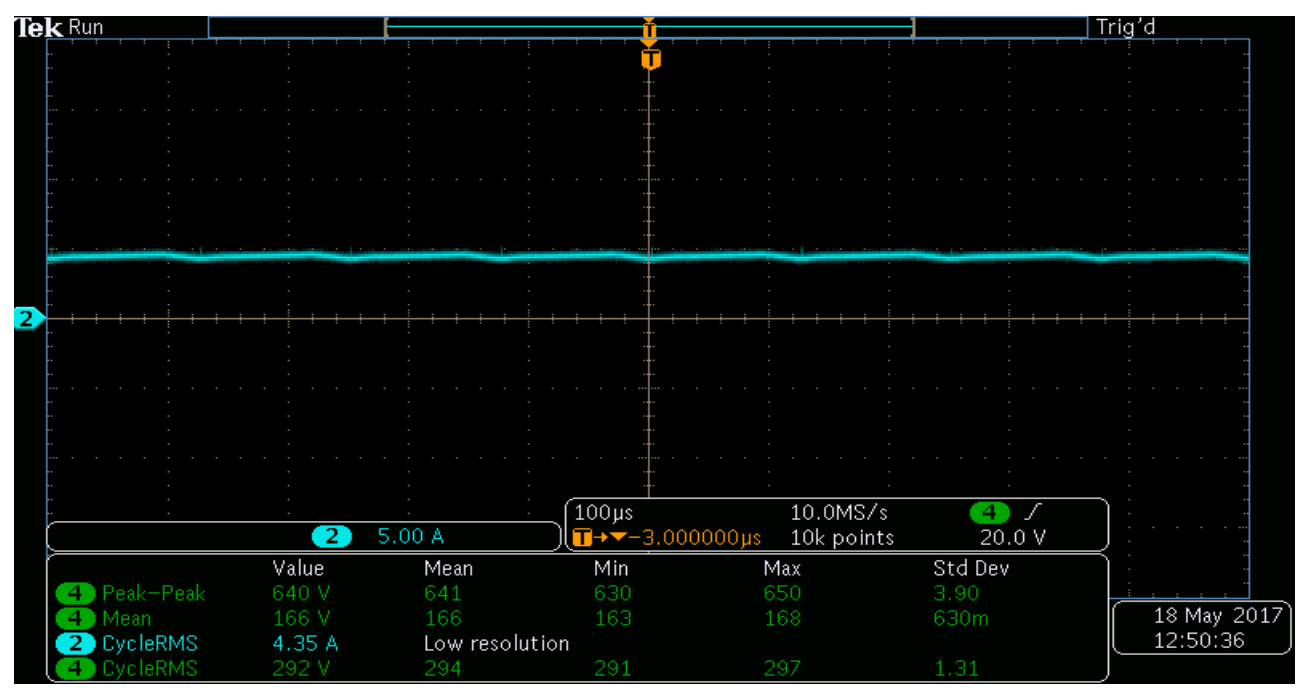

Figure 5.7: Armature current monitored by oscilloscope 


\subsubsection{Encoder}

To collect data and monitor the mechanical shaft behavior, E6 encoder is used. The E6 Series encoder can be easily mounted on the shaft to provide digital feedback information. E6 is a quadrature encoder that performs 8000 counts per revolution. Module NI-9361 is used to count the edges. By using the equation below the speed in rpm is calculated and monitored on real-time interface.

$$
\text { Speed in rpm }=\frac{\text { Number of edges }}{8000} \times 60
$$

\subsection{Tuning PI Controllers In Power System Lab}

The current and power control loop are desinged using the same $\mathrm{Kp}$ and $\mathrm{Ki}$ value gained in the SMIMULINk model.

Current PI controller value: $\mathrm{Kp}=0.6, \mathrm{Ki}=35$

Power PI controller parameters: $\mathrm{Kp}=0.066, \mathrm{Ki}=0.033$

Note: The parameters set in Simulink for the Power PI controller did not work in the power system lab. The reason could be due to the synchronous generator 10s time constant which is not considered in the Simulink model. Therefore, the PI control is tuned again and the new parameters are $\mathrm{Kp}=0.0007, \mathrm{Ki}=0.002916$.

LabVIEW and National Instruments are employed to provide Real-Time power and current control. By collecting data such as voltage and current from the SG output, active, reactive power and power factor can be calculated and monitored. The schematic below 
shows the design of power and current control for the DC motor and Synchronous Generator using NI-9225, NI-9246.

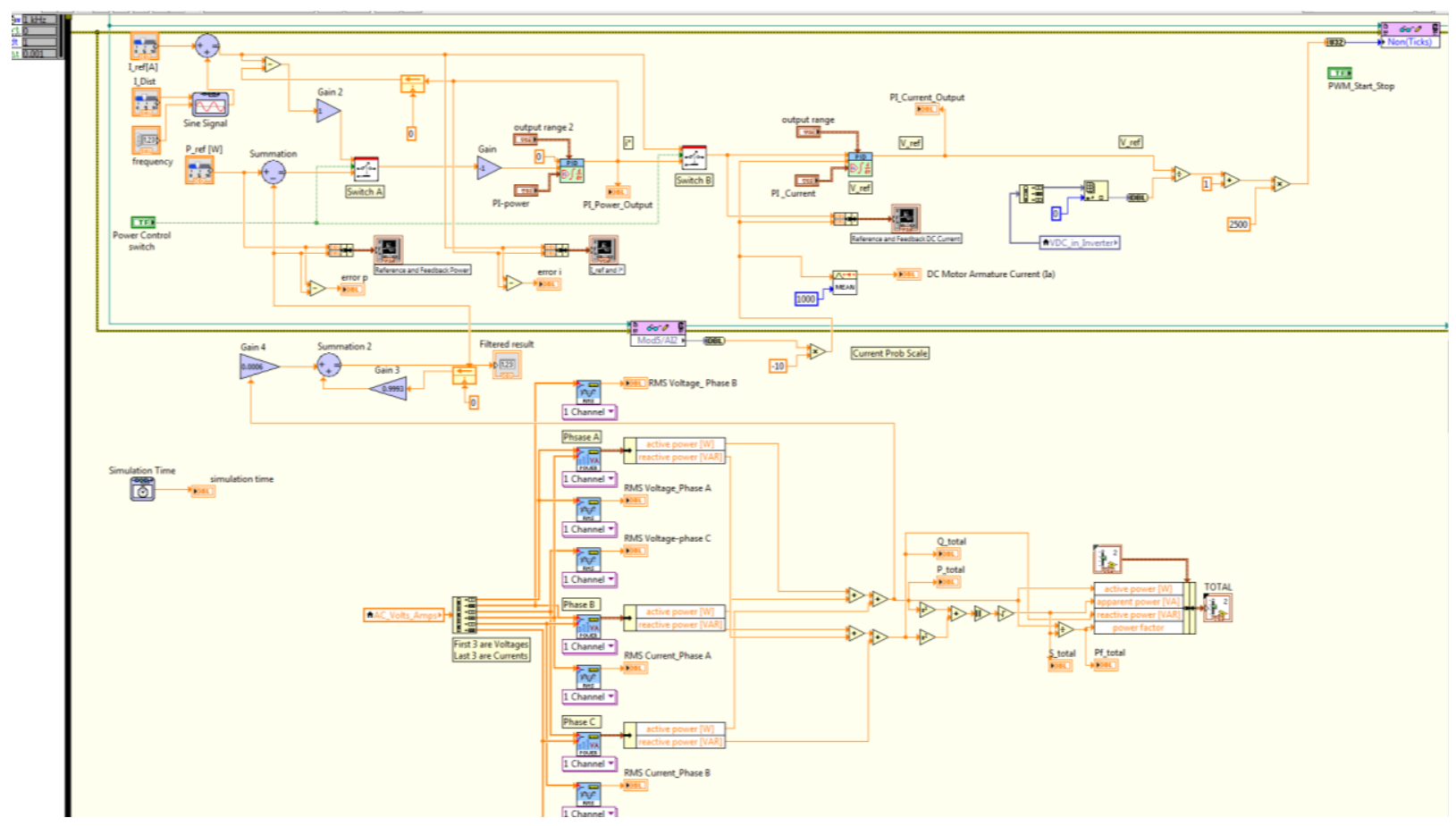

Figure 5.8: Real-Time control panel in LabVIEW for current and power control

The current control loop can speed up the DC motor and SG to $1800 \mathrm{rpm}$ which matches the grid frequency $60 \mathrm{~Hz}$. After synchronization, the current control is switched to power control. As the real-time interface in the figure below shows, power control pushes $1 \mathrm{KW}$ to the transmission line. In the real-time control panel, synchronous generator current, voltage, active power and reactive power output can be monitored. Further, by changing the slide bar on the real-time control panel active power can be increased or decreased. 


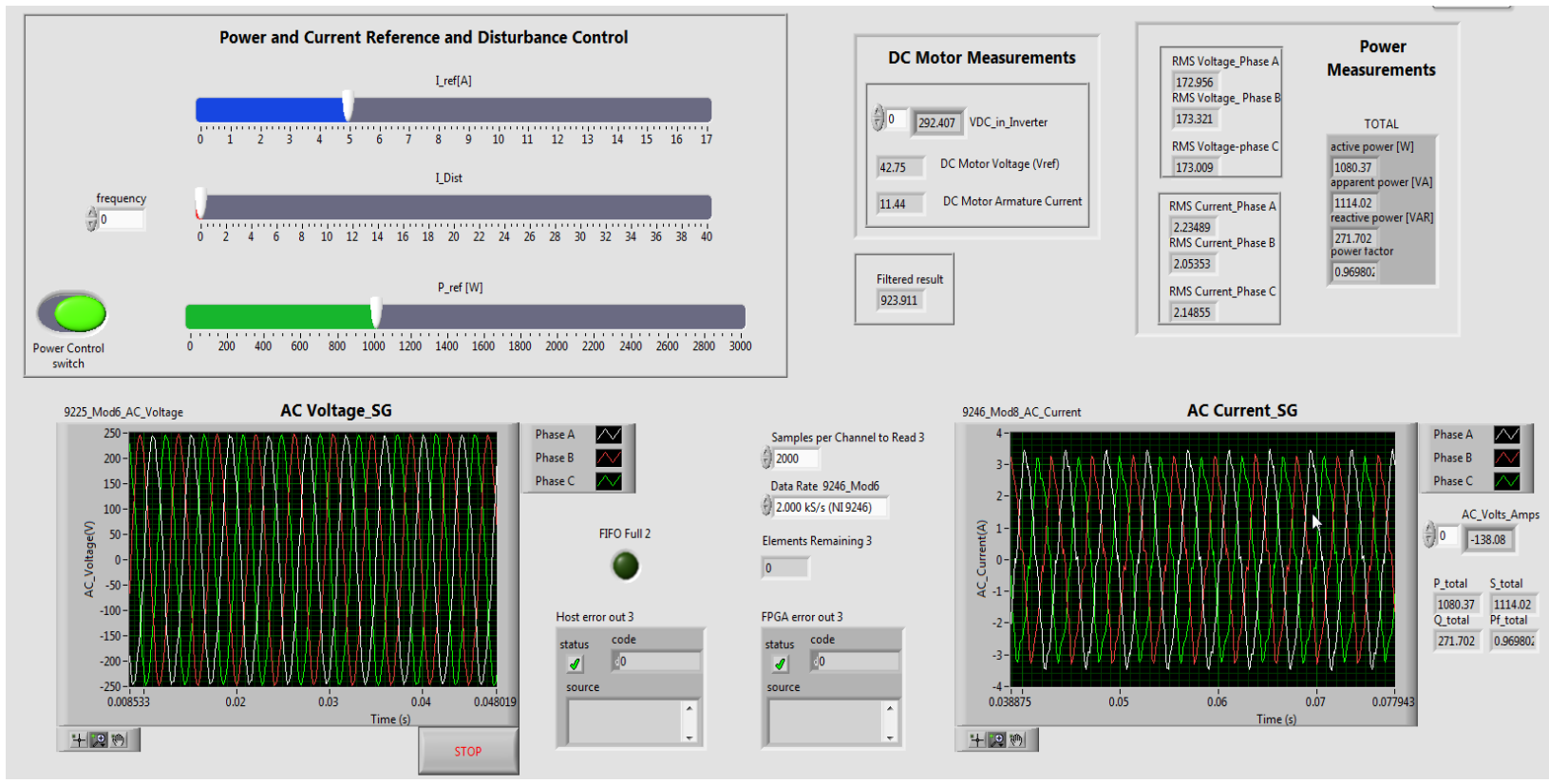

Figure 5.9: Real-Time front panel control in LabVIEW

\subsection{Implementing Transfer Function in LabVIEW}

The transfer function is designed in LabVIEW to emulate oscillation to the prime mover at certain frequency. However, after investigation on the transfer function, the output reached to a negative current. Meaning it would push current back to the capacitors inside the converter and creates the possibility of damaging the caps. Therefore, an AC signal generator is used in LabVIEW to create the disturbance on the DC motor shaft. This gives the system the ability to vary the current magnitude and frequency.

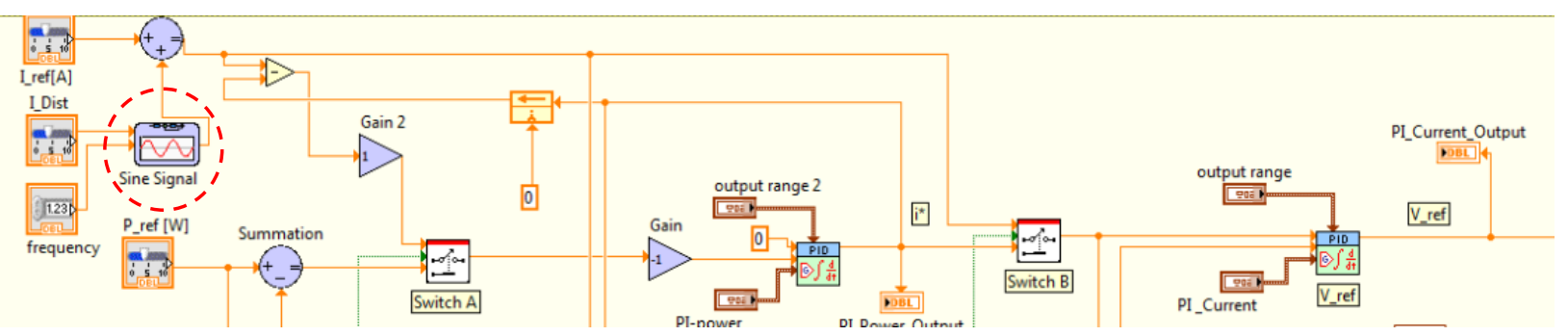

Figure 5.10: AC Signal Generator in LabVIEW 


\subsection{Power System Protection}

The SSR test could make the system unstable and have a huge impact on the synchrono us generator current output. Hence, an overcurrent and voltage protection is designed. It separates the transmission line and synchronous generator if the current exceeds 20 amps. Moreover, the protection shuts down the PWM and turns the DC motor off. The NI-9381 is used which is a multifunction input-output module. This module sends a signal to a relay NTE-R95-121 and trips the contactor GE-CR205AP1 if there is an overcurrent issue. An algorithm for the protection logic circuit is written in LabVIEW. The NI module collects instantaneous current from each phase of the synchronous generator output. If the current exceeds 20 amps, it trips the contactor.

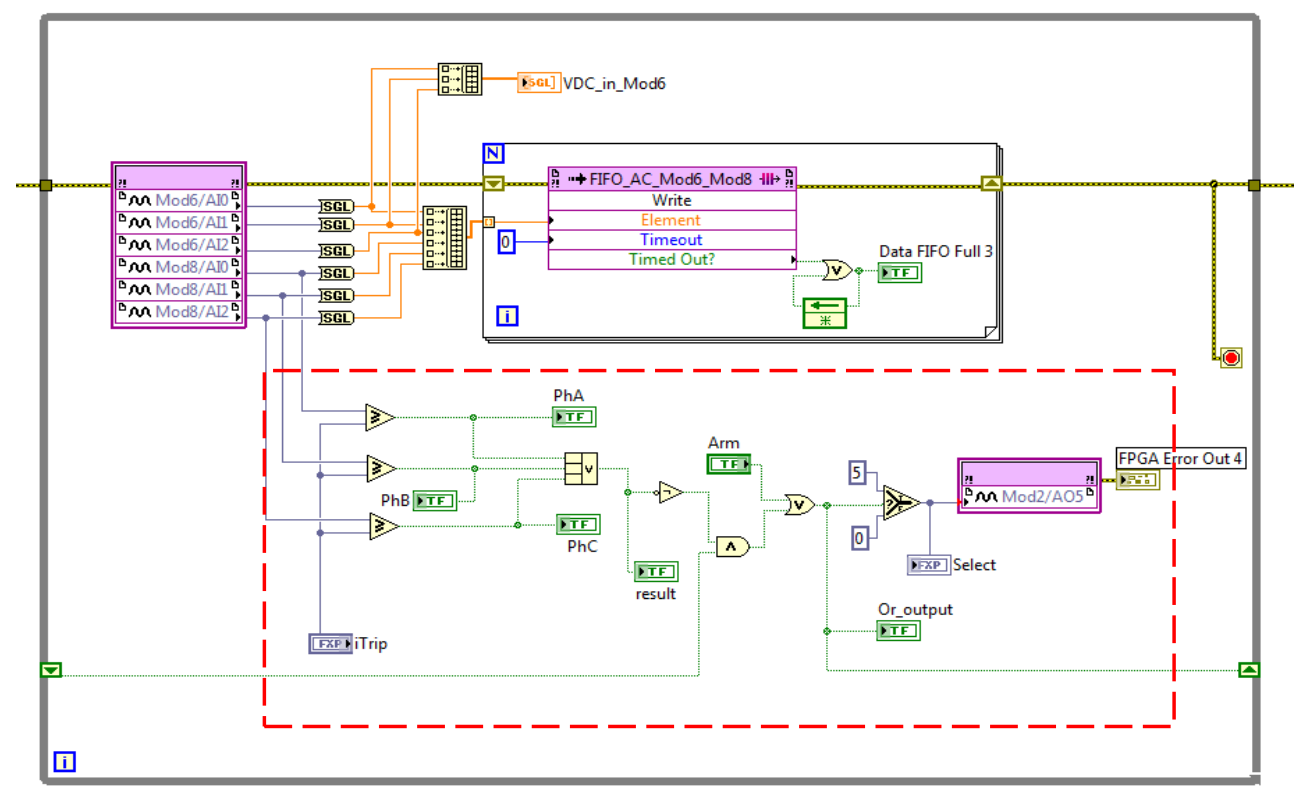

Figure 5.11: Protection logic circuit for LabVIEW FPGA 
To control the relay, a conventional relay controller is used to trip the contactor.

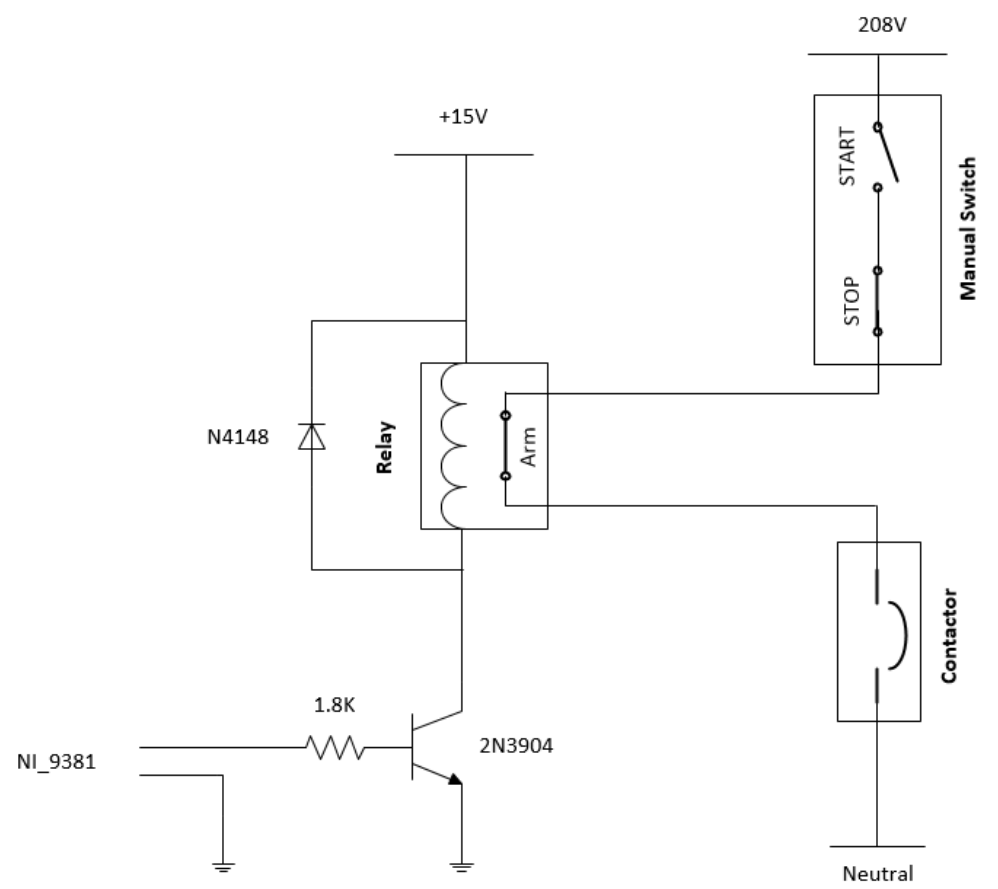

Figure 5.12: Conventional relay controller

\subsection{Fast Fourier Transform Technique (FFT)}

To analyze the harmonics and the frequency of the power system model in this test, FFT technique is used. This technique demonstrates the frequency behavior on the prime mover and transmission line before and during disturbances. The investigation is focused on the current which carries all the disturbances. For this purpose, the power analyzer PA2200 series is employed to analyze FFT in real-time. Since the PA2200 cannot provide FFT with less than $1 \mathrm{~Hz}$ resolution, the data is imported to Matlab script from PA2200. The FFT script is used to identify and analyze harmonics and frequency on the transmission line. 


\section{Chapter 6}

\section{Experimental Results}

\subsection{Introduction}

The experimental results of the proposed grid connected power system model are presented in this chapter. The first results provided verification of the FFT technique and harmonics identification on the transmission line. The effect of the compensated line on the power system stability is shown, including SSR test and interaction between mechanical and electrical side during disturbances.

\subsection{FFT Waveform Results}

The figure below illustrates the FFT on the transmission line which is synchronized to 60 $\mathrm{Hz}$ grid without series compensated line. There is no disturbances on the power line in the Figure 6.1. 


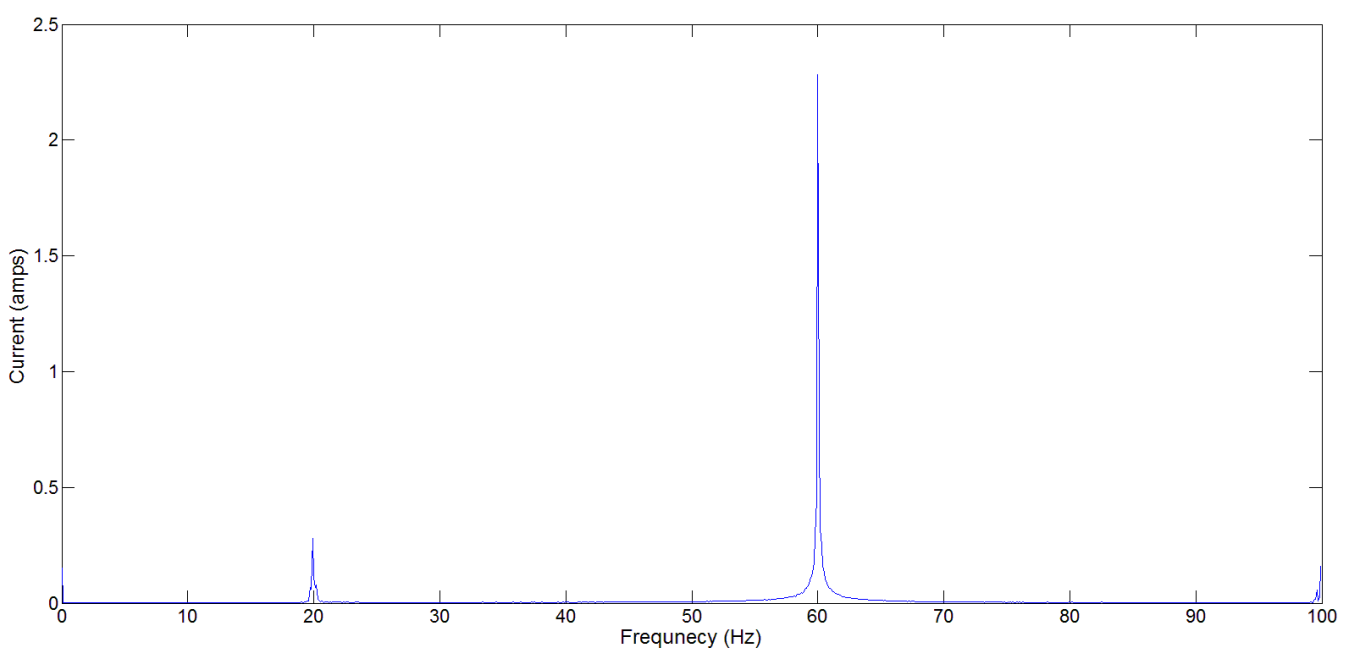

Figure 6.1: Power grid FFT analysis

As it shown below, the $20 \mathrm{~Hz}$ is due to aliasing back or folding back effect. If the bandwidth increases to $200 \mathrm{~Hz}$, this can be explained by the alias effect. The sampling frequency is at $100 \mathrm{~Hz}$.

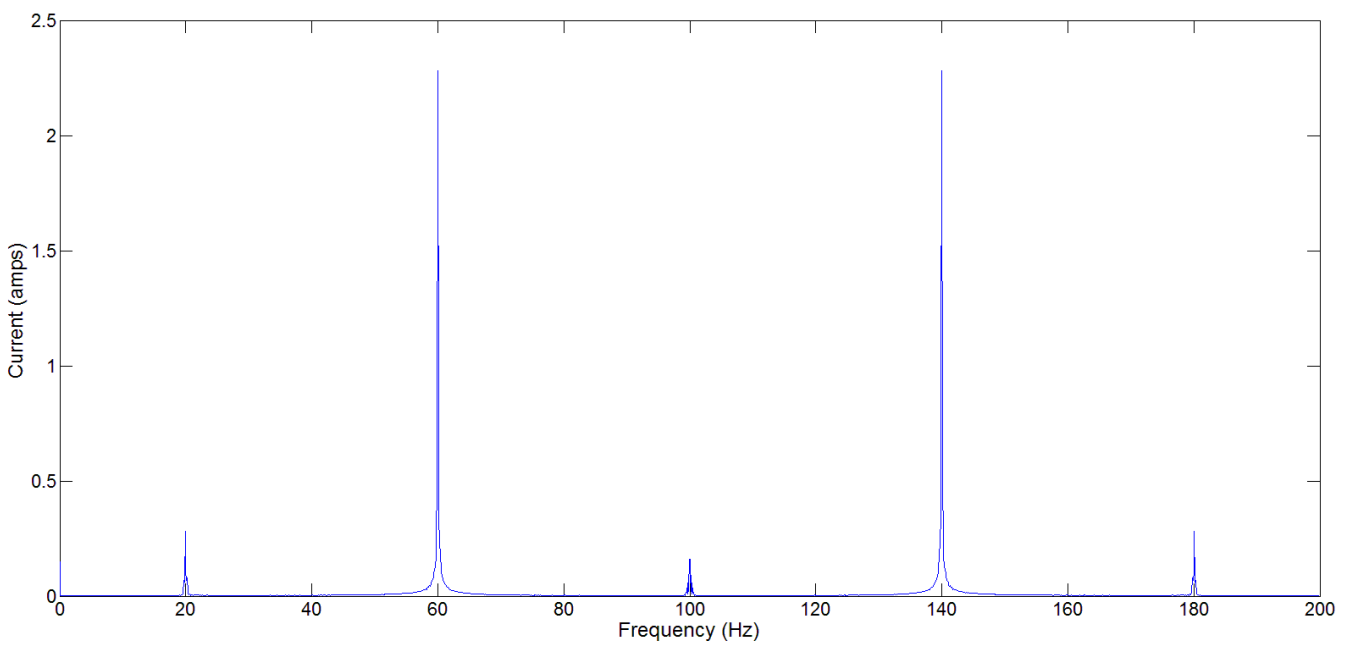

Figure 6.2: Alias effect 


\subsection{SSR Test}

By adding $700 \mathrm{uF}$ series caps which brings $41 \mathrm{~Hz}$ resonance frequency to the transmission line and oscillating the prime mover at $19 \mathrm{~Hz}$, it is expected that SSR can be monitored. However, as it illustrated in Figure 6.3 SSR didn't occur at $41 \mathrm{~Hz}$ and the oscillation was not a desired result.

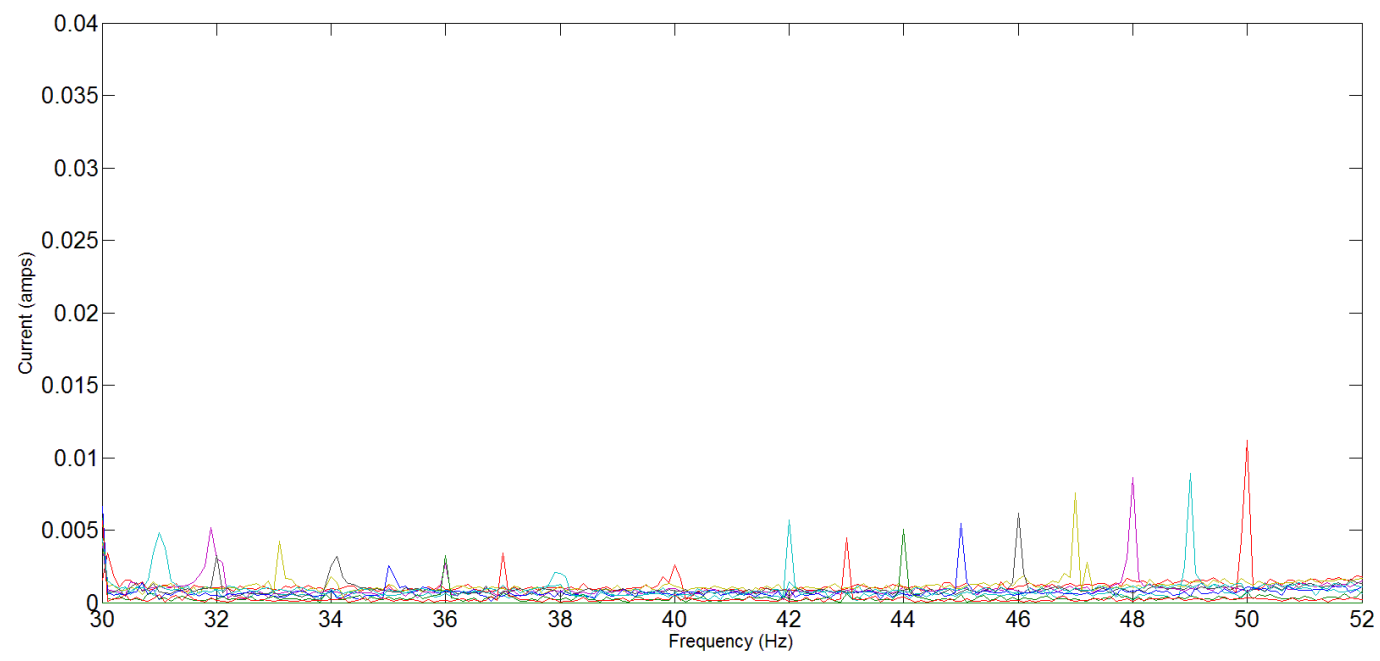

Figure 6.3: SSR test for 700uF compensated line

Further investigations were carried out and it was found the synchronous generator dampers windings, damped out the oscillations. Synchronous generator dynamic model is investigated in Chapter 3. As it shown in equation (3.51) the damper windings in the synchronous generator come in series with RL of the transmission line and they will be added to the total RL of the line. The new RL value shifts the resonance frequency and this 
explains why SSR didn't occur at $41 \mathrm{~Hz}$ with $700 \mathrm{uF}$ series cap. In addition, Figure 3.9 shows that by removing the synchronous generator dampers the total inductance of the winding will increase and less oscillation is expected. Therefore, to find the resonance frequency on the transmission line a new calculation is required.

\subsection{Calculation of Resonance Frequency}

As it explained previously, the impedance of the power line is changed due to adding the SG damper winding and resistance to the total RL of the line. Therefore, it is necessary to calculate the resonance frequency with the new condition.

$L_{\text {Line }}=1.8 \mathrm{mH} * 12=21.6 \mathrm{mH}$ Total inductance for 12 pi-sections

$L_{l s}=2.844 \mathrm{mH}$ Stator leakage inductance

$L_{l k d}=4.8 \mathrm{mH} \quad$ Damper winding $\mathrm{d}$-axis

Note: The value of $L_{\text {Total }}$ is inductance of the line $L_{\text {line }}$ plus $L_{l s}$ and $L_{l k d}$ viewed from stator (d-axis).

$L_{\text {Total }}=L_{\text {line }}+L_{l s}+L_{l k d}=29.24 \mathrm{mH}$

The resonance frequency on the electrical side for $700 \mathrm{uF}$ capacitors using equation (4.9) would be: 


$$
f=\frac{1}{2 \pi \sqrt{29.24 \times 10^{-3} \times 700 \times 10^{-6}}} \approx 35 \mathrm{~Hz}
$$

To validate the results, a script file is written in MATLAB to calculate the Impendence of pi-lines and the resonance frequency of the line. Further, for $700 \mathrm{uF}$ there is a resonance around $35 \mathrm{~Hz}$ as shown below.

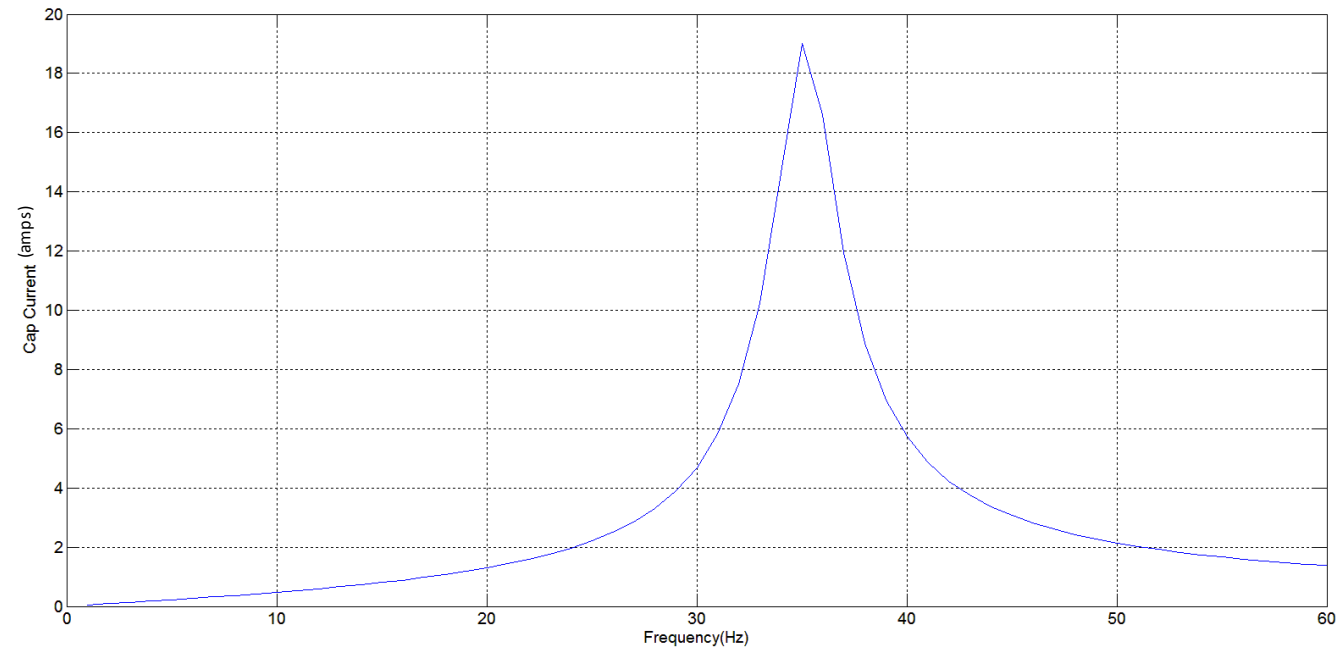

Figure 6.4: Frequency Vs cap current

\subsection{Series Compensated Line Tests}

After modifying the SG damper winding, a test with and without series cap is performed to study the influence of series compensation on the transmission line. A 330uf cap $(52 \mathrm{~Hz}$ 
resonance) was added and $10 \mathrm{H}$ oscillation was injected on the prime mover. All conditions are the same for both tests and the FFT results are normalized.

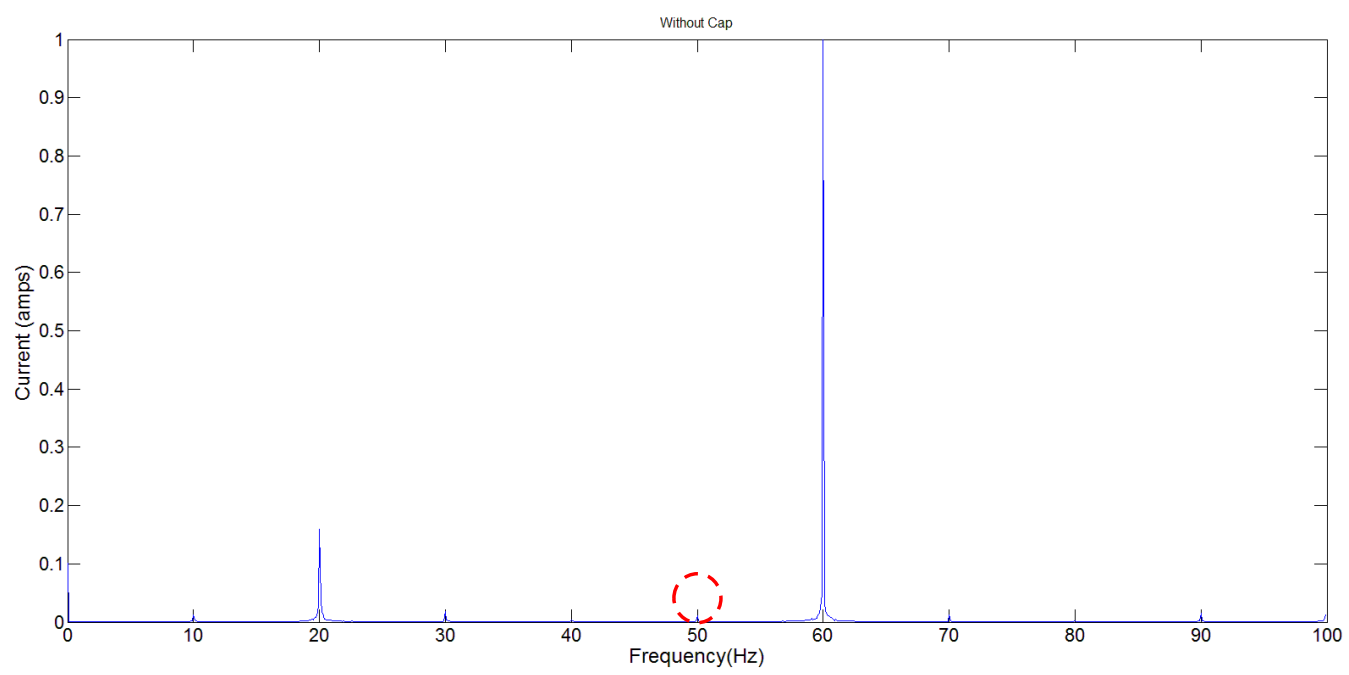

Figure 6.5: SG current output without cap

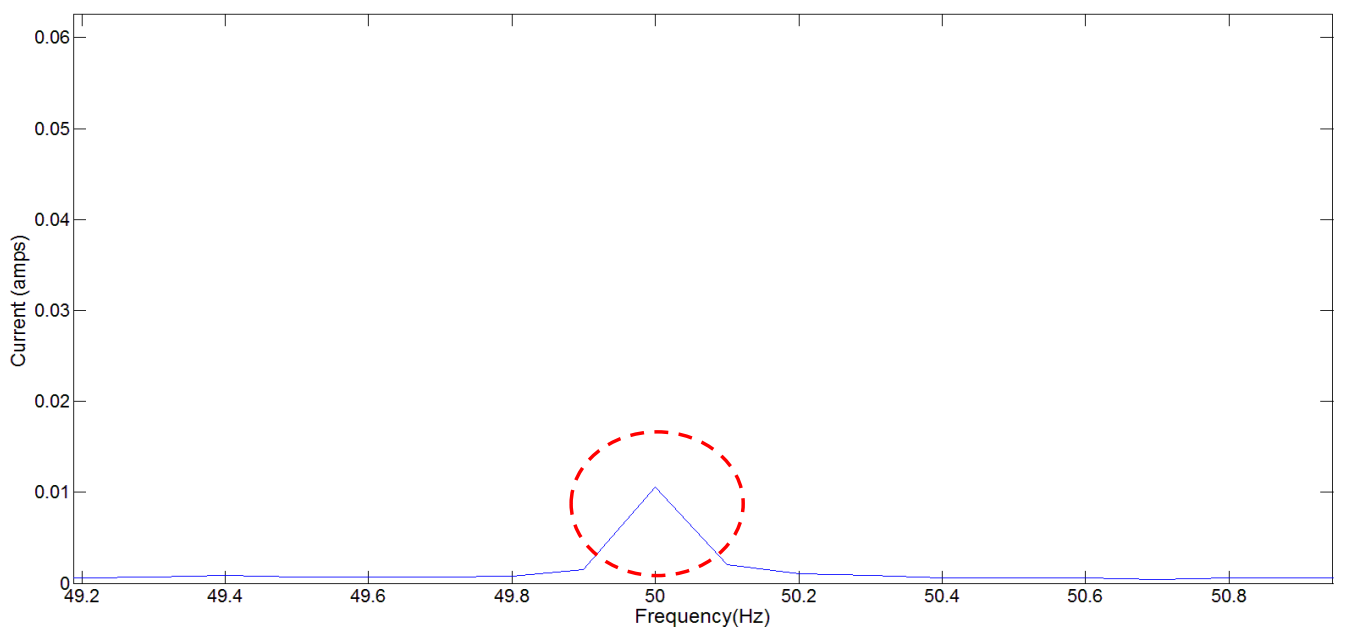

Figure 6.6: SG current output without cap (zoomed in) 


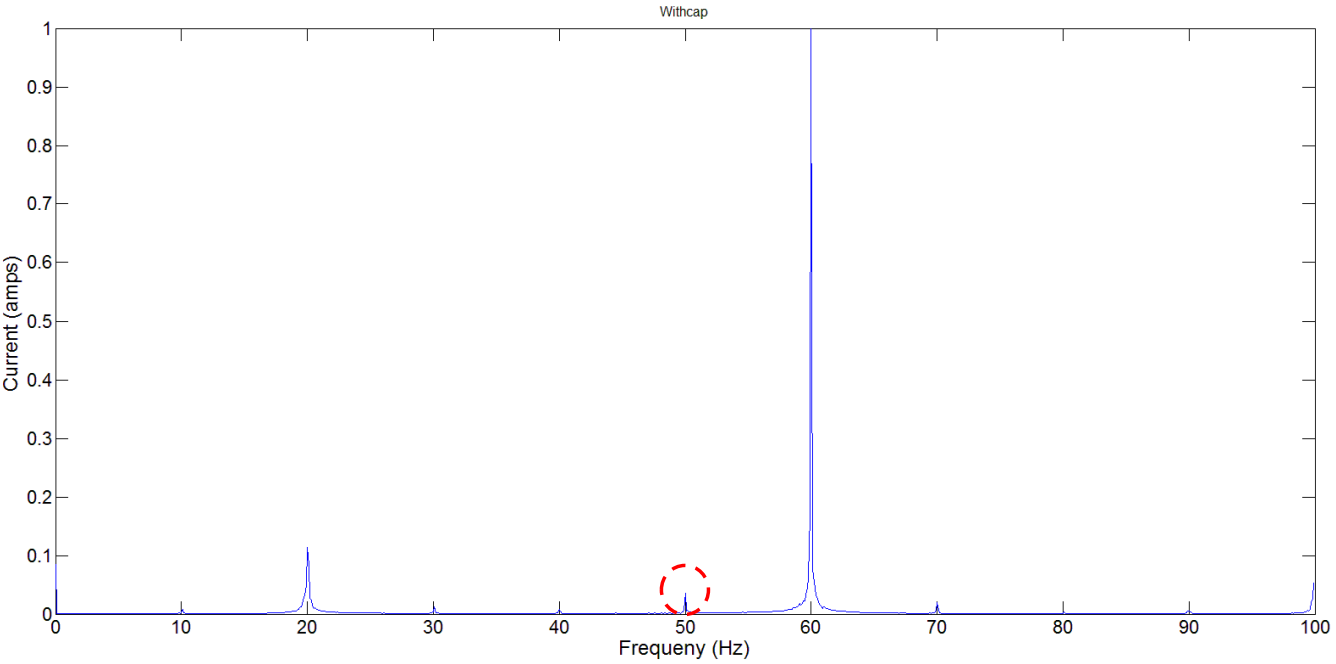

Figure 6.7: SG current output with cap

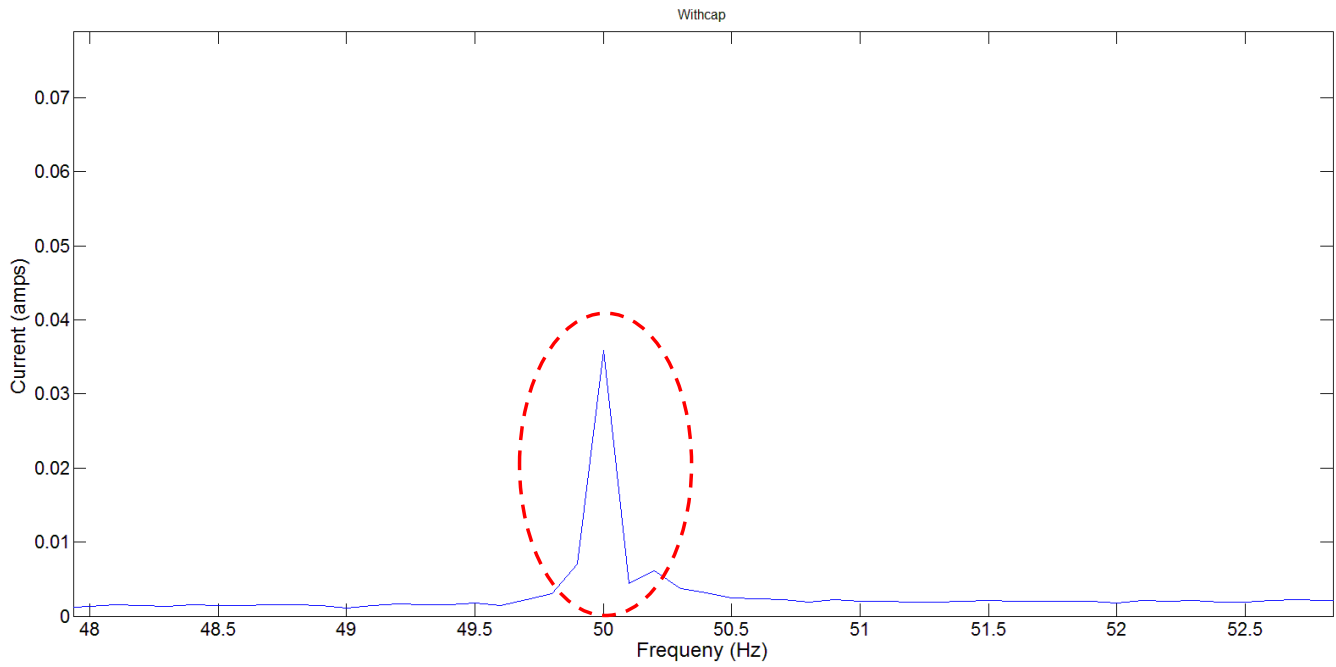

Figure 6.8: SG current output with cap (zoomed in) 
In Figure 6.9 the $10 \mathrm{~Hz}$ oscillation is monitored on the prime mover. This $10 \mathrm{~Hz}$ is the desired oscillation on the shaft which is controlled by the LabVIEW.

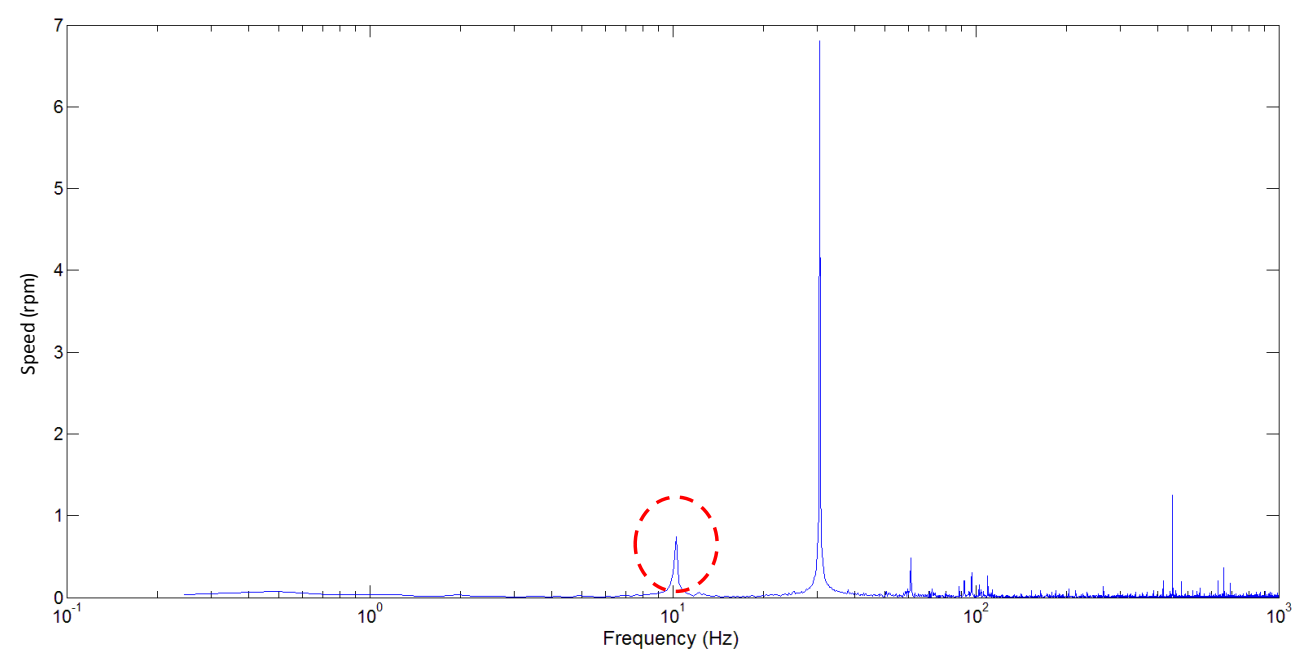

Figure 6.9: DC motor shaft FFT

Having series caps would result in amplifying the oscillation at $50 \mathrm{~Hz}$ and increase the magnitude of oscillation roughly 4 times bigger than the test with no series caps. After testing series cap and validating the FFT results, a 700uF caps are added to the transmis sion line. This procedure investigates the influence of a $700 \mathrm{uF}$ series cap on the power system model, and provide results for comparison. With the new impedance calculation, the resonance frequency should happen around $35 \mathrm{~Hz}$. However, the test results show that the resonance frequency for $700 \mathrm{uF}$ is occurring at $32 \mathrm{~Hz}$. The reason is due to the mechanical mode which usually varies from $0.1-2 \mathrm{~Hz}$.

The figures below demonstrate the interaction between transmission line resonance frequency and mechanical shaft oscillation during SSR. This test is carried out with 700uF series caps on the power line and 28,24 , and $20 \mathrm{~Hz}$ oscillation on the DC motor shaft. The 
results are normalized for a better comparison. Conditions and current disturbances are the same for those three frequencies.

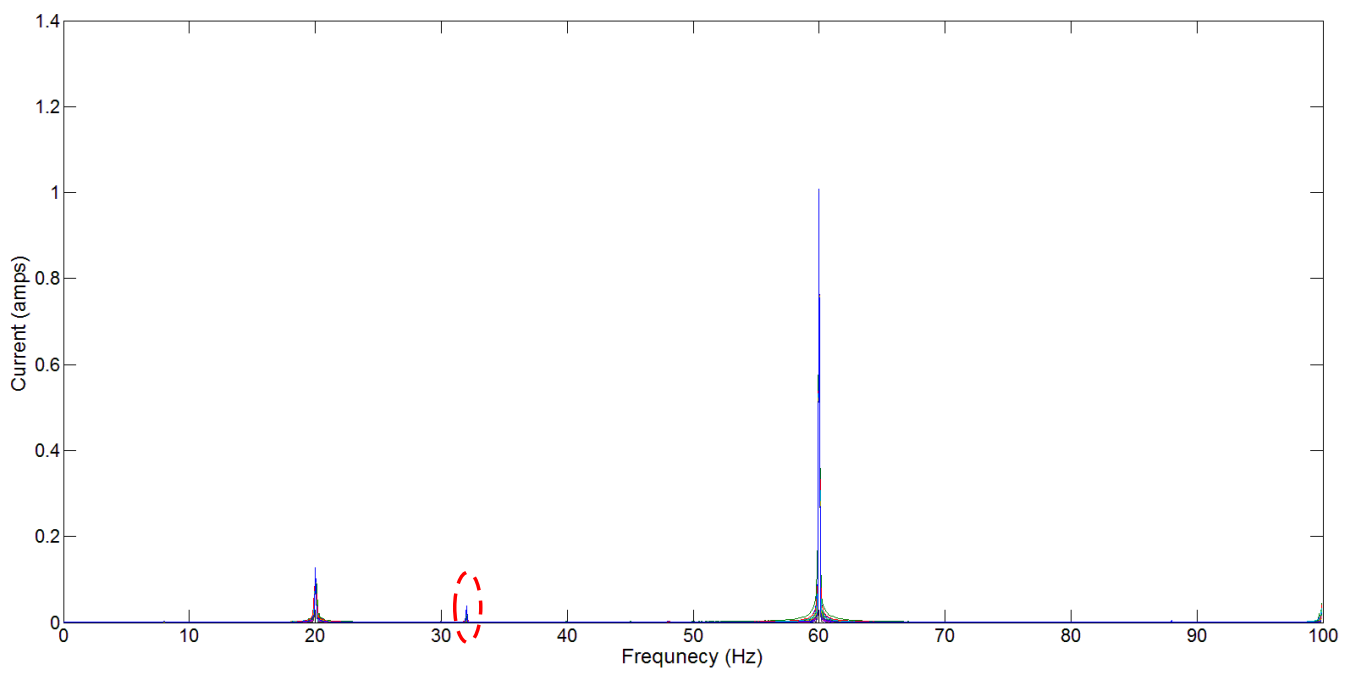

Figure 6.10: $32 \mathrm{~Hz}$ oscillation on electrical side with $700 \mathrm{uF}$

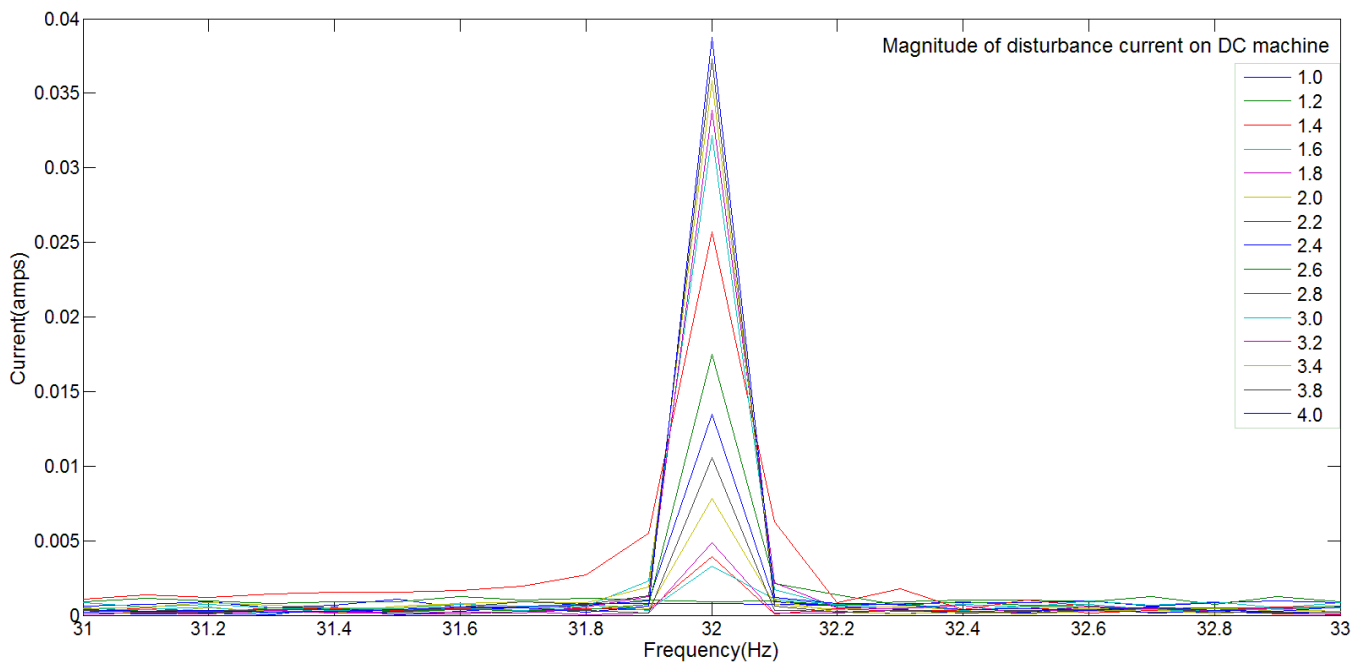

Figure 6.11: $32 \mathrm{~Hz}$ oscillation on electrical side with $700 \mathrm{uF}$ cap plus $28 \mathrm{~Hz}$ oscillation on prime mover 


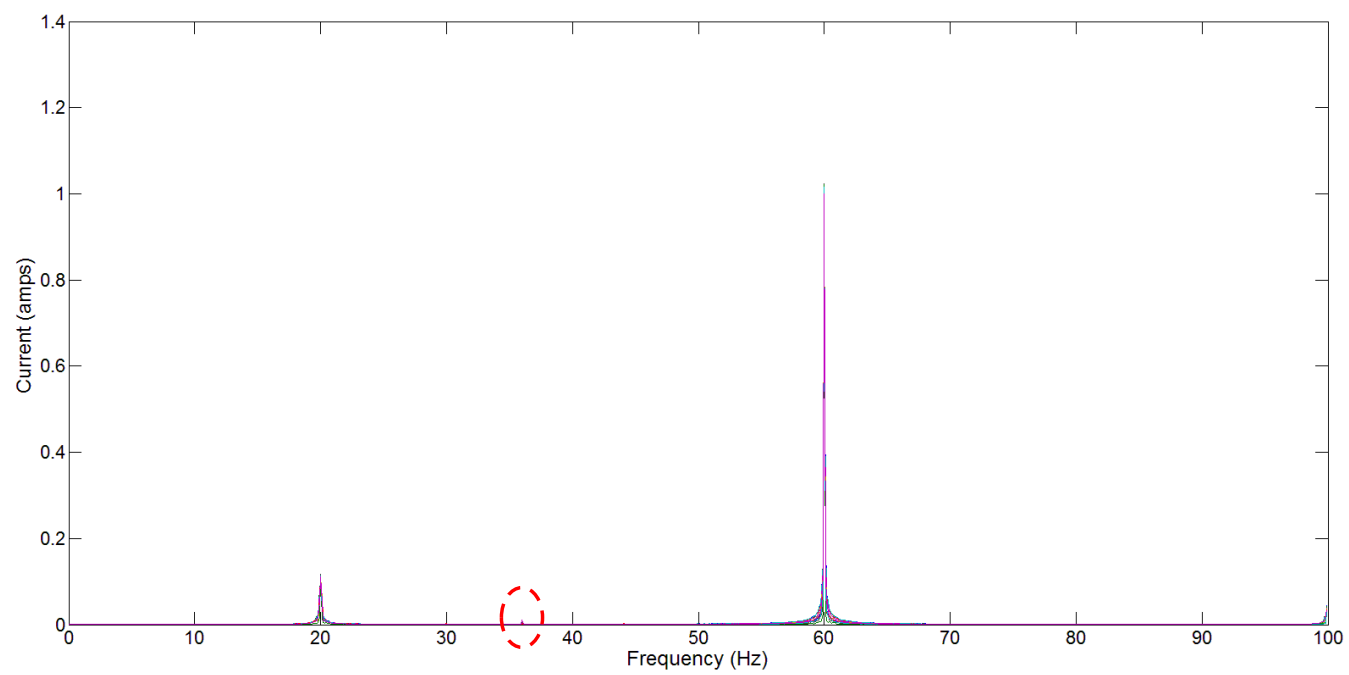

Figure 6.12: $36 \mathrm{~Hz}$ oscillation on electrical side with $700 \mathrm{uF}$

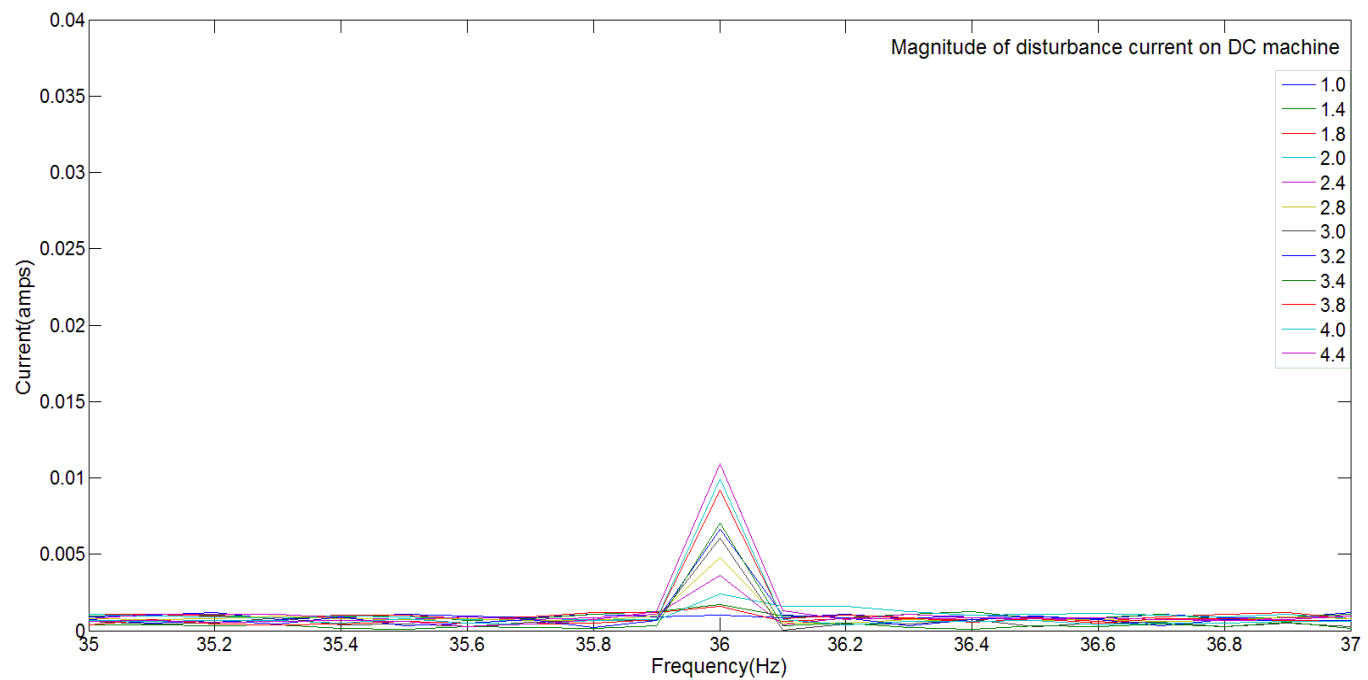

Figure 6.13: $36 \mathrm{~Hz}$ oscillation on electrical side with $700 \mathrm{uF}$ cap plus $24 \mathrm{~Hz}$ oscillation on prime mover 


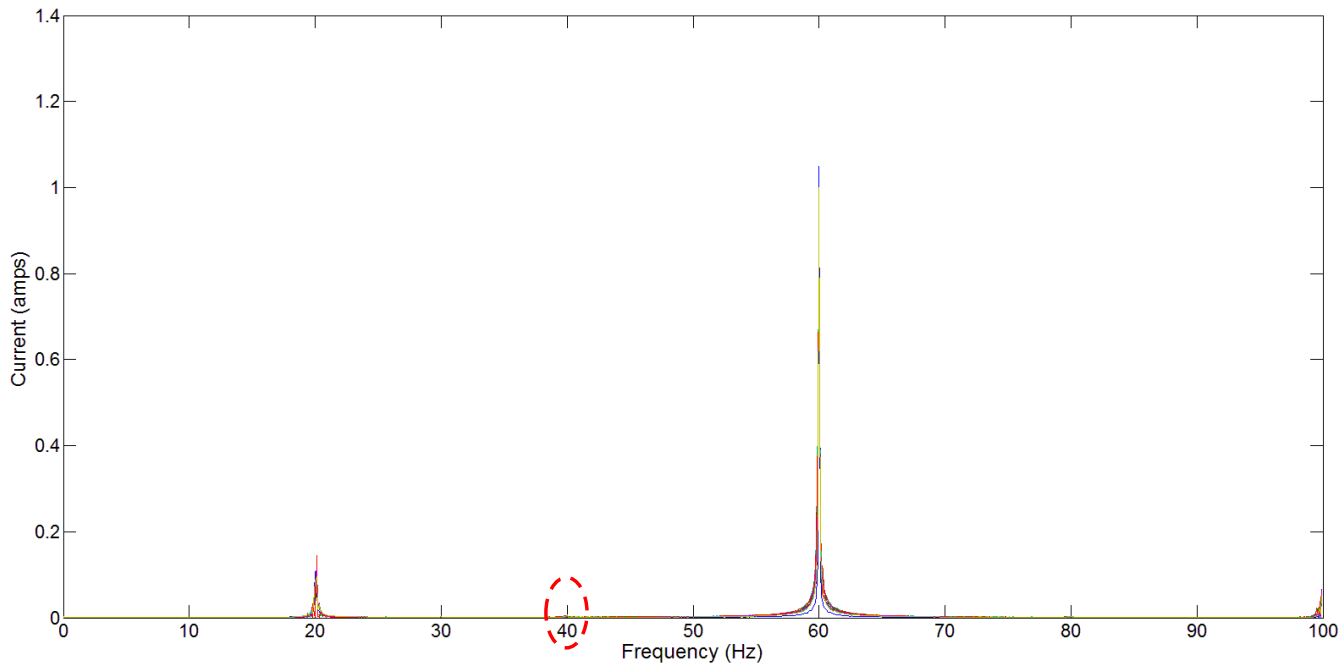

Figure 6.14: $40 \mathrm{~Hz}$ oscillation on electrical side with $700 \mathrm{uF}$

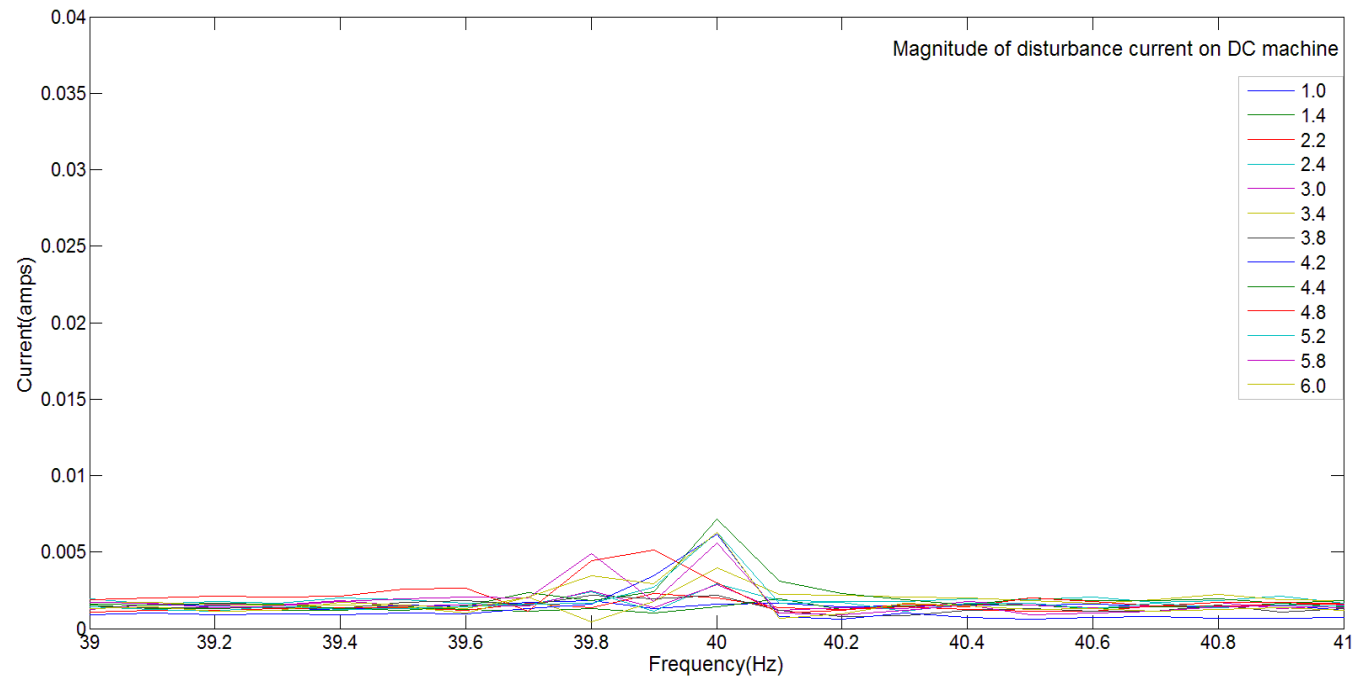

Figure 6.15: $40 \mathrm{~Hz}$ oscillation on electrical side with $700 \mathrm{uF}$ cap plus $20 \mathrm{~Hz}$ oscillation on prime mover 
In conclusion, the biggest oscillation occurs at $32 \mathrm{~Hz}$ during different frequency test. For instance, for the same amount of disturbance current, in Figure 6.11 oscillation at $32 \mathrm{~Hz}$ on the electrical side is around 0.04 which is three times higher than $24 \mathrm{~Hz}$ and at $20 \mathrm{~Hz}$ there is almost zero oscillation. The results are as expected. There is a growth of SSR at $32 \mathrm{~Hz}$ which does not occur at other range of frequency. The magnitude of oscillation is not as big as expected, since the magnitude of the current disturbance block is limited for the sake of safety. Evidently by increasing the current, bigger oscillation can be demonstrated. Oscillating the mechanical side at $28 \mathrm{~Hz}$ results in $32 \mathrm{~Hz}$ oscillation on the electrical side which is the complimentary of $60 \mathrm{~Hz}$, and it validates SSR results in this project.

After emulating SSR, different caps value are used in order to observe how much resonance frequency can be shifted. Different caps value are added and disturbances from $10 \mathrm{~Hz}$ to $30 \mathrm{~Hz}$ are injected to DC motor shaft to investigate which frequency on the prime mover has the biggest interaction with resonance frequency on transmission line. The results are show below:

\subsection{SSR Tests with Series Compensated Line}

To investigate the interaction between mechanical and electrical side during SSR, a test is carried out in the power lab with $700 \mathrm{uF}, 600 \mathrm{uF}$ and $500 \mathrm{uF}$ series compensated line. 


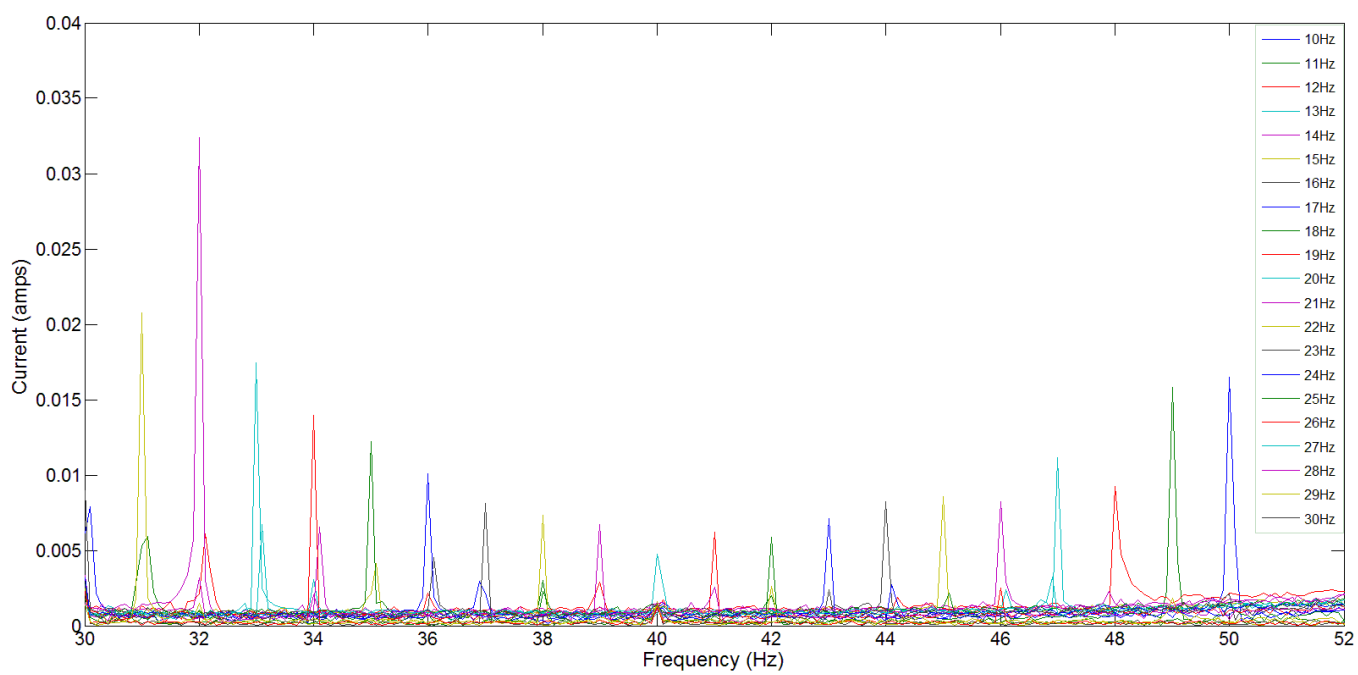

Figure 6.16: FFT results for $10-30 \mathrm{~Hz}$ frequency range with $700 \mathrm{uF}$ cap

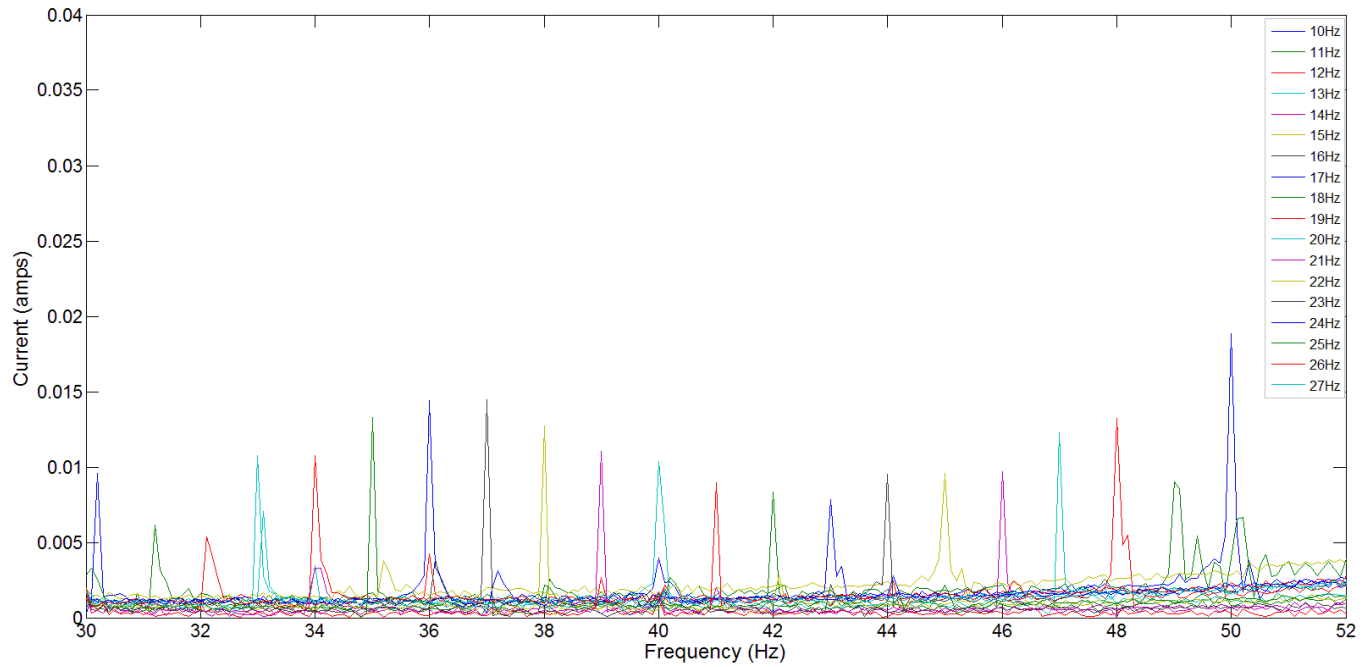

Figure 6.17: FFT results for $10-27 \mathrm{~Hz}$ frequency range with $600 \mathrm{uF}$ cap 


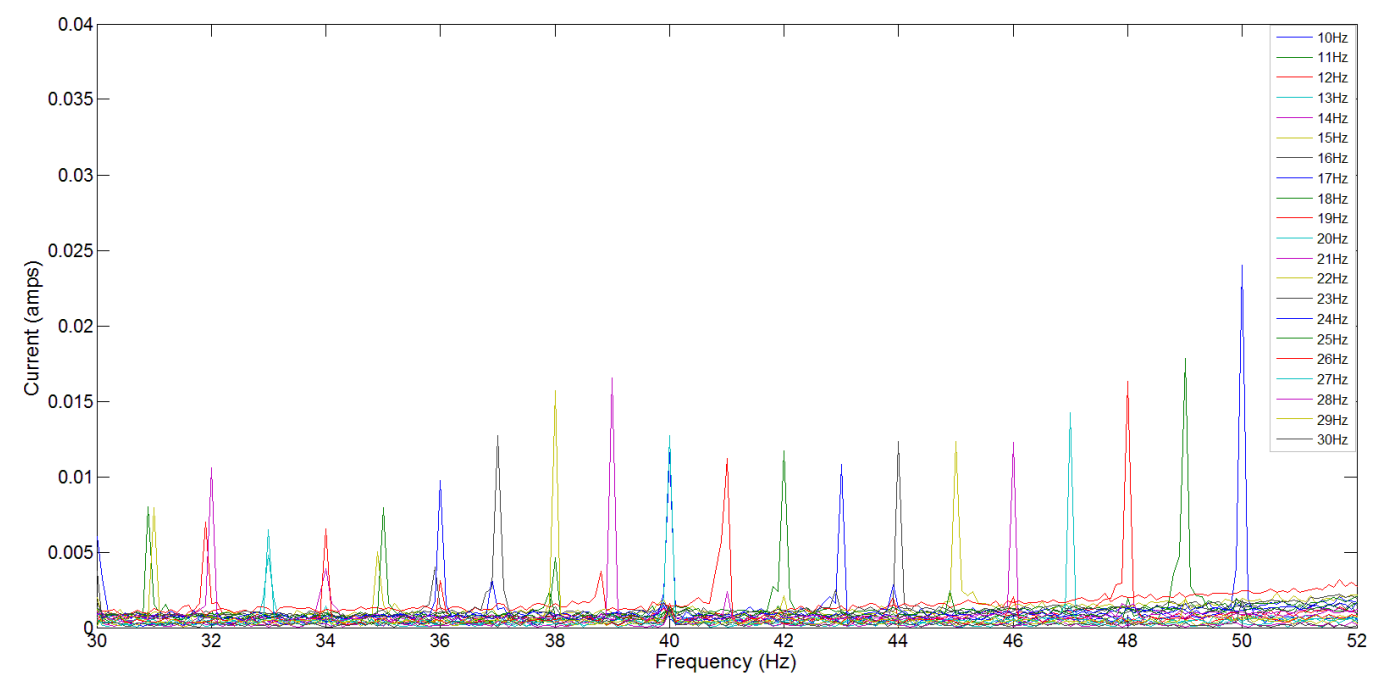

Figure 6.18: FFT results for $10-30 \mathrm{~Hz}$ frequency range with 500uF cap

As explained above, the resonance frequency for $700 \mathrm{uF}, 600 \mathrm{uF}, 500 \mathrm{uF}$ are 32,36 , $38 \mathrm{~Hz}$ respectively. However, these numbers are different compared to the impedance frequency calculation with $2-3 \mathrm{~Hz}$ error. This error is due to not considering mechanical mode or other components in power system which shift the resonance. As it depicted below, the series compensated line can shift the resonance frequency. 

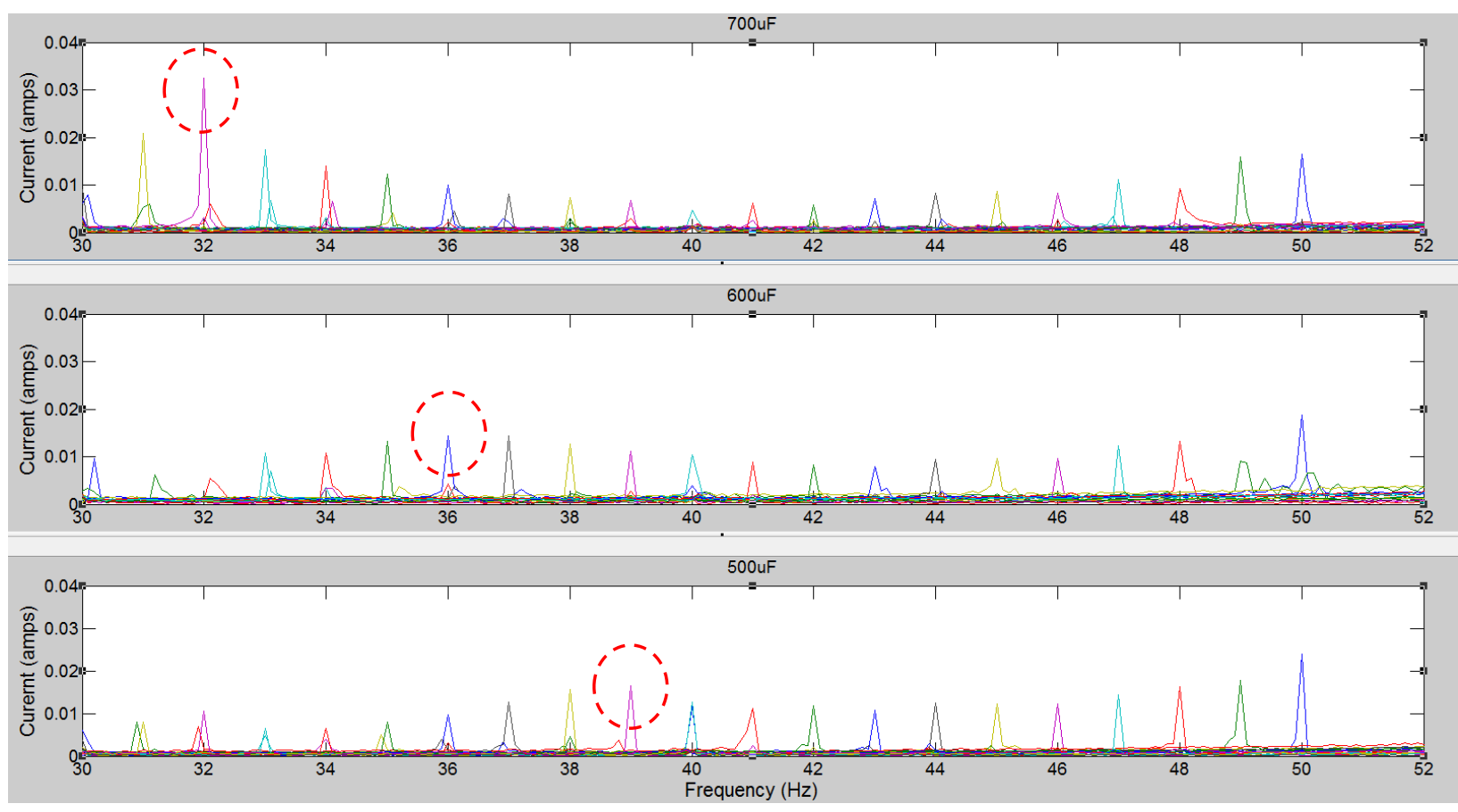

Figure 6.19: 700,600 and 500uF series compensated line 


\section{Chapter 7}

\section{Conclusion and Future Work}

\subsection{Conclusion}

The existence of sub-synchronous conditions and their severity can be verified using power system software such as SIMULINK/MATLAB and EMPT-RV as a simulation and analytical tool.

To simulate and study power disturbances like SSR, calculating generator parameters plays a significant role. In some cases, the owners of the generator cannot provide all the parameters due to lack of data sheets which either no longer or partially exist. Therefore, parameters are estimated based on similar models or gained by different tests. In this experiment, part of the work is dedicated to finding the parameters to provide precise results.

The results presented in this thesis, clearly stated that the network frequencies depend on series compensation level. The experiments show that a $28 \mathrm{~Hz}$ torsional oscillation on a generator connected to the $60 \mathrm{~Hz}$ system will generate $32 \mathrm{~Hz}$ electrical oscillation. Adding series capacitor compensation can cause negative electrical damping in the subsynchronous frequency range, and Torsional interaction with the negative damping effect becomes unstable. However, an uncompensated transmission system will have positive electrical damping in the sub-synchronous frequency range. 
The investigation and results are distinctive, since the generator has $10 \mathrm{sec}$ time constant and it is connected to a solid $600 \mathrm{~km}$ high-voltage transmission line. Therefore, the results obtained can be replicated to a full-scale power system. The SSR has been simulated and emulated in this thesis. From the studied results, the specific conclusions are as follows.

First having series cap amplifies oscillation at a certain frequency and increases the magnitude of oscillation compared to no caps test at the same frequency.

Second synchronous generator dampers windings, damp out the oscillations. The damper windings in synchronous generator come in series with transmission line's inductance and resistance. It will be added to the total inductance of the line. Hence, resonance frequency will be shifted.

Third the cases investigated in this thesis provide an analytical comparison between different series cap configuration. Moreover, it shows each synchronous generator has a unique behavior to series compensation line. In other words, this experiment illustrates the worst-case scenario occurs at $32 \mathrm{~Hz}$ which could be different for other synchronous generator types.

Generally, in some applications series capacitors may introduce adverse side effects, including SSR and transient torque amplification. Torsional relays are used to protect turbine generators from damage if mitigations fail, or unanticipated system events occur.

\subsection{Future work}

The mechanism of the sub-synchronous resonance is well understood. Numerous mitigation schemes have been developed and successfully implemented, and series capacitors have been installed and operated without incidents since the first two shaft 
failures of the Mohave unit in 1970 and 1971 [6]. System studies of SSR enable power system engineers to evaluate potential risks due to SSR as well as choose appropriate SSR mitigation schemes and build transmission systems that avoid adverse SSR effects on turbine-generators [6].

SSR studies help planners to establish acceptable series compensation levels for a power system design and develop power quality and system's reliability.

The AESO (Alberta Electric System Operator) provides necessary support and review to ensure that the SSR study is carried out with credible system conditions and contingencies. Studies and analyses will be required when there is a concern of SSR between turbine-generator units and the nearby serious compensated lines. Studies are also required when there is a potential sub-synchronous control interaction (SSCI) between the wind farms, particularly the DFIG (Type III), and serious capacitor compensated lines or a nearby HVDC terminal. The AESO, Transmission Facility Owner or the consultant will identify the need for SSR or SSCI studies. The SSR study report will document the results and identify the scenarios in which torsional interactions may exist and whether mitigation measures are required [28].

Future students will continue this work based on the model in this thesis to propose different mitigation methods and provide an ideal solution to increase reliability.

As previously stated, series capacitors have been extensively used as an effective means of increasing power transfer capability of transmission systems. Therefore, there is a need to investigate and analyse SSR when planning inclusion of components such as series capacitors for new or existing power systems. 


\section{Bibliography}

[1] L. Xiang, S. Li, and W. Cui, "Measurement and analysis of torsional vibration signal for rotating shaft system," Proc. - 2012 9th Int. Conf. Fuzzy Syst. Knowl. Discov. FSKD 2012, no. Fskd, pp. 1851-1854, 2012.

[2] O. J. Suresh, S. Ghadilai, "Study of Subsynchronous Resonance in Power Systems," Electrical Engineering Department, S.C.E.T, Surat, India.

[3] E. Lidstrom, D. Wall, and J. Persson, "Grid interference on operations," 2015.

[4] P. M. Anderson, B. L. Agrewai, and J. E Van Ness, Subsysnchronous Resonance in Power System, ". IEEE press.

[5] S. T. Nagarajan and N. Kumar, "Mitigation of induction generator effect due to SSR with STATCOM in synchronous generator," India Int. Conf. Power Electron. IICPE, 2012.

[6] D. H. Baker, G. E. Boukarim, R. D'Aquila, and R. J. Piwko, "Subsynchrono us resonance studies and mitigation methods for series capacitor applications," 2005 IEEE Power Eng. Soc. Inaug. Conf. Expo. Africa, no. July, pp. 11-15, 2005.

[7] N. I. Yousif and M. Al-Dabbagh, "Subsynchronous Resonance Damping in Interconnected Power Systems,” no. January, pp. 1-4, 2011.

[8] D. G. Ramey, B. L. Agrawal, and R. G. Farmer, Power System Dynamic Interaction with Turbine Generators, 3rd ed.

[9] I. S. R. W. Group, "Reader's guide to subsynchronous resonance," IEEE Trans. 
Power Syst., vol. 7, no. 1, pp. 150-157, 1992.

[10] IEEE Committee Report, "Second Benchmark Model for Computer Simulation of Subsynchronous Resonance," IEEE Trans. Power Appar. Syst., vol. PAS-104, no. 5, pp. 1057-1066, 1985.

[11] S. H. Hosseini and O. Mirshekar, "Optimal control of SVC for subsynchronous resonance stability in typical power system," Ind. Electron. 2001. Proceedings. ISIE 2001. IEEE Int. Symp., vol. 2, pp. 916--921 vol.2, 2001.

[12] D. Jiang, Y. T. Yang, and X. X. Zhou, "Analyzing Subsynchronous Resonance Using a Simulation Program,” vol. 0, pp. 775-781, 2000.

[13] B. L. Agrawal and R. G. Farmer, "Use of frequency scanning techniques for subsynchronous resonance analysis," IEEE Trans. Power Appar. Syst., vol. PAS98, no. 2, pp. 341-349, 1979.

[14] 'IEEE Subsynchronous Resonance Task Force of the Dynamic System Performance Working Group Power System Engineering,” Spring, pp. 1565-1572, 1977.

[15] S. A. N. Sarmadi and V. Venkatasubramanian, "Inter-Area Resonance in Power Systems From Forced Oscillations,” vol. 31, no. 1, pp. 378-386, 2016.

[16] K. R. Padiyar, "Analysis of Subsynchronous Resonance In Series Compensated Line with Booster Transformer,” p. 262, 1999.

[17] J. V Milanovic, "Damping of the low-frequency oscillations of the generator: dynamic interactions and the effectiveness of the controllers," Engineering.

[18] D. a. Alves, I. C. P. da Silva, and V. F. da Costa, "A power sensitivity model 
including generator damper windings for electromechanical oscillations studies," PowerTech Budapest 99. Abstr. Rec. (Cat. No.99EX376), p. 73.

[19] General Electric, "Power System Stabilizer." [Online]. Availab le: http//www.geenergyconsulting.com/practice-area/global-power-projects/powersystem-stabilizers.

[20] G. Rogers, Power System Oscilllation. 2012.

[21] B. Pal, Bikash, Chaudhuri, No Robust Control in Power SystemsTitle. 2005.

[22] C. Rajagopalan, B. Leaieutre, P. W. Sauer, and M. A. Pa, "Dynamic aspects of voltagelpower characteristics in multi-machine power systems," vol. 7, no. 3, 1992.

[23] V. Cutsem and Vournas, Voltage Stability of Electric Power Systems. 1998.

[24] Padiyar and K.R, Analysis of Subsynchronous Resonance in Power Systems. 1999.

[25] B. C. Pal, "Robust Damping Control of Inter-area Oscillations in Power System with Super-conducting Magnetic Energy Storage Devices,” Imperial College London, 1999.

[26] L. Heamkumar, "Literature Survey on Intelligent Wide Area Signals Based Damping of Power System Oscillations Using Virtual Generators,” Int. Res. J. Eng. Technol., pp. 2395-56, 2015.

[27] G. E. Martin, F. R. Schleif, and R. R. Angell, "Damping of System Oscillations with a Hydrogenerating Unit," Power, pp. 438-442, 1967.

[28] AESO, "Connection Proposal Template," Alberta Electric System Operator." [Online]. Available: https://www.aeso.ca/assets/Uploads/connection-study-scope- 
template.docx.

[29] National Instruments, "Pulse Width Modulation." [Online]. Available: ww.digital.ni.com.

[30] A. M. Knight, "Torque and Power Oscillations of a Salient Pole Synchronous Machine Torque and Power Oscillations of a Salient Pole Synchronous Machine," no. November, 2009.

[31] AESO, "Power System Stability." [Online]. Available: https//www.aeso.ca/assets/Uploads/Southern-Alberta-NID-DEC15-POSTED.pdf.

[32] M. Bongiorno and A. Petersson, "The impact of Wind Farms on Subsynchronous Resonance in Power Systems-Elforsk rapport 11:29,” no. April, pp. 1-55, 2011.

[33] L. Harnefors, "Analysis of subsynchronous torsional interaction with power electronic converters," IEEE Trans. Power Syst., vol. 22, no. 1, pp. 305-313, 2007.

[34] K. M. Alawasa, Y. A. R. I. Mohamed, and W. Xu, "Modeling, analysis, and suppression of the impact of full-scale wind-power converters on subsynchronous damping," IEEE Syst. J., vol. 7, no. 4, pp. 700-712, 2013.

[35] K. M. Alawasa, S. Member, and Y. A. I. Mohamed, "New Approach to Damp Subsynchronous Resonance by Reshaping the Output Impedance of VoltageSourced Converters," no. 1, 2013.

[36] C. Karawita and U. D. Annakkage, "Control block diagram representation of an HVDC system for sub-synchronous frequency interaction studies," 9th IET Int. Conf. AC DC Power Transm. (ACDC 2010), pp. P06-P06, 2010. 
[37] R. J. Piwko, G. E. Company, and G. Electric, "HVDC system control for damping of subsynchronous oscillations," no. 7, pp. 2203-2211, 1982.

[38] T. Rauhala, "On effect of HVDC on subsynchronous damping," 8th IEE Int. Conf. AC DC Power Transm. (ACDC 2006), vol. 2006, no. 3, pp. 125-129, 2006.

[39] A. K. Moharana, "Subsynchronous resonance in wind farms," no. October, pp. 1298, 2012.

[40] S. For and S. Oscillations, "Terms, definitions and symbols for subsynchronous oscillations," IEEE Trans. Power Appar. Syst., vol. PAS-104, no. 6, pp. 1326-1334, 1985.

[41] P. M. Anderson, Series compensation of power systems. 1996.

[42] H. Klee and R. Allen, Simulation of Dynamic Systems with MATLAB and Simulink, 2nd ed. 2011.

[43] M. El-Marsafawy, "Use of frequency-scan techniques for subsynchrono usresonance analysis of a practical, seriescapacitor compensated AC network," IEE Proc. C Gener. Transm. Distrib., vol. 130, no. 1, pp. 28-40, 1983.

[44] MATLAB/SIMULINK, "Synchronous Machines Help." .

[45] Mariesa L. Crow, Computational Methods for Electric Power Systems. 2009.

[46] M. R. Iravan and A.-A. Edris, "Eigen analysis of series compensation schemes reducing the potential of sub-synchronous resonance," vol. 10 , no. 2, pp. 876-883, 1995.

[47] K. Narendra et al., "New microprocessor based relay to monitor and protect power 
systems against sub-harmonics,” 2011 IEEE Electr. Power Energy Conf. EPEC 2011, pp. 438-443, 2011.

[48] ERCOT, "Subsynchronous Resonance," 2015. [Online]. Availab le: http://www.ercot.com/content/wcm/key_documents_lists/77251/ERCOT_SSR_W orksho_1204_2015.pdf.

[49] G. V Gotmare and V. B. Virulkar, "Eigenvalue Analysis of Subsynchronous Resonance Study in Series Compensated Wind Farm,” 2014.

[50] M. S. Pasand, "Fuzzy Logic PSS Desing," University of Calgary, 1994.

[51] Q. Wu, "Fuzzy Logic Based Power System Stabilizer," University of Calgary, 1993.

[52] H. Barbey and J. Marchand, "Control of Field Current in Saturated Synchronous Machines," University of Calgary, 2009.

[53] A. Sohby and A. Farag, "Real-time digital governor for a generating unit," Univeristy of Calgary, 1974.

[54] P. Krause, Analysis of electric machinery and drive systems, 3rd ed. 2013.

[55] "SEMIKRON AN-8005I.” [Online]. Available: http://educypedia.karadimov.info/library/AN-8005_Techning_System.pdf. 


\section{APPENDIX A}

\section{Parameters of the Single Machine Infinite Bus System}

Table A.1: SG nameplate data [52]

\begin{tabular}{|c|c|}
\hline$V_{n}$ & $220 / 127 \mathrm{~V}$ \\
\hline$I_{n}$ & $7.9 \mathrm{~A}$ \\
\hline$S_{n}$ & $3 \mathrm{KVA}$ \\
\hline$\omega_{n}$ & $1800 \mathrm{rpm}$ \\
\hline Pole pairs & 2 \\
\hline$f$ & $60 \mathrm{~Hz}$ \\
\hline
\end{tabular}

Table A.2: Mechanical parameters of the model [52]

\begin{tabular}{|c|c|}
\hline Parameters & Value \\
\hline$H$ & $12 \mathrm{~s}$ \\
\hline$P$ & 2 \\
\hline
\end{tabular}


Table A.3: Synchronous Generator PU parameters [50], [52]

\begin{tabular}{|c|c|}
\hline Parameters & Value in pu \\
\hline$r_{d}, r_{q}$ & 0.0026 \\
\hline$r_{k d}, r_{k q}$ & 0.0083 \\
\hline$r_{f}$ & 0.000747 \\
\hline$x_{q}, x_{d}$ & 1.20 \\
\hline$x_{k q}, x_{k d}$ & 1.25 \\
\hline$x_{m d}, x_{m q}$ & 1.129 \\
\hline$x_{f}$ & 1.27 \\
\hline
\end{tabular}

All the PU parameters are calculated by following equations below. In the pu system X_pu and L_pu are the same.

$$
\begin{gathered}
x_{d}=x_{m d}+x_{l d} \\
x_{q}=x_{m q}+x_{l q} \\
x_{f}=x_{m d}+x_{l f d} \\
x_{k d}=x_{m d}+x_{l k d} \\
x_{k q}=x_{m q}+x_{l k q} \\
x_{l f d}=l_{l f d} \cdot 120 \pi
\end{gathered}
$$


Table A.4: The stator base values used in Simulink [44]

\begin{tabular}{|c|c|}
\hline$V_{\text {sbase }}=\frac{V_{n} \sqrt{2}}{\sqrt{3}}$ & $\begin{array}{c}\text { base stator voltage = peak nominal } \\
\text { line-to-neutral voltage }(\mathrm{V})\end{array}$ \\
\hline$I_{\text {sbase }}=\frac{P_{n} \sqrt{2}}{V_{n} \sqrt{3}}$ & base stator current (A) \\
\hline$Z_{\text {sbase }}=\frac{V_{\text {sbase }}}{I_{\text {sbase }}}=\frac{V_{n}^{2}}{P_{n}}$ & base stator impedance $(\Omega)$ \\
\hline$\omega_{\text {base }}=2 \pi f_{n}$ & base angular frequency $(\mathrm{rad} / \mathrm{s})$ \\
\hline$L_{\text {sbase }}=\frac{Z_{\text {sbase }}}{\omega_{\text {base }}}$ & base stator inductance $(\mathrm{H})$ \\
\hline
\end{tabular}

